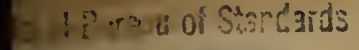

Litian, th. W. Bus. NOV 161949

U. S. DEPARTMENT OF COMMERCE NATIONAL BUREAU OF STANDARDS CENTRAL RADIO PROPAGATION LABORATORY W ASHINGTON, D. C.

THE MICROWAVE FREQUENCY STANDARD AT THE CENTRAL RADIO PROPAGATION LABORATORY BY W. D. GEORGE, H. LYONS, J. J. FREEMAN AND J. M. SHAULL 

Report No

CRPL-8-1, 9-4
NATIONAL BUREAU OF STANDARDS

CENTRAL RADIO PROPAGATION LABORATORY

WASHINGTON 25, D。C.

\section{THE MICROWAVE FREQUENCY STANDARD AT \\ THE CENTRAL RADIO PROPAGATION LABORATORY}

By W.D.Goorge, H. Lyons, J.J.Frooman and J.M. Shaull

\section{Abstraot}

This report describes the equipment set up in 1945 at the National Bureau of Standards to generate standard microwave frequencies and to make microwave frequency measurements, tests and calibrations. All frequencies are derived from, or measured directly, in terms of the National primary standard of frequency, the absolute accuracy of which is known at all times to better than 1 part in 100 million. Highly constant oscillators of narrow tuning range are mixed with the multiplied standard frequencies making available an $8 \%$ bandwidth at output center frequencies of $29.7,89.1,267.3$ and $801.9 \mathrm{Mc} / \mathrm{s}$ 。 Harmonics of these output frequencies, generated by silicon-crystal multipliers, give continuous coverage of the range from 342 to somewhat above $30,000 \mathrm{Mc} / \mathrm{s}$ with a known accuracy of 1 part in 10 million or better. In this range a total of over 870 fixed frequencies of approximately $1 \%$ separation, entirely generated from the primary standard and accurate to 1 part in 100 million, are also made available. Measurements are normally made at controlled temperature and humidity in a shielded room. Absolute accuracy of calibration is usually considerably less than that of the reference froquencies, being limited by the operating band-pass characteristic and dial mechanism for frequency meters, or by the short time frequency changes of oscillators under test. Instructions in the operation and maintenance of the equipment aro given. Detailed descriptions, circuit diagrams and photographs of the individual units are also included.

\section{Contents}

General jescription

1. Introduction

2. The calibration room

3. The primary standard of frequency

4. The frequency-generating equipment

a. General-coverage system

b. Fine-tuning and spot-frequency arrangement

c. Frequency-measurement equipment

d. Harmonic-generating and detection equipment

5. Accuracy of calibrations

a. Unknown oscillator frequencies

b. Frequency meter calibrations

c. $Q$ measurements

d. Dependence of resonance frequency on tomperature for cavities wi thout temperature compensation

e. Dependence of resonence frequency on humidity

6. Calibration services of the National Bureau of Standards 
Apendix

I. Operating instructions

1. Procedure for making calibrations using adjustable-frequency oscillator

2. Measurement of adjustable-oscillator frequencies

3. Use of fine-tuning and spot-frequency equipment

4. Operating technique and precautions in use of equipment

a. Frequency standard

b. Crystal multipliers

c. Spurious frequencies

d. Frequency meters

e. Spectrum analyzers

II. Detailed unit descriptions

(arranged in the following order for each unit)

a. Description

b. Operation and service instructions

c. Parts list

d. Illustrations

1. Frequency multiplier; output $7.5 \mathrm{Mc} / \mathrm{s}$

2. Frequency converter-multiplier; output 28.5 to $30.9 \mathrm{Mc} / \mathrm{s}$

3. Adjutable-frequency oscillators; 2.0 to $2.4 \mathrm{Mc} / \mathrm{s}$ and 2.4 to $2.8 \mathrm{Mo} / \mathrm{s}$

4. Three-stage rrequency multiplier; outputs 85.5 to $92.7 \mathrm{Mc} / \mathrm{s}$, 256.5 to $278.1 \mathrm{Mo} / \mathrm{s} ; 769.5$ to $834.3 \mathrm{Mc} / \mathrm{s}$

5. Distribution amplifier; $100 \mathrm{kc} / \mathrm{s}$

6. Adflistable-frequency oscillator; 500 to $600 \mathrm{kc} / \mathrm{s}$

7. Frequency multiplier and dual frequency converter; outputs 1500 to $3000 \mathrm{kc} / \mathrm{s}, 1000$ to $2000 \mathrm{kc} / \mathrm{s}, 2000$ to $3000 \mathrm{kc} / \mathrm{s}$

8. Decade frequency generator; outputs at $100-\mathrm{kc}$ intervals from 100 to $1000 \mathrm{kc} / \mathrm{s}$

9. Harmonio series generator

10. Audio-frequency interpolation oscillator

11. Nulti-band receiver and monitoring speaker

12. Fide-band oscilloscope

13. Frequency divider; $100 \mathrm{kc} / \mathrm{s}$ to $10 \mathrm{kc} / \mathrm{s}$ to $1 \mathrm{kc} / \mathrm{s}$ to $0.1 \mathrm{kc} / \mathrm{s}$

\section{Ilustrations}

Fig. 1. Block schematic of microwave frequenoy equipment at National Burcau of Standards

Fig. 2. Frequency in Mc/s output of silicon-crystal frequency multiplier

Fig. 3. Diagram of rack and panel arrangement of equipment

Fig. 4. Diagram of shielded room and rack wiring

Fig. 5. Photograph of complete microwave frequency standard

Fig. 6. Photograph of complete microwave frequency standard with connecting leads

Fig. 7. Photograph of spectrum analyzer, frequency meters, and crystal multiplier; 8,500 to $10,000 \mathrm{Mc} / \mathrm{s}$

Fig. 8. Layout drawing of frequency multiplier; 100 to $7500 \mathrm{kc} / \mathrm{s}$

Fig. 9. Circuit schematic of frequency multiplier; 100 to $7500 \mathrm{kc} / \mathrm{s}$

Fig. 10. Photograph of frequency multiplier; 100 to $7500 \mathrm{kc} / \mathrm{s}$ (top-front view) 
Fig. 11. Photograph of frequency multiplier; 100 to $7500 \mathrm{kc} / \mathrm{s}$ (bottom view)

Fig. 12. Layout drawing of frequency converter-multiplier; output 28.5 to $30.9 \mathrm{Mc} / \mathrm{s}$.

Fig. 13. Circuit schematic of frequency converter-multiplier; output 28.5 to $30.9 \mathrm{Mc} / \mathrm{s}$.

Fig. 14. Photograph of frequency converter-multiplier; output 28.5 to $30.9 \mathrm{Mc} / \mathrm{s}$ (top-front view)

Fig. 15. Photograph of frequency converter-multiplier; output 28.5 to $30.9 \mathrm{Mc} / \mathrm{s}$ (bottom view)

Fig. 16. Layout drawing of adjustable-frequency oscillator; 2.0 to $2.4 \mathrm{Mc} / \mathrm{s}$ and 2.4 to $2.8 \mathrm{Mc} / \mathrm{s}$

F1g. 17. Circuit schematic of adjustable-frequency oscillator; 2.0 to $2.4 \mathrm{Mc} / \mathrm{s}$ and 2.4 to $2.8 \mathrm{Mc} / \mathrm{s}$

Fig. 18. Photograph of adjustable-frequency oscillator; 2.0 to $2.4 \mathrm{Mc} / \mathrm{s}$ and 2.4 to $2.8 \mathrm{Mc} / \mathrm{s}$ (top-front $v i$ ew)

Fig. 19. Photograph of adjustable-frequency oscillator; 2.0 to $2.4 \mathrm{Mc} / \mathrm{s}$ and 2.4 to $2.8 \mathrm{Mc} / \mathrm{s}$ (bottom view)

Fig. 20. Layout drawing of three-stage frequency multiplier and power supply.

Fig. 21. Circuit schematic of three-stage frequency multiplier and power supply

Fig. 22. Photograph of three-stage frequency multiplier (front view)

Fig. 23. Photograph of three-stage frequency multiplier (top view)

Fig. 24. Photograph of three-stage frequency multiplier (bottom view)

Fig. 25. Photograph of power supply for three-stage frequency multiplier (top-front view)

Fig. 26. Photograph of power supply for three-stage frequency multiplier (bottom view)

Fig. 27. Layout drawing of distribution amplifier; $100 \mathrm{kc} / \mathrm{s}$

Fig. 28. Circuit schematic of distribution amplifier: $100 \mathrm{kc} / \mathrm{s}$

Fig. 29. Photograph of distribution amplifier; $100 \mathrm{kc} / \mathrm{s}$ (top-front view)

Fig. 30. Photograph of distribution amplifier; $100 \mathrm{kc} / \mathrm{s}$ (bottom view)

Fig. 31. Layout drawing of adjustable-frequency oscillator; 500 to $600 \mathrm{kc} / \mathrm{s}$

Fig. 32. Circuit schematic of adjustable-frequency oscillator; 500 to $600 \mathrm{kc} / \mathrm{s}$

Fig. 33. Photograph of adjustable-frequency oscillator; 500 to $600 \mathrm{kc} / \mathrm{s}$ (front view)

Fig. 34. Photograph of adjustable-frequency oscillator: 500 to $600 \mathrm{kc} / \mathrm{s}$ (top view)

Fig. 35. Photograph of adjustable-frequency oscillator; 500 to $600 \mathrm{kc} / \mathrm{s}$ (bottom view)

Fig. 36. Layout drawing of frequency multiplier and dual frequency converter; outputs 1500 to $3000 \mathrm{kc} / \mathrm{s}, 1000$ to $2000 \mathrm{kc} / \mathrm{s}, 2000$ to $3000 \mathrm{kc} / \mathrm{s}$

Fig. 37. Circuit schematic of frequency multiplier and dual frequency converter

Fig. 38. Photograph of frequency multiplier and dual freauency converter (front view)

Fig. 39. Photograph of frequency-riultiplise and dual frequency converter (top view)

Fig. 40. Photograph of frequency multiplier and dual frequency converter (bottom view)

Fig. 41. Layout drawing of decade frequency generator; outputs at 100-kc intervals from 100 to $1000 \mathrm{kc} / \mathrm{s}$

Fig. 42. Circuit schematic of decade froquency generator

Fig. 43. Photograph of deoade frequeney generator (front view)

Fig. 44. Photograph of decade frequenoy generator (top view) 
Fig. 45. Photograph of decade frequency generator (bottor view)

Fig. 46. Circuit schematic of harmonic series generator

Fig. 47. Photograph of harmonic series generator (top-front view)

lig. 48. Photogr ph of hamonic series generator (bottom view)

\section{GENERAL DESCRIPTION}

\section{Introduction}

The microwave frequency standard at the Central kidio Propagation Laboratory, National Bureau of Standards, makes use of the National primary standard of frequency by extending its range to cover the microwave region. This is dore by multiplying the 100-kc frequenoy of the primary standard or a very constant and specially derived frequency measured in terms of the primary frequency, to give fixed points or complete coverage in the desired portion of the microwave spectrum.

\section{The Calibration Room}

The microwave frequency standard is installed in a temperature and humidity controlled, eloctrically-shielded room. Room temperature is normally held to $25^{\circ} \pm 1^{\circ} \mathrm{C}$, at a relative humidity of $50 \% \pm 2 \%$. The room may be readily operatec over a fairly wide range of temperature and humidity conditions if desirod. The standard-frequency distribution lines and the a-c power line entering the shielded room are filtered to reduce interference from outside radio-frequency sources: The room is shielded with one layer of $5 \mathrm{oz}$, electrolytic.sheet copper. All power supplied the room is regulated by external a-c regulators.

\section{The Primary Standard of Frequency}

The National primary standard of frequency consists of nine quartz-crystalcontrolled oscillators which operate continuously and are automatically compared with Naval Observatory time and with each other. The absolute value of frequency from each of these standards is thereby known within 1 part in 100 million at all times. Short-time constancy ( 1 hour or less) of these standards is usially better than 1 pert in $10^{9}$. Output from one or more of these oscillators is distributed to laboratory equipment where higher and lower standard frequencies are derived. One of the standard oscillators controls the continuous radio broadcast of standard frequencies from the Bureau's station iWW.

Details concerning the broadcast of technical radio services irom station WWV are given in an announcement obtainable on request.

4. The Freouency Gonerating Equipment

\section{a. General-Coverage System}

The method by which other standard frequencies are derived from the primery frequency standard may be seen by reference to the block diagram in Fig. 1. The standard frequency, $100 \mathrm{kilocycles}$ per second, is multiplied to a very-high or ultra-high frequency and thon impressed across a siliconarystel rectifier, the harmonics from which are selected to give the desired microwave standard frequencies. Continuous coverage is obtrined by adding, 
in a frequency converter, the output of precision, adjustable-frequency oscillators to the output of one of the multipliers and then continuing the multiplication.

Referring to Fig. I this process may be traced through in detail. The $100 \mathrm{kc} / \mathrm{s}$ is first multiplied to $7500 \mathrm{kc} / \mathrm{s}$ by conventional multipliers with sufficient filtering to reduce, to a very low value, all spurious sidefrequencies and harmonics in the desired output. The resultant frequency is added to the output of oscillator A or B and then tripled to the 28.5 to $30.9 \mathrm{kc} / \mathrm{s}$ range. Each of the precision oscillators $A$ or $B$ is adjustable over the range shown, with 8000 dial divisions and a very linear scale. Aftor further multiplication, the final frequencies are obtained for application to the crystal-rectifier harmonic generators. The same types of crystals are used in the different ranges of frequencies for harmonic generators as are normally used as mixers or converters in receivers for these same frequency ranges. The frequencies available at points $D, E$, and $F$ aro generated by multipliers using $829 \mathrm{~B}, 832 \mathrm{~A}$, and $2 \mathrm{C} 40$ tubes, respectively, and giving adjustable output levels as high as 2,2 , and 1 watts. Multiplier circuits are of the ordinary lumped-constant type except for the output circuit of the $270 \mathrm{Mc} / \mathrm{s}$ multiplier which uses parallel lines and the $810 \mathrm{Mc} / \mathrm{s}$ multiplier which uses a butterfly circuit.

It is seen that about $25 \%$ of the frequency stability of the output is derived from oscillators $A$ and $B$ whilo $75 \%$ is derived from the primary frequency standard. However, the instantaneous frequency of $A$ or $B$ may be determined by means of the usual calibrating enuipment shown to the right in the block diagram. This equipment also serves to monitor the frequency of oscillator $A$ or $B$ if it is desired to maintain a given frequency over a period of time.

\section{b. Fine-Tuning and Spot-Frequency frrangement}

For applications where finer control or a more constant frequency is needed the arrangement show at the left in the block diagram is used. Here, the output from the adjustable oscillator C mixes with outputs derived from the decade frequency generator and multiplier to give continuous coverage from 2000 to $2800 \mathrm{kc} / \mathrm{s}$, which is again mixed with the $7500 \mathrm{kc} / \mathrm{s}$ in the main converter in place of oscillators $A$ or $B$. For example, to obtain outputs from 2700 to $2800 \mathrm{kc} / \mathrm{s}$, the $900 \mathrm{kc}$ output may be multiplied to $1800 \mathrm{kc} / \mathrm{s}$ and $400 \mathrm{kc} / \mathrm{s}$ added in converter L to obtain $2200 \mathrm{kc} / \mathrm{s}$, to which the output from oscillator c may be added in converter $K$ to obtain the desired output. It will be seen that most of the combinations in the range 2000 to $2800 \mathrm{kc} / \mathrm{s}$ may be obtained by using only two of the three channels in the multiplior-converter unit. Since the converter channels may also be used as multipliars in their tunable ranges, it is evident that many combinations are available in obtaining most of the desired output frequencies. The output constancy is accordingly now controlled to the extent of about $5 \%$ by oscillator $\mathrm{C}$ and $95 \%$ by the primary standard. The output frequency range is covered by 64,000 dial divisions which gives an adjustment of approximately 4,12 , and $40 \mathrm{kc} / \mathrm{s}$ per dial division at frequencies of $3000,10,000$, and $30,000 \mathrm{Mc} / \mathrm{s}$, respectively. This is a frequency change of about 1 part in $10^{6} \mathrm{por}$ dial division, while oscillators $\mathrm{A}$ and $B$ give a change of about 5 parts in $10^{6}$ per dial division. An additional fineadjustment control on oscillator $C$ covers a range oqual to \pm 3 dial divisions for a $180^{\circ}$ rotation. 
The arrangement shown in the left in the block diagram of Fig. 1 also serves to give outputs from 2000 to $2800 \mathrm{kc} / \mathrm{s}$, at $100 \mathrm{kc} / \mathrm{s}$ intervals, derived entirely from the primary standard. This gives fixed frequencies with an a.ccuracy of 1 part in $10^{8}$ or better at approximately $1 \%$ intervals throughout the range of the equipment. When using oscillators A or B for continuous covergge an accuracy of frequency of 1 part in $10^{7}$ or better is obtained. By using the fine-tuning equipment and oscilistor $\mathrm{C}$, an accuracy of 2 parts in $10^{8}$ may be obtained. For convenience in checking and higher accuracy, oscillator $C$ may be monitored at the fourth harmonic using the same interpolation range and equipment as used for monitoring oscillator A. The outputs will remain constant in frequency to these stated accuracies for several minutes when using the acjustable oscillators; and the interpolation equipment allows continuous determination of f'requency over longer periods of time.

\section{c. Frequency-Measurement Equipment}

The equipment for measuring the frequencies of oscillators $A, B$, and $C$ is of conventional type. Briefly, an audio-frequency interpolation oscillator is used to measure the frequency difference botwoen the oscillator's output and harmonic check points derived from the primary-standard frequency. A harmonic series generator and level mixing unit supplies harmonics of $100 \mathrm{kc} / \mathrm{s}$ and $10 \mathrm{kc} / \mathrm{s}$, derived from the primary standard, combined with the adjustable oscillator's output, into a radio receiver tuned to the oscillator frequency. When properly tuned and adjusted, the output of the receiver will contain a beat note of between 0 and $5,000 \mathrm{c} / \mathrm{s}$, which is compared directlv on an oscilloscope with the output of the interpolation oscillator covering a 0 to $5,000 \mathrm{c} / \mathrm{s}$ range and having a linear calibration. When properly adjusted this oscillator has an accuracy of $\pm 1 \mathrm{c} / \mathrm{s}$ throughout its entire range, thus the frequency of the unknown oscillator may be determined within $\pm 1 \mathrm{c} / \mathrm{s}$, or approximately 1 part in 2 million for any one of the three oscillators. If higher accuracy is required in determining the frequency of the adjustable oscillator, its irequency may be measured at a harmonic, with a proportionate gain in measurement accuracy. This, however, is not justified, except where continuous monitoring is employed, as the short-time stability of the oscilla. tor ( 3 minutes) is only of the order of 1 part in 2 million. Beats very near to $O$ may be conveniently checked at harmonic in this manner, or, if $s$ till tc low, may be counted.

\section{d. Harmonic Generating and Detection Equipment}

The final output of the multipliers at points $D, E$, and $F$ is impressed across a silicon-crystal rectifier of appropriate type in order to generate harmonics in the. microwave bands. These rectifiers are installed in the standard coaxial mounts or mixers ot frequencies up to about $3,000 \mathrm{Mc} / \mathrm{s}$ and in waveguide mounts at higher irequencies. Various arrangements can be used. Nixers, such as Radiation Laboratory type TPX-35GM and TPK-23KL, are satisfactory as harmonic generators. Frequencies thus obtained in the coaxia] or waveguide transmission system constitute the frequency standards and are utilized in the measurement of unknown frequencies or calibration of frequency meters. 
The frequency range covered by these harmonies is show in Fig. 2 . Har monics of the 85.5 to $92.7 \mathrm{Mc} / \mathrm{s}$ output overlap in renge from about $1300 \mathrm{Mc} / \mathrm{s}$ up, those of the 256.5 to $278.1 \mathrm{Mc} / \mathrm{s}$ output overlap from $3200 \mathrm{Mc} / \mathrm{s}$ up, and those of the 769.5 to $834.3 \mathrm{Mc} / \mathrm{s}$ output overlap from $9200 \mathrm{Lc} / \mathrm{s}$ up. When a choice of multiplier output is possible, the higher output frequency will, of course, utilize the lowest order of harnonic and give the highest microwave output in the desired range. The directly-dorived fixed-frequency outputs, which occur at approximately $1 \%$ intervals throughout the spectrum, divide each harmonis range shown into eight equally spaced parts, the frequencies being accurate to 1 part in $10^{8}$ or better. The order of harmonis boing usod is, in each case, checked by use of a previously calibrated frequency meter; or, if one is not available within the range, by the agreement of two separate measurements using different harmonics in esch case.

Although the microwave pover derived from the harmonic generators is low, by the use of sensitive radio receivers or spectrum analyzers, calibrations and frequency measurements may be made. Ordinarily, the calibrating and unknown frequencies are fod into the spectrum analyzer and tho standard froquency adjusted until the indicated pips on the screen of the spectrum analyzer coincide. An unknown oscillator of sufficient constancy may bo accurately measured by heterodyning with a standard fixed frequency.

To determine the resonance frequency of cavity-type frequency meters a similar procedure may be used in which the frequency of an external oscillator set at the resonance frequency of the cavity is determined by comparison with the standard. Or, alternatively, the standard frequency itself may be used to excute the cavity and adjusted until a maximum or minimum is seen on the spectrum analyzer, depending on whether a transmission-type or reaction-type cavity is being measured. With the addition of a frequency of approximately id $/ 2 Q$ fod into the harmonic-generator crystal at proper amplitude along with the standard frequency, so as to give a side-band frequency on each side of the cavity resonanoe curvo at about the half-power point, an improvement of from 2 to 5 times in accuracy of oalibration may be obtained. Resonance is then indicated when the standard frequency is adjusted to give equal amplitudes on eacil side-band pip. When using this method, however, it is important that the response of the overall analyzer equipment following the frequency meter be flat. Operating near the edgo of an oscillator "mode" and critical matching stub adjustments should be aroided.

Superheterodye search receivers with panoramic adapters are available for calibration and measurement work over the range from 300 to $3000 \mathrm{Mc} / \mathrm{s}$. In addition, spectrum-analyzer equipment is readily available with detection equipment covering the ranges of 2,400 to $3,750 \mathrm{Mc} / \mathrm{s}, 5,200$ to $8,000 \mathrm{Mc} / \mathrm{s}, 8,400$ to $10,000 \mathrm{ic} / \mathrm{s}$, and 21,500 to $26,400 \mathrm{Mc} / \mathrm{s}$. Accordingly, even though the frequency standard has complete and continuous coverage, it is at present somewhat more difficult to make frequency measurements of unknown frequency meters outside the above ranges. Additional plumbing and local oscillator equipment is being made available so that complete coverage of the ontlre microwave spectrum may be conveniently hendled. Multiple conversion, measurement of harmonics, and beat-frequency measurements without speotrum analyzers are other methods which may bo utilized. 
4 spectrum analyzer (Radiation Laboratory tyoe) with plumbing covering the runge 3,400 to $10,000 \mathrm{Mc} / \mathrm{s}$ approximately, with crystal harmonic genorator and unknown and calibrated frequency metors in position is shown in Fig. 7.

Complete coverage of the range from about 300 to $100 \mathrm{Mc} / \mathrm{s}$ is obtained by jeeding the output from the 28.5 to $30.9 \mathrm{Mc} / \mathrm{s}$ multiplier through a harmonic generator of the coaxial type. Also, by the use of the converter-stage outputs on the fine-tuning unit, complete coverage of the lower freguencies from audio frequencies up to $300 \mathrm{Mc} / \mathrm{s}$ may be obtained.

\section{Hecuracy of Calibrations}

\section{Unknown Oscillator Frequencies}

The limit of accuracy with which the frequency of an unknown oscillator can be measured is the absolute accuracy to which the standard frequency itself is known, or as previously stated, to 1 part in $10^{8}$. (Frequency intercomparisons betwoen the various primary-standard oscillators are regularly made to 1 part in $10^{10}$ ). Using the regular oquipment with osciliators $A$ or $B$, a maximum accuracy of 1 part in $10^{7}$ may be achieved if the frequency of the unknown is sufficiently constant. Witen using the spot-frequency or fine-tuning equipment 1 or 2 parts in $10^{3}$ are the approximate limits of accuracy.

After reaching operating temperature, when using oscillator combinations $A$ and $B$, or $C$, the constancies of these oscillators are such that accuracies of the output frequencies of 1 part in $10^{7}$ and 2 parts in $10^{8}$, respectively, may be maintained over a three-minute period without adjustment. For most microwave oscillators, this constancy is considerably better than that, of the froquency being measured.

\section{b. Frequency Meter Calibrations}

The accuracy certified in calibration of a frequency moter depends on constancy of the meter, its $Q$ and on the sensitivity of the resonance-indicating derice. The useful accuraoy of the calibration also depends upon the sensitivit. of the method followed to set on resonance in use, and on whether or not the reactance coupled into the carity by the external circuits is the same as that whon the calibration was made. To reduce frequency pulling, due to coupled reactance, callbrations are usually made with matohed attenuators haring onough attenuation to effectively isolate the frequency meter.

For cavity-type frequency meters, sealed against humidity changes and either temperature-compensated or made of invar, the effects of humidity and temperature can be greatly reduced. For unsealed cavities, calibration in the controlled standards room greatly improves the accuracy of calibration, but use of the cavity under conditions other than standard will involve additional errors eren though corrections are made. These arise because of errors in the measurements of temperature and humidity, failure of the cavity to come to equilibrium, and errors in the correction data to bo applied.

The accuracy of tunable-type cavity frequency meters is also limited by backlash and dial inaccuracies and by the fact that those meters are seldom of the sealed type. 
The accuracy of calibration of a cavity frequency meter depends on how closely it can be set to resonance. Since it resonates over a finite bandWdth determined by its loaded $G l$, the accuracy of calibration will bo a function of the $Q$ of the cavity. This can bo determined by calculating. the sensitivity of setting the cavity to resonance in terms of the smellest change in output response which can bo soen on the output indicator used for dotermining resonance. If the output indicator is a speetrum onalyzer, the helght of response on the osoilloscope will be proportionel to the $8-f$ innut power to the analyzer; this dependence is brought about by proper design of the second detactor circuit and is done in order to show an energy spectrum on the oscilloscopo. This increases the sensitivity of setting a cavity to rosonance compared to that obtained with a receiver having output proportiongl to input roltage.

The height of rosponse on a spoctrum analyzer can bo calculated erorn the equivalent circuit shown below, where there is also shown a curve of gesponse versus frequency.
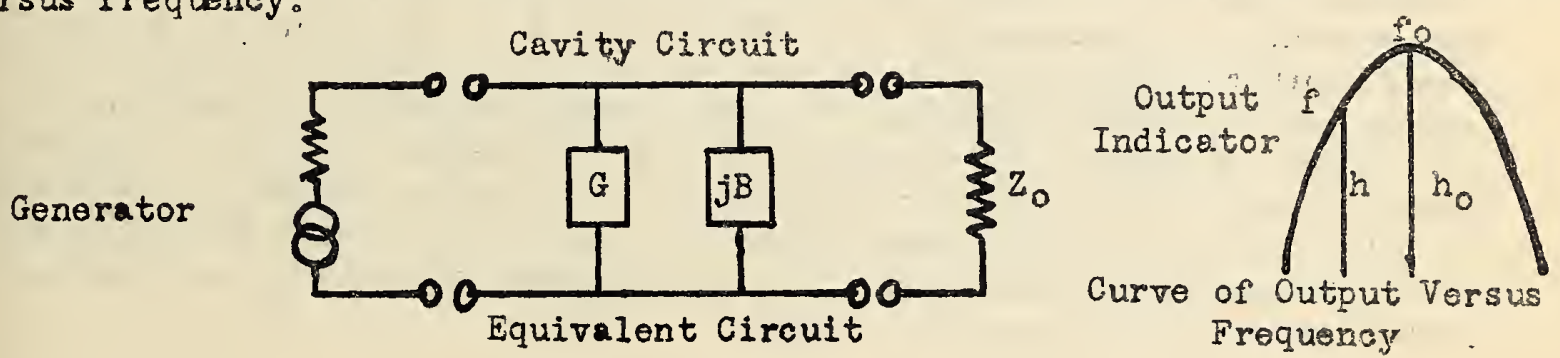

This equiralent circuit is derived from cavity theory for a symmotrioal. cavity and shows the cavity as a parallel resonant circuit having conductance $G$ and susceptance $B$. The oquivalent constant voltage generator transmis power to the matched output load $z_{0}$. The ratio of power transmitted of resonance, $P$, to that transmitted on resonance $P_{O}$, will be equal to the ratio of zesponse off resonance, $h$, to that on resonance, $h 0^{\circ}$ This can be show to be given by the following formula,

$$
\frac{h}{h_{0}}=\frac{\dot{p}}{p_{0}}=\frac{1}{1+4 \frac{q_{l} \Delta r^{2}}{p_{0}}}
$$

where $\Delta f=f_{0} \rightarrow f$. The fractional uncertainty in setting to resonance is given from this formula as

$$
\frac{\Delta f}{r_{0}}=\frac{1}{2 Q R} \sqrt{\frac{\Delta h}{h_{0}}}
$$

whon $\Delta h \ll h_{0}$ as is the case for the faral $Q_{l}$ values encountered. Here $\Delta h=h_{0}-h$ and is tho snallest change in response that can bo determined on the output indicator. For a cavity having a loaded Q2 of 10,000 and $\Delta h / h_{0}=1 / 25$ this equation gives $\Delta f / f_{0}$ as one part in 100,000 . Actual tests show that this is the order of accuracy of setting obtainabie whis presentwday spectrum analyzers when trying to set to the maximum of the response curve where the slope is zero. By careful work, accuracies sonem what better than this can bo obtained. However, when much greatar sensitivities for setting to resonance are needed, it is necessary to us other 
methods, some of which work on the steep sides of the resonance curves, such as the method described under 3-d. A cavity $Q$ moter omploying such methods gives sensitivities several times greater than that obtained by sotting at the peak of the resonance curve. Increased sensitivity would also bo obtained by sharpening the response curve by means of circuits for which the output response of the spectrum analyzer goes up faster than the case where it is projortionel to the input power.

\section{c. 2 Measuroments}

In accurate messuresitint of the loaded $Q$ of transmission-type frequency meters, or other synumitic trensmission-type components, may bo made by measuring the frequencies at which the power transmission drops to 0.5 of the resonance-frequency power. The $Q$ then equals $f_{0} /\left(f_{2}-f_{1}\right)$. For high $Q$ components the limit of accuracy using this method ls determined by the precision to which the 0.5 power points can bo set. A conservative estimate that these points can bo set to $\pm 2 \%$ of the $f_{0}$ maximum rosponse value (which is approximately a $\pm 3 \%$ variation in amplitude at the halfpowor points) would result in a maximum error of about $4 \%$ in the $r_{2}-f_{1}$ value, as the voltage response is very nearly inversely proportional to the number of cycles off resonance in the half-pover regions. This would give a similar $4 \%$ maximun uncertainty in the $Q$ value caused by limitations in doternining the half-power points and should constitute the principal error in such $Q$ measurements. This can be soen by solving the equation given abovo for $a$ from which we have

$$
Q_{2}=\frac{r_{0}}{2 \Delta f} \sqrt{\frac{h_{0}-h}{h}}
$$

where $h=1 / 2 h_{0}$ at the half power point.

For measuring the $Q$ of reaction type cavities it is usually nocessary to terminate the line with the cavity and to neasure the standing wave ratio, with a slotted line, as a function of frequency. This curve can be plotted and $\Delta f$ determined as the distance between points on the curve where the standing wave ratio is given by

ing wave ratio at resonanco. The loaded $Q_{l}$ is then $r_{0} / \Delta f$.

$$
\frac{r_{0}+1+\sqrt{r_{0}^{2}+1}}{r_{0}+1-\sqrt{r_{0}^{2}}+1} \text { where } r_{0} \text { is the stend- }
$$

Components having low $Q$ values (less than several thousand) cannot be roliably measured diroctly by using the microwave frequency standard as a source of excitation, since the $Q$ of the multiplier circuits and the matching components in the crystal multiplier assemblies is fairly high and the mixer and local oscillator plumbing may also be fairly froquency-sensitive. Then low $a$ values are to be determined, a local oscillator with constant output over the range to be oxplored should be coupled directly to the component to bo measured and a detecting system of linear or known response used to set the half-power points. This oscillator is then measured by comparion with the microwave frequency standard. With this method tho accuracy of $Q$ mesurements is usually limited by the precision with whioh the halfpower points can bo set and the constancy of output maintained by the oscillator over the range used. 


\section{d. Dependence of Kesonsince Frepuency on Teruperuture for Cavities without Tomperature Compensation}

Since the resonance frequency of a cavity is a function of its linear dimensions, and since these vary with temperature, the calibration of a frequency meter requires a specification of its temperature at the time of measurement. From the principle of electrodymanic similitude it follows for a perfectly conducting cavity that regardless of the type of moce or shape if all linear dimensions be varied proportionately, then the reciprocal of the frequency will vary in the same proportion. In general, for cavities of finite conductivity, neglecting secondorder effecta,

$$
\frac{\Delta Q}{b}=-\frac{\Delta A}{f}=\alpha\left(T-T_{0}\right)
$$

where $\frac{\Delta l}{l}$ represents the fractional increase in linear dimension, and is

the thermal coefficient of expansion for the material from which the cavity is made, assuming this is homogeneous. Since the temperature of the cavity in general will be uniform within $0.1^{\circ} \mathrm{C}$, and may be spocified at the time of calibrition to that figure, the frectional error in frequency of calibration due to the uncerteinty in the temperature is, under these conditions,

$$
\frac{\Delta r}{r}=-\frac{\alpha}{10}
$$

The expension cofficient $\mathcal{C}$ is the increase in length per unit length per degree Centigrede and has values of $0.9 \times 10^{-6}, 9.6 \times 10^{-6}, 19.0 \times 10^{-6}$, for invar, stainless steel, and brass, respectively.

\section{- Dependenoe of kesonance Frequency on Hurnidity}

The resonance frequency of a cavity is also a function of the dielectric constant of the medium it encloses. For porfectly conducting cavities, regardless of shape or mode, it follows from the principle of electrodymamic similikcio, that, all other factors remaining constant, a rractions incresse in dielectric constant, $\Delta \in$, produces a fractional decrease in frequency givan by $\frac{\Delta r}{r}=\frac{\Delta E}{2 E}$

The dieloctric constant of the air within a cavity is a function of the partial pressures of dry air and water vapor, and the temperature, ox what is equivalont, the relative humidity. Report 599, entitled "Standards for microwave frequencies," issued by the Radiation Laboratory, discusses the effect of relative humidity on resonance frequency of carities, and gires graphs of the dielectric constant of air over varying conditions. Reporti 599 ircludes a nomograph giving the change in frequency of a resonant cavity due to changes in tho relatire humidity. 
Unsealed or somi-sealed carities may be subject to additional errors due to mode-lampint materials. Some materials such as poly-iron used for modedamping are hygroscopic and in giving up moisture will keep the atmosphere in the cavity at a higher relative humidity than that of the outside controllod atmosphere. Since the amount of moisture in the material is unknown and depends upon the previous history of the cavity, the cavity should be thoroughly flushed out wi th the controlled atmosphere and allowed to stand for several days under controlled conditions until equilibrium is reached.

The accuracy with which calibrations of cavities can be made can be summed up by stating that commercial cavities with a $Q$ of about 10,000 have been measured with an accuracy of 1 part in 50,000 to 200,000 or better depending on whether the cavity was sealed or not. I sealed and compensated cavity might be calibrated much more closely by using more sensitive methods of setting on resonance. Ajustable cavities might not warrant such close calibrations because of mechanical inaccuracies of the tuning and dial arrangement.

\section{Calibration Service of the National Bureau of Standards}

The services of the Central Radio Propagation Laboratory of NBS, in connection with frequency standards, include measurements, tests and information on instruments which are in turn used as standards to test or measure considerable numbers of other instruments.

The frequency standards services are available without charge to the Army, Navy, and other Govermment agencles. The Army and Nary may arrange that similar services bo supplied, wi thout charge, to industrial concerns thet need such services directly in connection with inrmy or Navy contracts. Frequency standardization tests are available to the publio, with fees charged in accordance with the normal NBS policy.

All requests for tests of oscillators or frequency meters in the range above $300 \mathrm{Mc} / \mathrm{s}$ should be made in writing to the Director. National Bureau of Stardards, Attention Central Radio Propagation Laboratory, Division XIV, Section 9, and sholid state the frequency or frequencies to be covered, mothod of coupling, and any special limitations or operating conditions dosired for the test. Calibrations will normally be made at room conditions of $25^{\circ} \mathrm{C}$ and 50 -persent relative humidity.

All requests for tests for contractors for Army or Navy should reach the NBS in writing via an inspection, liaison or other office of the Army or Nevy.

Appendix

I. Operating Instructions

Efsicient, operation of the microwave froquency standard requires a knowledge of the relative advantages of the various possible combinations of equipments and auxiliaries. The location and proper use of the various controls and connecting circuits should also be understood. 
Generally, a frequency of $100 \mathrm{kc} / \mathrm{s}$ will be supplied through the filtered line to the standard frequency jack at the top-lest of the center rack. From this jack tine signal is connected through the distribution amplifier to the various other equipments as show in the block diagram. The use of external panel connections for all interconnecting leads is employed to obtain msximum flexibility and utility of the equipment. The $100 \mathrm{kc} / \mathrm{s}$ frequency supplied from one of the primary-standard oscillators, will normally be within 2 parts in $10^{7}$ of true frequenoy. Where measurements requiring a higher order of accuracy are being made, the absolute value within 1 part in $10^{8}$ ahould be obtained from the Frequency and Time standards group of Secticn 8.

In making calibrations or measuremorts it is necessary to decide which units of the equipment should be usad. Adjustablemtype frequency meters may bo most easily calibrated using the spot-frequeney equipment to generate harmonics entirely controlled from the primary standard, urilass $1 t$ is necessary that calibrations be made at certain specific frequencies. Fixed-type frequency meters must be calibrated by use of the adjustablo oscillator and interpolation equipment. The fine-tuning adjustable oseillator should be used only where extremely accurate measurements or maintenance of constant frequency over a long period are desired, since it involves the use of sereral added controls and additional steps in the computations.

Because of the high accuracy and wide coverage of the microware frequency standard, it is a rather complicated inatrument, Plaliminary soarehing or

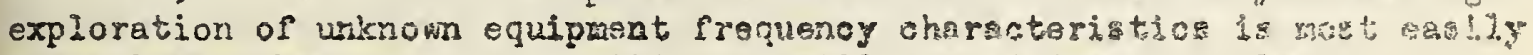
accomplished by use of an auxiliary oseilletor of fer oontrols.

\section{Procedure for Naking Calibrations Uging Adjustable-Frequency Ogci Ilatorí}

Before using the adjustable oscillator equipment for highly accurate cal. iorations, the oseillators should be allowed to stubilize for one hour or livis. The mitiplier and converter equipmont ray be used without tinle warmoup period without loss of accuraoy, but the tuning of 8 ome of the high $Q$ circuits may have to be readjusted periodically until temperaturs stabilization occurs. The a-c power to the entire threo-rack installation is controlled by oye of the breaker switches on the distribution-box and oach rodu"s antire aguipmento is controlled from the toggle switch on the right side of the top pant of ea rask.

The approximate microwate frequency required for calibrabion or masurement will aiready by wown or should be determined by use of a searoh oseiliator or by other means. A convenient method for doint this, where a fregieney metor to be calibrated lies within tho range of a spectrum analyzer, is to couple the meter closely to the analyzer input and sbserve the reation pip or tho local-oseillator "mode" curve. By matching this pip with on par a cali... brated frequency meter a fairly accurate preliminary alibration may be made. For adjustable irequenoy meters the approximate end. limits of frequency stould be determined and the desirod calibration points betwen these linits selectod.

After determining the desired epproxinate frequency, the harmonic rergo chart (Fig. 2) should be examined and the highest output range seiscted whish will give harmorics at the desired frequencies. If continuous coverage is 
desired over grater than an $8 \%$ frequency range, harmonies of the 12 th order and higher must be used. The use of the highest output range (and lowest harmonic order) gives the greatest amount of microwave power and requires the use of less gain in the spectrum analyzer. This reducos the amount of amplitude instahility or jumpiness of the pip on the analyzer sereen and the amount of "stub swiddling" or matching required to get a usable signal. The required frequency at a given output jack is divided by the proper multiple of 3 to get the approximate frequency at the 9.5 to $10.3 \mathrm{Mc} / \mathrm{s}$ output of the converter stage. The required adjustable oscillator frequency is obtained by subtracting $7.5 \mathrm{Mc} / \mathrm{s}$; the correct dial setting for the oscillator is obtained from the calibration chart or from one of the frequency graphs. is,

Forking upward from the converter stage, the microwave output frequency

$$
F_{m}=\left(7.5 \mathrm{MC}+F_{0 s c}\right) \mathrm{AB}
$$

where $A=9$ for the 90 Mc range; 27 for the 270 Mc range; 81 for the 810 Mc range

B - harmonic multiplication order of the crystal multiplier

Calibration charts are supplied for the 2.0 to $2.4 \mathrm{Mc} / \mathrm{s}$ and 2.4 to $2.8 \mathrm{Mc} / \mathrm{s}$ oscillators which give the dial setting for each even l0-kc point throughout their ranges. These dial settings may normally be relied upon to be within \pm 1 dial division or approximately $\pm 50 \mathrm{c} / \mathrm{s}$. Dial settings for erequancies botween these points are obtained by interpolation, or with greater ease and accuracy by the use of the interpolation equipment used to measure the final frequency. Charts giving the microwave frequency outputs from harmonics of the $30,90,270,810 \mathrm{Mo} / \mathrm{s}$ output stages with adjusteblo oscillator inputs of 2000 to $2800 \mathrm{ko} / \mathrm{s}$ at each $100 \mathrm{kc} / \mathrm{s}$ interval within this renge are also arailable. It is nocessary to determine the harmonic multiplication order of the crystal multiplier to compute the microwave frequency being measured. These harmonics are usually icienti. fied by uso of a previously calibrated frequency meter having suffici= "is accuracy to urmistakably identify the harmonic boing used. In the event that no ealibrated frequency meter is available in the range being used, severa? successive harmonics may be used to obtain the desired microwave frequency. It is best to use at least three soparate input frequencies to give these harmonic responses and through knowledge of the input frequencies determine the harmonic order for each input frequency. If only two froquencies are used it is sometimes possible to select harmonics that are not adjacont, but may be assumed so, thus giving an orroneous result. This may be more likely to occur if the measured microwave froquency range is not approximately known, but is very unlikely to occur if three separate harmonies are used.

2. Measurement of justable-Oscillator Frequencies

The adjustable oscillator frequencies are measured directly in terms of the primary standard of frequency by eomparison with frequencies or harnonics derived from the standard. A harmonic series generator is used to generate harmonics of $100 \mathrm{kc} / \mathrm{s}$ and $10 \mathrm{kc} / \mathrm{s}$ throughout the $550 \mathrm{ke}$ to $30 \mathrm{Mc} / \mathrm{s}$ range of the recelver. Only the frequency range of 2.0 to $2.8 \mathrm{M}$. is used in measuring the adjustable oscillator frequencies. The 500 to 
$600 \mathrm{kc} / \mathrm{s}$ oscillator, used with the fine-tuning arrangement, is measured on the fourth harmonic and the resulting frequency divided by four to obtain the greater accuracy which is desirable when this oscillator is used.

The resulting beat note from the receiver between the adjustable osoillator and the $10 \mathrm{kc} / \mathrm{s}$ standard-frequency markers is measured by means of the audio-frequency interpolation oscillator and comparison oscilloscope. This oscillator (G.R. type 617-C) has frequency range of 0 to $5000 \mathrm{c} / \mathrm{s}$ and, when checked against the $100 \mathrm{c} / \mathrm{s}$ from the standard-controlled frequency divider at 100 cycle intervals, has an accuracy of $\pm 1 \mathrm{c} / \mathrm{s}$ throughout its range. The approximate frequency of the adjustable oscilletor is determined from the dial calibration and the observed beat frequency added to, or $s u b$ tracted from, the proper $10 \mathrm{kc} / \mathrm{s}$ multiple to get the exact oscillator frequency. Where the beat note is either very near 0 or $5000 \mathrm{c} / \mathrm{s}$, a slight adjustment of the oscillator dial after the beat frequency has been noted, and observation of the direction of change will determine if the beat frequency should be added or subtracted. By using the crystal silter on the receiver and proper tuning, frequencies up to $5000 \mathrm{c} / \mathrm{s}$ may be measured. Beat frequencies too near to zero beat to be measured on the oscilloscope may be measured at a higher frequency on the receiver or counted.

The harmonic series generator panel includes mixer controls by which the relative strengths of the standard and unknown signals may be adjusted for maximum beat frequency output. Fixed insertion-type attenuators are also provided for a rough control of these output levels.

In similar manner the receiver and interpolation equipment may be used to measure the frequency of any signal in the erequency range of from 0 to 30 $\mathrm{Mc} / \mathrm{s}$.

3. Use of Fine-tuning and Spot-Frequency Equipment

The fine-tuning arrangement makes use of the outputs from the 500 to $600 \mathrm{kc} / \mathrm{s}$ oscillator, the deoade frequency generator, and the frequency mul. tiplier and dual-frequency converter to gite a highly accurate, precisely controlled, continuous coverage of the frequency range of 2.0 to $2.8 \mathrm{Mc} / \mathrm{s}$. This output is supplied to the main frequency converter in place of the adjustable oseillator outputs of 2.0 to $2.8 \mathrm{Mc} / \mathrm{s}$ to give very fine tuning control and much higher stabllity for critical measurement applications in the microwave frequency band. Normally, the multiplier stage or the first converter stage will be used to generate multiples of $100 \mathrm{kc} / \mathrm{s}$ of from 1500 to $2200 \mathrm{kc} / \mathrm{s}$, obteined by multiplying or mixing outputs from the docade frequency generator. Do these respective frequencies the 500 to $600 \mathrm{kc} / \mathrm{s}$ from the oscillator is added, through use of the second converter stage. The osciliator should always be patched into the right-hand input jack on the converter stages to reduce harmonic interference or spurious frequencies in tho output. These spurious frequencies are caused by harmonic distortion of the oscillator froquency in the converter tube and, when these harmonics fall near tine desired output frequency, may be of susficient amplitude to be bothersome under certain conditions. If such interference occurs, the other side-band or difference frequency may be used in some cases to obtain the same output frequency, or the oscillator frequency may be injected at the first converter and fixed frequency substituted the second converter. 
The latter method requires that one more tuning control be kept in step when adjusting the oscillator frequency. Spurious frequency responses are treated in detail under section 4-C. When using the converter stages for multiplication only or for mixing frequencies entirely derived from the standard, no harmonic side-frequencies are generated.

Fixed frequencies at $100 \mathrm{kc} / \mathrm{s}$ intervals in the frequency range 2.0 to $2.8 \mathrm{Mc} / \mathrm{s}$ are generated by multiplying or combining in the converters the outputs from the decade frequency generator. Several combinations are possible for many of the frequencies and, since no harmonic-generated side frequencles are present, any readily obtained combination may be used. The microwave outputs, when using these frequencies, are most useful for calibrating tunable frequency meters or for supplying marker frequencies in any portion of the microwave spectrum.

\section{Operating Technique and Precautions in Use of Equipment}

\section{a. Frequency Standard}

In using the microwave frequency standard, the desired oscillator units should be tumed on and stabilized and the proper interconnections completed. The meter on the 100 to $7500 \mathrm{kc} / \mathrm{s}$ multiplier should be adjusted to read at one-helf scale when the meter switch is in the left-hand position by moans of the level control on the $100 \mathrm{kc} / \mathrm{s}$ distribution amplifier. This meter also serves as a convenient indication that the $100 \mathrm{kc} / \mathrm{s}$ is being supplied when starting up the equipment. Lamp loads are available for the various output jacks anc power levels and serve as convenient relative-power-output indicators when tuning up or adjusting the various circuits.

Tuning of the various stages should progress from the lowest-frequency stage un through the various mixers and multipliers to the output stage. Meters ale available on each tunable stage for adjusting to resonance. These meters give no indication of the power output; in most cases they show conditions of maximum radio-frequency current. plate-current meters are also provided for the 90,270 , and $810 \mathrm{Mc} / \mathrm{s}$ multiplior output stages, but since the multiplier efficiency is low in these stages, these meters show slight indications of resonance and are chiefly useful for determining tube loading. The very low efficiency of the output stages makes the system practically fool-proof. Detuning of any of the stages or operation at minimum bias control settings will not overload the tubes. Considorable caution should bo observed when using crystal multipliers on any of the outputs, that the crystal is not burned out from a sudden overload as the output stage is tuned up. Output levels for each of the three output stages are adjusted by means of a bias control for each stage. Tho excitation to the $90 \mathrm{Mc} / \mathrm{s}$ stage is so balanced that output from this stage may be controlled from 0 to approximately 2 watts. Output from each of the other stages is normally adjusted by means of this same $90 \mathrm{Mc} / \mathrm{s}$ control, the other bias controls being adjusted for optimum operation and left there. Filament switches are provided on the 270 and $810 \mathrm{Mc} / \mathrm{s}$ stages for turning these tubos off when not in use. A grid-range switch in the 810-Mc untuned input must a.280 be thronn to the proper position when using the 270 or 810 -Mic stages. 
The practice of turning off all of the equipment except the oscillators for standby periods of several hours or greater will save considerably on tube replscoments. The considorable reduction in heating also reduces the load on the air-conditioning unit during such periods.

\section{b. Crystal Multipliers}

The use of silicon-crystal rectifiers of the series IN21, IN23, IN26, or other types to generate high harmonics from the standard frequency outputs at $30,90,270$, and. $810 \mathrm{Mc} / \mathrm{s}$ simplifies considerably the messurement of microwave frequencies. These rectifiers, however, have certain limita. tions which must be considered when used in this manner. Since the power outputon any particular harmonic is very low (the order of microwatts) it is nocessary to work the crystal rectifier at very nearly the maximum power input it will stand under continuous operation. This power is of tho order of 0.1 to 0.5 watt depending on the type and condition of the crystal being used. Crystal input impedances generally range from 100 to 500 ohms.

The optimum excitation is readily apparent for any particular harmonic if the output is observed on the spectrum analyzer oscilloscope. Increasing power input beyond the optimum point will result in rapid loss of output which will drop to zero at possibly twice the optimum input power. If a meter is connected $s 0$ as to read rectified crystal current, its reading will be maximum when the greatest harmonic power is being generated. This decrease in output current or rectification efficiency under overloaded conditions is genorally attributed to a reduction of the reverse resistance of the crystal. Maximum current will genesally bo of the order of 20 to 50 milliamperes. The use of an indicating moter gives a convenient means of ajusting for maximum hamonic output and 180 serves to show, to some extent, tho condition of the erystal. Operation at, or very near the point of maximum harmonic power output reduces considerably the tendency toward jumplness of the recoived igal on the odcilloscope. However, oporation of a crystal rectifier at input above the maximum current or harmonic output point for any considerabie period of time will result in los of sensitivity or burn-out of the erystia.

In the wayomide mounts where the base of the crystal is clamped at one side of the wave guide, an insulated connoction may be installed for use in operating a rectisiedocurreat meter. A button condenser is userul in making the outlet low inpadanes to microwave power. By use of 8 . variable resistor in the neter circuit, a roctified nogativo bias can be used or tho crystal which may improve the generation of harmonics by as much as 5 db in some cases. This reduces the power dissipation in the crystal but increases the revers voltage appliod. The use of some of the newer types of highoback voltago crystals such as woldod germanium crystals may incroase considerably the amount of microwave power output. On the other types of erystal mounts. some form of shunt feed on the center conductor of the radionfrequency inplit cable can bo used to obtain the connoction point for cryalal-current meter and bias control. 
By moans of the crystal current tap or through a rogular coaxial I connection, an additional frequency may be injected into the crystal multiplier to give ide bands on both sides of every harmonic of the multiplier output. Those side bands are useful as additional marker frequencies and as a means of higher accuracy in the calibration of frequency moters, if the side bands are generated at approximately the half-power polnts. Undesired spurious sidebands and responses and some of their causes are discussed in soction $c$ below under "spurious frequencies".

In tuning up the multiplier it is best to adjust the bias control to give low output, maximize each of the tuned stages, including the final output stage and then maximize the harmonic output by adjustment of the $90 \mathrm{Mc}$ bias control. This insures that each radio-frequency stage is tuned properly and has not been falsely detuned to show maximum harmonic output because the crystal had been overloaded at resonance.

The use of "line stretchers", matching transformers, etc。, in the line feeding the crystal multiplier is usually not necessary, except perhaps at the 810-Mc input frequency. Since the crystal impedance is generally several times as high as that of the line, standing waves will develop. By having adequate reserve power the optimum crystal excitation may still be maintained. In the 810-Mc stage the use of a line stretcher of six to eight inches variation may prove helpful.

\section{c. Spurious Frequencies}

Spurious or undesired frequencies in the outputs from the crystal multipliers are introduced from several sources which will be discussed separately It should be noted that spurious frequencies slightly separated from the desired driving irenuency and 30 to $40 \mathrm{db}$ down in level, may, when passed through the crystal multiplier, come out at equal amplitudo with the desired harmonics or in some cases even completely obscure the desired frequency. Proper converter adjustment, reducing these interfering frequencies by 50 to $60 \mathrm{db}$ in the range where harmonic interference devolops and careful tuning of the other stages will reduce these interforenses to a satisfactory level.

\section{(1) Multiplier Side-Frequencies}

Side-frequenoies are generated in the frequency-...iliplier stages which consist of adjacent harmonios to the desired harmonic output. These adjacent harmonics appear in the output with a ratio to the desired frequency which is determined by the relative harmonic content generated and by the selectivity of the output tank or filter employed. The higher the harmonic order, the more difficult it becomes to separete a given harmonio from the adjacent rns, as the per cent of separation becomes increasingly less. Where multi-stage frequenoy multipliers are used, these side-frequencies have a tendency to rice on through successive stages, giving side-frequencies in the outputs which are spaced the original side-frequency difference from the desired output as well as harmonics of this difference. The side-frequencies may or may not be symmetrically located around the desired frequency and certain of these frequencies may be missing or very highly attenuated. 
It is obvious that, where these side-frequencies prove bothersome, the logical place to reduce them is in the stages where they are generated in each case. The use of several separately tuned sircuits, loosely coupled, or a multi-section conventional filter is usually sufficient to reduce the amplitude of such responses to a satisfactory point. Such filter networks will be noted in the detailed circuit schematics of the various multiplier and converter units. Crystal filters are also useful when the separation is small (less than about 10\%) but must usually be used in conjunction with the conventional networks.

In using the output from one of the multiplier stages to drive a crystal multiplier to obtain high harmonics for microwave frequency measurements it is possible to obtain responses from other than the desired source frequency. This is most likely to occur if the output stage driving the crystal multiplier is greatly detuned, but might occur through considerable detuning of an earlier stage. Usually these responses are of greatly reduced amplitude and are eliminatod by proper tuning. They are more likely to occur when using the 270 to 810 -ic stages, where the 30 and $90-M c$ sidefrequencies are separated by a smaller percentage of the operating frequency. Sufficient filtering has been omployed in all but the high-lovel output stages to reduce theso spurious frequencies to a negligible amount.

\section{(2) Converter-Generated Harmonic Interference}

This type of interference is caused where a harmonic of one of the frequencies of a converter stage beats with one of the other froquencies, giving a heterodyne whistle in the output as the tuning is varied. Higher harmonics of both mixed signals in a converter may at times give difference frequencies which are near the desired sum or difforence froquency and introduce a spurious beat, or sideband frequency in the desired output.

is specific example of this type of interference occurs in the main frequency converter when the $7.5 \mathrm{Mc} / \mathrm{s}$ and approximately $2.5 \mathrm{Mc} / \mathrm{s}$ from the adjustable oscillator are added to obtain frequencies in the region of 10 $\mathrm{uc} / \mathrm{m}$. If the oscillator is set on $2510 \mathrm{kc} / \mathrm{s}$, the desired output frequency will be $10,010 \mathrm{kc} / \mathrm{s}$. The fourth harmonic of the $2510 \mathrm{kc} / \mathrm{s}$ is $10,040 \mathrm{kc} / \mathrm{s}$ and this frequency will also appear in the output of tho converter. The amplitude of this interfering frequency depends upon how far it detiates from the resonance frequency of the plate filter network and upon the type and operating conditions of the frequency converter. For a given converter output band-width, the higher harmonic orders (larger ratio botwoen the two inixed frequenciss) would cause less interferenco but would require a greater oscillator tuning range and might give several harmonic cross-over points. Push-push or push-pull converter circuit arrangements may be utilized to reduce the even or odd harmonic responses, but it seoms very difficult to obtain both results with a givon arrangement.

The main converter unit uses a balanced circuit arrangement to attenuate the even harmonic responses as the fourth harmonic of the lower mixed frequency is the only one which falls within the operating range. Needless to say, the mixed froquency itsolf should be very free of such interfering harmonics; he interfering frequencies are thon only those generated by tho 
non-linear operations of the converter element. A balancing resistor is used in the screen circuit of the two converter tubes to minimizo the harmonic interference. Because of stray coupling and phase changes with tuning, complete cancellation does not occur but a definite adjustment minimum is obtained. An additional front-panel control is available for adjusting the oscillator input power when working in the 10-llc output range of the converter. By this means satisfactory operation is maintained throughout the interfering range; this control may be operated at maximum throughout the remainder of the frequenoy range. Improper operation in the intorfering range is immediately apparent when using a spectrum analyzer on che crystalmultiplied output by the appearance of a nuber of pipes on the screon very close to the desired signal. In some cases of improper adjustment the desired signal will be completely ebsent, with a band of spurious requencies or "grass" on each side of the desired frequency. Reduction of oscillator input will allow the correct signal to come through and will reduce or eliminate the interference. Slight adjustment of the converter tuning control will often improve a signal which shows slight interference. When proporly adjusted, the ratio of harmonic-generated interforence to desired output at the 30-ac jack is of the order of - 50 to - $50 \mathrm{db}$. When misadjustod, through unbalancod screen resistor or unbalanced converter tubes, or through too high an input power of the adjustable oscillator frequency, a ratio of approximately - $40 \mathrm{db}$ or lower may result in unusable frequency output in the microwave region.

In the frequency multiplier and dual frequency converter a somewhat different method is used to reduce the harmonic-generated interference. Theso units cover a wider range of frequencies so that both oven and odd harmonic frequencies wouid appear in the output. As single-onded converters of the tunablo type are of much simpler design, these were mployed. An advantage of desired frequency to harmonic interference of 55 to $80 \mathrm{db}$ was obtained (depending on the interfering hamonic order) by using $6 A C 7$ tubes as converters at very low efficiency. The harmonicoproducing froquency is applied to the cathode at rery low level with the other sequoncy applied at class C ievel to the control grid. In this maner a compistely usable output is obtained by following the converter etage with sufficiont pawer amplification. Should interferenco devolop, the flexibility of the cable connections and the number of possible fraquency combinations allow a harmonicifree operating point to bo choson.

\section{(3) Farasitic Oscillations}

Spurious frequencios of this type should not be presont in any of the oquipment when oparating rormaliy. Aging of components, inrreased secondary emission, or changes in tube cheracteristics which sonetimes accur, might cause oscillations of this type to develop. Such oscillation is often of the forced type and is not etident when tuning by meters or bulb loads. However, if observed on a spectrum analyzer, such oscillation is immediately apparent as a heavy "grass" or zo:se on the base line with no central signal. If listenod to on a recoiver, the signal vill tune broedly and have a very high noiso level. Installation of a new tube o: proper circuit adjustment should eliminate any such condition. A troublosome two-3tate cscillation between the 90 and 270-kic states was eliminatod by insulating the three-stage shield cover at the $90-$ hic end, which proved to be a source of coramon coupling. 


\section{(4) Spectrum inalyzer Responses}

The various spectrum analyzer differentiating circuits introduce pips on the analyzer screens. By proper positioning of the various switches and controls on the analyzer, thos pips can be reduced or placod out of the working range to avoid confusion with the desired responses. When in doubt as to the source of such a signal, the standard frequency radiofrequency power may be cut off momentarily by the plate switch on the adjustable oscillator or decade frequency generator if used. "If the pip disappears, it is identified as a harmonic of the standard frequency being supplied to the crystal multiplier.

\section{d. Frequency ileters}

In the calibration of frequency meters by use of a spectrum analyzer, a calibrated reaction-type frequeacy meter is generally coupled to the analyzer converter arrangement so as to obtain an approximate calibration of the locel oscillator on the analyzer, and also to identify the harmonic order of the multipliod standard frequency. The frequency meter to bo calibrated is then placed between this calibrated metor end the crystal frequency multiplier. Reaction-type froquency meters are coupled by use of a I connection in the coaxial line or waveguide, with an isolnting, matched resistive attenuator placed on ach side of the $T$ to reduce reactive coupling to the frequency meter being calibrated. Iransmission-type frequency meters are coupled directly into the line with similar use of matched attenuators on ench side of the frequency meter. Fixed attenuators of $10 \mathrm{db}$ each have proven generaliy satisfactory; adjustable attenuators are convenient but may introduce somewhat greater mismatching.

For a symmetrical transmission-type cavity frequency-meter, effects of mismatch on observed resonance frequency may be judged by means of the following formula -

$$
\frac{\Delta f}{I}=\sqrt{T} \frac{r^{2}-1}{8 Q^{r}}
$$

In this formula $\Delta f$ is the magnitude of the maximum frequency shift corresponding to external loading of the catity on one side (either input or output) by an impedance characterized by a voltage standing wave ratio $r$. $f$ is the resonance frequency, $Q l$ is the $Q$ of the cavity with matched loads on both input and output, and $T$ is the ratio of power transmitted to power incident on the cavity at resonance. The maximum total frequency shift with mismatchos on both input and output is the sum of the individual frequency shifts calculated by the above formula. The formula is a good approximation if $Q_{\ell}$ is large and $r$ is not much greater than unity. As a numerical example, let $r=1.15, Q_{\ell}=4000, T=1 / 4, f=10,000 \mathrm{kc}$. Then the maximum total fre. quency shift corresponding to a mismatch of $r=1.15$ on both sides of the cavity is approximately 0.1 ix.

When calibrating tunable transmission-type frequency meters it is neces sary that both the frequency meter and the local oscillator on the analyzer be tumed very accurately to the froquency boing used for calibration and that this frequency be adjusted to give a usable output. A groat amount of 
adjustment and searching can be aroided if a $T$ connoction is placed on oach side of the froquenoy meter boyond the attenuators: a flexiblo piece of waveguide or coaxial line is thon used to bypass the frequenoy meter and attenuators while the crystal multiplior, froquency stendard, and local oscillator are adjusted. This connection is then broken at one ond and this frequency moter tuned for maximum responso. In this mannor, transmission-type erequency moters are no more difficult to calibrate than those of the reaction-typo.

When setting up a frequency meter for calibration, the unsealed type should bo left discomnocted for a suficient time to stabilize humidity within the cavity. Also, the froquency meter should bo mounted far onough away from the spectrum analyzer ard other heat-gonerating equipment to allow the cavity to remin at the temperature of the calibrating room.

Cars shouid be taken when varying the output frequency of the frequency standard that the output level romins constant or the frequency at which a maximum or minimum is measured will be in orror.

\section{e. Spectrum Aralyzers}

Spectrum analyzers of sotoral typos are available, but all aro essentially high-gain recoivers of the "panoramic" type with cathode-ray tubes as indicators. The local oscillator is frequency nodulated by a saw-tooth froquency in symchronism with the sweop frequency of the osoillosoopo tubs, allowing one to observo the rosponse of signals within the range coverod. hs no image rejection is employed ahead of the orystal froquenoy converter, an indication will appear when the local oscillator is either lowe or higiner than the received signal by an amount equal to the intermediate ampifilex frequancy. Host of the analyzors may bo adjusted from zero sweep wijth to a ralue wide enough to show both responses as the local osciliatar is swept. Provision is also made, through a video amplifier driven by rectif al convertor-crystal current variations, for observing the "mode" a.justinexts or sweep range of the klystron local osoillator. By matohing pips or this curve, an approximate calibration of frequeney meters may be rigde.

In calibration work, the klystron local oscillator is usually operated with a wide frequency swing during preliminary adjustment and then narrowed dowa for sijal obsex"ations. Greater offective gain is obtained when eweeping over a nerrow range $2 . s$ this gives the resonant circuits in the intermediatem requency amplifier more time to build up as the frequency is swept by tro pass-band of tho amplifier. The maximum resolution of an analyzer, or ability to differentiate between closely adjecent frequencies, is determined by the band-width of the i-f amplifier.

Fig. 7 showa a photograph of a spsetrum analyzor, crystal multiplier, and frequeney meters set up for calibration in the 8,500 to $10,000 \mathrm{Mc} / \mathrm{s}$ frequancy range. 
II. Detailed Unit Descriptions

The following detailed descriptions are given as an aid in maintaining the equipment. Voltage and current readings on the various tubes are not given as in frequency multipliers and radio frequency amplifiers these values vary widely with excitation, loading and bias adjustments. In no case is the maximum recommended value exceeded.

The entire installation is assembled in three heavy duty enclosed relay racks. Panels are standard 19-inch sizes for rack mounting. Connector cables and jacks are either General Radio coaxial type or Army-Navy type $N$. Each unit is individually fused and a-c power is supplied through a miniature motor-base type of connector. A master switch and plug fuses are also provided in each rack.

\section{Frequency Nultiplier; Output $7.5 \mathrm{kc} / \mathrm{s}$}

\section{a. Description}

The purpose of this unit is to multiply the $100 \mathrm{kc} / \mathrm{s}$ from the primary frequency standard to $7500 \mathrm{kc} / \mathrm{s}$, which is one of the input frequencies of the main converter-multiplier unit. The multiplier consists of two pushpull quintupler stages and one push-pull tripler stage, all using 6SJ7 tubes. It is necessary that the output frequency bo very free of harmonics and multiplied side-frequencies in order to avoid generation of undesirable spurious components in the converter unit. The side frequencies are reduced in each multiplier stage by the use of multiple tuned filter transformers, very complete shielding, and decoupling networks. The 7.5-3ic froquency is also passed through an additional filter in the converter unit.

\section{b. Operation and Service Instructions}

The 100-kc input power should be adjusted by means of the left-hand control to give meter reading of 200 to 300 microamperes with the meter switch in position ono. The meter switch positions 1 to 6 provide rolative readings of grid and cathode currents in each stage. Proper alignment may be checked by removing the cover plate on the rear edge of the chassis and adjusting condensers $C_{I}$ through $C_{7}$ for maximum grid current in each stage as aligament progresses. The output-stage trimmer, $C_{8}$, should be adjusted for maximum output on an external indicator or for minimum cathode current with the switch in position six.

Operating characteristics are as follows:

Power input: $110 \mathrm{v}_{0}, 60 \mathrm{co}$, at 50 watts

$\mathrm{R}-\mathrm{f}$ input: $\quad 100 \mathrm{kc} / \mathrm{s}, 50$ to $100 \mathrm{mw}$ at 500 ohms

R-f outputs: $500,2500,7500 \mathrm{kc} / \mathrm{s}$ at 25 to $50 \mathrm{mw}, 100$ ohms

R-f output purity:

$\begin{array}{lll}7500 \mathrm{kc} / \mathrm{s} & 2500-\mathrm{kc} \text { side-frequencies } & -60 \mathrm{db} \\ & \text { other side-frequencies } & -80 \mathrm{db} \\ 3 r d \text { harmonic } & -60 \mathrm{db} \\ & \text { other harmonise } & -80 \mathrm{db}\end{array}$




$\begin{array}{lll}2500 \mathrm{kc} / \mathrm{s} & 500-\mathrm{kc} \text { side-frequencies } & -45 \mathrm{db} \\ & \begin{array}{l}100-\mathrm{kc} \text { side-frequencies } \\ \text { harmonics }\end{array} & -100 \mathrm{db} \\ & \text { side-frequenoies and harmonics } & -60 \mathrm{db} \\ 500 \mathrm{kc} / \mathrm{s} & & -60 \mathrm{db}\end{array}$

c. Parts List

Fig. 8 .

Resistor and condenser values are given in the schematic diagram,

Tuned transformer deta are as follows:

$\mathrm{T}-1$ Input transformer, $100 \mathrm{kc} / \mathrm{s}$

pri.: 150 turns No. 36 on. silk cov. Wire wound betweon seconderies. sec.: balanced winding No. 36 on. silk cov. wire with $1 / 4$ inch

between pies, total inductance $12 . \mathrm{mh}$.

tuning condenser: dual ceramic-mounted, 125 Huf max. each section, in parallol.

shield can: aluminum, $4^{\prime \prime} \times 2^{\prime \prime} \times 17 / 16^{\prime \prime}$.

T-2 Output transformer, $500 \mathrm{kc} / \mathrm{s}$

pri.: balanced winding $5 / 41$ litz, $1 / 8$ inch botwoen pies, total

inductance $0.92 \mathrm{mh}$.

sec.: 10 turns $7 / 41$ litz, wound betweon primary sections.

tunine condenser: dual ceremie-mounted, 80 puf max. onoh section, in parallol.

shield oan: aluminum, $41 / 8^{\prime \prime} \times 23 / 8^{n} \times 2^{n}$.

T-3 Coupling filter, $500 \mathrm{kc} / \mathrm{s}$

pri.: 5/41 litz, wound on powdered-iron cylindrical

core $7 / 8^{\prime \prime} \times 3 / 8^{\prime \prime}$, inductance $0.5 \mathrm{mh}$ (no secondary)

tuning condenser: dual ceramie-mounted, $125 \mu$ max. each section,

in parallel.

shield can: aluminum, $4^{\prime \prime} \times 2^{\prime \prime} \times 17 / 16^{\prime \prime}$.

$\mathrm{T}-4$ Input transformer, $500 \mathrm{kc} / \mathrm{s}$

pri.i 10 turns $7 / 41$ litz, wound between secondaries.

sec.: balanced winding, $5 / 41$ litz with $1 / 8^{\prime \prime}$ between pies, total inductance $1 \mathrm{mh}$.

tuning condenser: dual ceramic-mounted, 125 upf maximum. shield can: aluminum, $4^{\prime \prime} \times 2^{\prime \prime} \times 17 / 16^{\prime \prime}$.

T-5 Output transformer, $2500 \mathrm{kc} / \mathrm{s}$

pri.: 66 turns, center-tapped, No. 26 en. wire on 1 inch bakelite form, total inductance $70 \mu \mathrm{h}$.

80c.: I turn No. 26 on. wire on $1 / 2^{\prime \prime}$ form and centered insido primary winding.

tuning condenser: dual ceramic-mounted, $80 \mu \mu f$ max. each section, in parallol.

shield can: aluminum, \&1/8" $\times 23 / 8^{\prime \prime} \times 2^{\prime \prime}$. 
T-6 Coupling filter, $2500 \mathrm{kc} / \mathrm{s}$

pri.: 62 turns No. 36 on. silk cov. wire toroidally wound on powdered-iron core $1 / 2^{\prime \prime} \times 1 / 2^{\prime \prime}$ with $3 / 16^{\prime \prime}$ dia. hole, inductance $90 \mu \mathrm{h}$ (no secondary).

tuning condenser: dual ceramic-mounted, $125 \mu \mu f$ max. each section, in parallel.

shield can: aluminum, $4^{\prime \prime} \times 2^{\prime \prime} \times 17 / 16^{\prime \prime}$.

T-7 Input transformer, $2500 \mathrm{kc} / \mathrm{s}$

pri.: 2 turns $7 / 41$ litz wound toroidally at center of balanced socondary.

sec.: 56 turns No. 36 en. silk cor. wiro, conter tapped, toroidally wound on powdered-iron core $1 / 2^{\prime \prime} \times 1 / 2^{\prime \prime}$ with $3 / 16^{\prime \prime}$ dia. hole, inductance $80 \mu \mathrm{h}$.

tuning condenser: dual ceramic-mounted, $125 \mu \mu f$ max. each section, in series.

shiold can: aluminum, $4^{\prime \prime} \times 2^{\prime \prime} \times 17 / 16^{\prime \prime}$.

T-8 Output transformer, $7500 \mathrm{kc} / \mathrm{s}$

pri.: 30 turns No. 26 en. wiro, center-tapped, wound on 1-inch

bakelito form, total inductance $20 \mu \mathrm{h}$.

sec.: 1 turn No. 26 on. wire wound on $1 / 2$ inch bakelite form and centered inside primary winding.

tuning condenser: dual ceramic-mounted, $80 \mu$ fr max. each section, in parallel.

shield can: aluminum, $41 / 8^{\prime \prime} \times 23 / 8^{\prime \prime} \times 2^{\text {"n }}$.

d. Illustrations

Fig. 8. Layout drawing of frequency multiplier;

100 to $7500 \mathrm{kc} / \mathrm{s}$

Fig. 9. Circuit schematic of froquency multiplier;

100 to $7500 \mathrm{kc} / \mathrm{s}$.

Fig. 10. Photograph of frequency multiplior;

100 to $7500 \mathrm{kc} / \mathrm{s}$ (top front view).

Fig. 11. Photograph of frequency multiplier; 100 to $7500 \mathrm{kc} / \mathrm{s}$ (bottom view).

2. Frequency Convertor ifultiplier; Output 28.5 to $30.9 \mathrm{Mc} / \mathrm{s}$

\section{a. Description}

This unit contains a balanced frequency convertor stage, using 6 SA7 tubes, which mixes $7500 \mathrm{kc} / \mathrm{s}$ derived from the primary standard of frequency and a very stable adjustable-oscillator frequency or other standard frequency. $T_{\text {ho }}$ resultant sum frequency, between 9.5 and $10.3 \mathrm{Mc} / \mathrm{s}$, is passed through $a$ tunablo filter to a tripler stage using a $6 A C 7$ tubo. This stage is followed by a tuned amplifier stage using a $65 K 7$ tube and having a low impodance output which is used to drive the threo-stage froquency multiplier. The tripler and amplifier tuning controls are ganged and tuning meters are provided for both tho converter and triplor-amplifier stages. 


\section{b. Operation and Service Instructions}

Operation of the unit is straightforward; the proper inputs are connected and the stages tuned for maximum meter response. The dial ranges are such that only the desired modulation product or harmonic falls within the tuning range in each case. The $7.5 \mathrm{Mc} / \mathrm{s}$ is passed through an additional filter and applied in push-pull to the converter grids. The 2.0 to $2.8 \mathrm{Mc} / \mathrm{s}$ is passed through an adjustable attenuator and then through a band-pass filter and applied to the grids in parallel. 'In this manner, harmonics of the lower input frequency which might be present in the input or generated in the tubes are greatly reduced, as the plates are connected in push-pull. This is an important consideration as the fourth harmonic of the adjustable ... Ilator, when operating in the range of $2500 \mathrm{kc} / \mathrm{s}$, will cause interferenco with the desired frequency if it is allowod to get into the output circuit. i. ijustment of the input to give just sufficient output to drive the next stage when operating in this region will reduce this interference to a negli. gible mount. An adjustable resistor in the screen circuit is provided on the chassis to allow balancing the converter tubes to roduce this interforence; this control should be chocked if the converter tubes are changed.

Alignment of the various circuits may be checked by connecting the proper input frequencies and adjusting the successive trimmer condensers for maximum meter response. These adjustments should be made at the high-frequency ond of the band and checked for uniform response throughout the band, making slight readjustments if necessary. The 2.0 to 2.8 - llc band-pass input filter may be checked by removing one converter tube, substituting a vacuum-tube voltmeter between the No. 1 socket pin and chassis and aligning the trimmers for uniform response throughout the band.

Adjustment of the balancing resistor for reducing harmonic crossover interference is carried out by tuning the adjustable oscillator to $2.5 \mathrm{Mc} / \mathrm{s}$ and listening to the resulting 30-Mc output on the receiver. The osoillator is then adjusted to give a beat note of about $1000 \mathrm{c} / \mathrm{s}$ in the receiver. The 2.5-Mc input-level control is decreased to give just enough excitation for maximum output at $30 \mathrm{Mc} / \mathrm{s}$ and the screon balancing control is then adjusted for minimum audio output in the recoiver. follows:

Operating characteristics of the converter-multiplier unit are as

Power input: $110 \mathrm{v}, 60 \mathrm{c}$ at 50 watts.

k-f input: $\quad 7.5 \mathrm{Mc} / \mathrm{s}$ and 2.0 to $2.8 \mathrm{Mc} / \mathrm{s}, 25$ to $50 \mathrm{mw}$ at 100 ohms.

R-f output: 28.5 to $30.9 \mathrm{Mc} / \mathrm{s}$, I watt at 100 ohms.

R-f output purity: higher order modulution components in operating band $\quad-60 \mathrm{db}$

harnonic crossover interference at $30-\mathrm{Mc}$ point 


\section{c. Parts List}

Resistor and condenser values are given in the scheratic diagram,

Fig. 13.

Tuned transformer data are as follows:

T-1 60 turns No. 34 en. wire, toroidally wound on $1 / 2^{\prime \prime} \times 1 / 2^{\prime \prime}$ powderediron core with 5/16" dia. hole. C-3, 1.5 to $15 \mu \mu f$, National Co. Uw-15.

T-2 pri.: 2 turns No. 28 en. wire toroidally wound.

sec.: 56 turns No. 34 en. wire, center-tapped, wound toroidally on $1 / 2^{\prime \prime} \times 1 / 2^{\prime \prime}$ powdered-iron core with $3 / 16^{\prime \prime}$ dia. hole.

$\mathrm{C}-4: \quad 1.5$ to $15 \mu \mu f$, National Co. UM-15.

T-3 pri.: 4 turns No. 28 en. silk cov, wire wound over secondary.

sec.: 56 turns No. 34 en. wire wound helically on $1 / 2^{\text {" }} \times 1 / 2^{\prime \prime}$ powdered-iron core.

ter, 56 turns No, $34 \mathrm{en}$. wire, conter-tapped, helically wound on $1 / 2^{\prime \prime} \times 1 / 2^{\prime \prime}$ powdered-iron core.

Spacing: betwoen secondary and tertiary coros, $1 / 16$ inch. C-1 and C-2: 45 to $140 \mu \mu f$, mica compression-type dual trimmers, ceramic mounted.

T-4 pri.: 32 turns, center-tapped, No. 34 en. wire toroidally wound on $1 / 4^{\prime \prime} \times 1 / 2^{\prime \prime}$ powdered-iron $\operatorname{cor} \theta$ with $3 / 16^{\prime \prime}$ dia. hole.

sec.: 1 turn No. 28 en. wire toroidally wound.

C-5: $\quad 1.5$ to $15 \mu \mu f$, National Co. UM-15.

C-5: 1.5 to $5 \mu \mu f$, National Co. UM-15 with two rotor plates removed.

T-5 pri.l 1 turn No. 28 en. wire toroidally wound.

sec.: 32 turns No. 34 en. wire toroidally wound on $1 / 4^{\prime \prime} \times 1 / 2^{\prime \prime}$ powderediron core with $3 / 16^{\prime \prime}$ dia. hole.

ter: 1 turn No. 28 on. wire toroidally wound.

C-?: 1.5 to $15 \mu$ pf, National Co. UM-15.

C-5: 1.5 to $5 \mu \mu f$, National Co. UM-15 with two rotor plates removed.

T-6 8 turns No. 28 en. wire on $1^{\prime \prime} \times 2^{\text {n }}$ low-loss bakelite form.

C-98 1.5 to $15 \mu$ f. National Co. UM-15.

C-108 1.5 to $5 \mu \mu f$, National Co. UM-15 with two rotor plates removed.

T-7 pri.: 8 turns No. 28 en, wire on $1^{\prime \prime} \times 2^{\prime \prime}$ low-loss bakelite form.

sec.: 1 turn No. 28 en. wire spaced 1/2" from low-impedance end of pri. winding.

C-11: 1.5 to $15 \mu \mu f$, National Co. UM-15.

C-12: 1.5 to 5 pris, National Co. UM-15, with two rotor plates removed.

d. Illustrations

Fig. 12. Layout drawing of frequency converter-multiplier: output 28.5 to $30.9 \mathrm{Mc} / \mathrm{s}$.

Fig. 13. Circuit schematic of frequency converter-multiplier; output 23.5 to $30.9 \mathrm{Mc} / \mathrm{s}$. 
Fig. 14. Photograph of rrequency convertermultiplier; output 28.5 to $30.9 \mathrm{ke} / \mathrm{s}$ (topafront vitw).

Fig. 15. Photograph of frequency convertor-multiplier; output 2.8 .5 to $30.9 \mathrm{Mic} / \mathrm{s}$ (bottom viow).

3. Adjus table-Frequency Oscillators; 2.0 to $2.4 \mathrm{Mc} / \mathrm{s}$ and 2.4 to $2.8 \mathrm{Mc} / \mathrm{s}$

a. Description

The output from these oscillators is mixed with the primary-standard frequencies to give complete coverage of the multiplied frequencies in the microwave spectrum. The oscillators are Lampkin Laboratories type 103, to which have been added a highly filtered, regulated power supply and two radio. frequency output stages using band-pass plate transformers. Only the oscillator tube and its associated circuit are used in the Lampkin units, the other components being removed from the chassis. The $6 A C 7$ amplifier tubes are operated class A to minimize harmonic interference in tho converter stage. One of the stages is provided with output impedances of 50 and 500 ohms, either of which may be selocted by means of a switch. A plate switch on the osoilla. tor is also provided for momentarily tuming of the radio-frequency output and still leaving the tubes in operating condition.

\section{b. Operation and Service Instructions}

The band-pass output transformers reduce the harmonic output and allow low inpedance coupling to the converter stago. Those double-tuned transformers are over-coupled and loaded so as to give essontially flat response throughuit the opsrating band. Adjustmont of the trimmer condensers is rant, easily carried out by using a $50 \mathrm{mohm}$ resistive load and a vacuum-tube voltmeter: on the output, setting the oscillator to $2080 \mathrm{kc} / \mathrm{s}$ (or $2480 \mathrm{kc} / \mathrm{s}$ for the higher frequency unit) and adjusting both trimmers for maximum output, repeating the adjustment soveral times. A final check at each ond of the band, and readjustment if necessary should rosult in the output being flat within it the oughout the band.

Tho ascillators are ealibrated at 10-ke intervals by use of the harmonio series generator and receiver and the oseillators may be set or checked at intermediate points by use of this same equipment. If the calibration drifts siighti.y through aging, it may be brought into agreement with the chart by an adjustmant of the correction trimmer condenser.

Operating characteristics are as follows:

Power input: $110 \nabla, 60 \mathrm{c}$ at 35 watts.

Rof ov.tput: 2.0 to $2.4 \mathrm{Mc} / \mathrm{s}$ and 2.4 to $2.8 \mathrm{Mc} / \mathrm{s}, 50 \mathrm{mw}$ approximately at 50 to 100 ohms.

iarmonic content

in output: second harmonic

$-60 \mathrm{db}$

third harmonic

$-70 \mathrm{db}$

fourth harmonic

$-80 \mathrm{db}$ 
Oscillator

constancy: Short-time variations (3-minute period), less than

$1 \mathrm{c} / \mathrm{s}$ or 1 part in 2 million approximately.

Day-to-day variation in dial settings (for a maximum variation of $10^{\circ} \mathrm{C}$ in ambient temperature), less than 2 small dial divisions, or approximately $100 \mathrm{c} / \mathrm{s}$ at 2.0 to $2.8 \mathrm{Mc} / \mathrm{s}$.

Backlash in micrometer-dial mechanism, less than I small dial division.

\section{c. Parts List}

Parts values not shown in the schematic diagram, Fig. 17, are as follows:

T-2 pri.: 2.0 to $2.4 \mathrm{Mc} / \mathrm{s}$; 56 turns No. 34 en. silk cov. wire on $1 / 2^{\prime \prime}$ $\times 1 / 2^{n}$ cylindrical powdered-iron core.

2.4 to $2.8 \mathrm{Nic} / \mathrm{s}$; 52 turns No. $34 \mathrm{en.} \mathrm{silk} \mathrm{cov.} \mathrm{wire} \mathrm{on} 1 / 2^{\prime \prime}$ $x 1 / 2^{\prime \prime}$ cylindrical powdered-iron core.

sac.: similar to primary in each case.

tertiary: 4 turns No. 28 en. silk cov. Wire wound over low-jotential end of secondary.

spacing: between primary and secondary cores, $1 / 16^{\prime \prime}$.

primary load resistor: 10,000 ohms, 1/2 watt.

trimmer condensers: $\mathrm{C}-11, \mathrm{C}-12$ and $\mathrm{C}-13, \mathrm{C}-14$; dual ceramic-mounted, mica-compression-type, 30 to 120 Muf each section.

T-3 Similar to T-2, except tertiary winding is 12 turns No. 28 en. silk cov. wire, tapped at 4 th turn.

\section{d. Illustrations}

Fig. 16. Lnyout drawing of adjustable frequency oscillator; 2.0 to 2.4 $\mathrm{Mc} / \mathrm{s}$ and 2.4 to $2.8 \mathrm{Mc} / \mathrm{s}$.

Fig. 17. Circuit schematic of edjustable-frequency oscillator; 2.0 to $2.4 \mathrm{Mc} / \mathrm{s}$ and 2.4 to $2.8 \mathrm{Mc} / \mathrm{s}$.

Fig. 18. Photograph of adjustablexfrequency oscillator; 2.0 to 2.4 $\mathrm{hic} / \mathrm{s}$ and 2.4 to $2.8 \mathrm{kc} / \mathrm{s}$ (top-sront view).

Fig. 19. Photograph of adjustable-frequency oscillator; 2.0 to 2.4 $\mathrm{Mo} / \mathrm{s}$ and 2.4 to $2.8 \mathrm{Mc} / \mathrm{s}$ (bottom view).

4. Three-Stage Frequency Hultiplier; Outputs 85.5 to $92.7 \mathrm{Mc} / \mathrm{s}, 256.5$ to $278.1 \mathrm{Mc} / \mathrm{s}, 769.5$ to $834.3 \mathrm{Mc} / \mathrm{s}$.

\section{a. Description}

The three-stage frequency multiplier has outputs with approximately $8 \%$ bondwidtiss at 90,270 and $810 \mathrm{kc} / \mathrm{s}$. These outputs are used to drive siliconcrystal frequency multipliers, the harmonics from which constitute the standard frequencies in the microwave spectrum. Harmonics $m$ om the 12 th through

the 36 th are used where complete coverage is required. 
The first tripler stage uses an $32 \mathrm{~S}-3$ push-pull beam pover tibo with an untuned band-pass input cireuit and a concentric-coupled, tuned output transformer. The second tripler stage uses an $832 \mathrm{~m}$ push-pull bean power tube with resonant parallol lines, condenser tuned. An untuned parallellines input circuit drives the final stage, a range switch bsing provided to reduce loading when the final stage is not being used. The third tripler stage uses two $2 C 40$ disc-seal tubes in push-pull, operating with the grids grounded and utilizing a butterfly tank circuit. Filament switches are provided on the penel for turning off the 270 and 810 -Mc stages when these outputs are not needed. A tuning meter is a.lso provided for each stage。

A separate chassis contains the plate and fllament supply, regulated bies supply and plate current meters for each stage. This unit also contains inaividual bias adjustment control: for regulating the power output of each stage.

\section{b. Operation and servioe instructions}

The dial gearings for the 90 and $270-$ Mc stages are chosen so that the operatiag bands cover about 80 divisions on the dial scales: for the 810 Me stage, the operating band covers about 20 dial divisions. All dial readings increase with increasing frequency.

The 829-B tube may be changed by taking off the shiold cover and removing the plate clips. If this tube is changed it may be necessary to retume the 30 - kc band-pass input transformer. These trimmers are adjusted by removing the bottom cover and tuning so as to give uniforn grid excitation throughout the operating band. The convertermultiplier unit and regular caneoting cable should bo used during this adjustment as it was round that, when using a loiger connecting cable, the trimmers could not bo properiy adjusted.

Tho $832-A$ tub may bo changed by loosening the set scrows in the tuning gear and disengeging the fiber condenser-drive shaft. The four mounting serowg in the supporting base axe then loosoned and tho plate clips sipped of the tube ping allowing the tube to be removed.

Tine 2040 tubes may be changed by Ionsening the plate clips and unhooking the concentric filiment leads at the lower end. The tube mounting ring roy then bo remored as a unit by taking out the four supporting screws.

Dosating charactoristios are as follows:

Power input: 110 \%。 60 o at 100 watts approximately

Pof Input: 28.5 to $30.9 \mathrm{Mc} / \mathrm{s}$ at 1 watt, 100 ohms approximately

Ruf outcut: 85.5 to 92. ? Ke/ a 3 watts, 50 to 100 ohms 256.5 to $2.78 .1 \mathrm{Mc} / \mathrm{s}$ at 3 wgtics, 50 to $100 \mathrm{ohms}$ 762.5 to $83 z_{0}$ ? $\mathrm{Mc} / \mathrm{s}$ at I watt, 50 to 100 ohms

Spurious frequencios (harmonics and side-irequencios) in the 90,270 , $810 \mathrm{Mc} / \mathrm{s}$ outputs when proparly tuced, lass than - $50 \mathrm{db}$. 
Approximate working $Q^{\prime}$ s of the output stages are as follows:

$90-\mathrm{Mc}$ stage 90

270-ife stage 180

810 -Mc stage 220

c. Parts list

Parts values not shown in the schematic diagram, Fig. 21, are as follows:

I-4 Band-pass input transformer, 28.5 to $30.9 \mathrm{Mc} / \mathrm{s}$

pri: 2 turns No. 28 on. silk cov. wire wound over conter of secondary. sec: 16 turns No. 32 en. silk cov. wire on $5 / 8^{\prime \prime} \times 2-3 / 8^{\prime \prime}$ polystyrene grooved form.

tertiary: 12 turns, center-tapped, No. 32 en. silk cov. wire on $5 / 8^{\text {" }}$ x $2-3 / 8^{\prime \prime}$ polystyrene grooved form, coupling with secondary adjustable.

loading: 100,000-chm, 1 watt resistor across tertiary winding. tuning condensers: dual ceramic, adjustablo trimers, 3 to 13 pur each.

T-5 $90 \mathrm{MC}$ transformer, tunable from 85.5 to $92.7 \mathrm{Mc} / \mathrm{s} ; 3$ turns, centertapped of coaxial copper tubing approximately $1.8^{\prime \prime}$ outside dia., coil $1^{11}$ dia. $x 1^{\prime \prime}$ length. The inner wire is usod as primary and outsido shield used as secondary or grid winding. Output link consists of 1 turn No. 14 wire epproximately $1 / 2^{n}$ dia. at center of coil. Tuning condenser, split-stator type 2 to $12 \mu \mu f$, is connected across grid winding.

T-6 270-Mc transformer, resonant parallel-lines type, tunablo from 256.5 to $278.1 \mathrm{Mc} / \mathrm{s}$. Primery consists of two $5 / 16^{\prime \prime}$ dia. copper tubes $51 / 2^{\prime \prime}$ long, spaced $3 / 4^{n}$ centor-to-center. Tuning is accomplishod by a 2 to $12 \mu \mu f$ split-stator condenser attached near center of lines. Output link is No. 10 copper wire loop $2^{\text {* }}$ long by $3 / 4^{\text {" }}$ spacing, placed $1^{\text {st }}$ from low-potential end of lines.

Grid excitation for the $810-H c$ stage is through $1 / 8^{\prime \prime}$ dia. coaxial copper tubing of approximately same length as plato lines. This stage is cathode driven, the heater power being fed through the center wires. This line is untuned, but a shunting link is provided for operation on the $810-110$ band. This link is oponed by a panel control to prevent loading the $270-4{ }^{\circ}$ stage when power is not desired from the 810 -llic stage.

T-7. 810-Mc transformer, butterfly type, tunsble output from 759.5 to 834.3

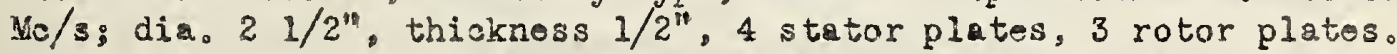
Both stator and rotor plates are shunted by brass bars at the back odges on each side at the high-potential points to oliminate a secondary rosonence occurring near the second harmonic range of the 270-lif driving voltage. Output link $1 / 2^{\text {h }}$ square, coupling adjustable, placed t highcurrent point at bottom of butterfly tank. Entire tank circuit shielded by $1 / 8^{*}$ thick brass box $5^{\prime \prime} \times 5^{\prime \prime} \times 2-3 / 8^{*}$. 
d. Illustretions

Fig. 20. Layout drawing of threastage froquenoy multiplier and power supply.

Fig. 2i. Cirouit scheratic of three-stage frequency multiplior and power supply.

Fig. 22. Photograph of three-stage frequency multiplier (front view).

Fig. 23. Photograph of threo-stage frequency multiplior (top view).

Fig. 24. Photograph of three-stage frequency multiplior (bottom viow).

Fig. 25. Photograph of power supply for three-stage frequency mult1plier (top-front view).

Fig. 26. Photograph of power supply for three-stage frequency multiplier (bottom view).

5. Distribution Amplifier; $100 \mathrm{kc} / \mathrm{s}$ "

a. Description

The 100-kc distrfbution amplifier serves as a docoupling device and supplies $100 \mathrm{kc} / \mathrm{s}$ at controllable power levels as required by various units of the microwave frequency standard. The unit contains a bufer amplifier 6VGGT tube, operated as a cathode follower and four output amplifiers using 6G6G tubes. If more complete tube shielding is desired, 6V6 tubes may bo substituted in all amplifier sockets without making any other changes.

b. Operation and service instructions

The output amplifier tubes may bo operated under class A or class $C$ conditions by adjustment of the input controls for oach stage. Becauso of the comparatively low $Q$ vaiues of the output transformers, considerablo harmonic distortion will result in the output under class $C$ conditions. This is no great disadvantage, as in the following units theso harmonics are purposely gonerated in most cases.

Alignment of the trimmer condensers on the transformers for maximum output may be done by using a 100-ohm resistive load and indicating motor. Tho two trimors in each transformer are in parallel.

Operating characteristics are es follows:

Power input: $110 \mathrm{\nabla}, 60 \mathrm{c}$ at 40 watts approximately

$\mathrm{R}-\mathrm{f}$ input: $100 \mathrm{kc} / \mathrm{s}, 50$ to $100 \mathrm{mw}$ at $100 \mathrm{ohms}$

$R=f$ output: four outputs $100 \mathrm{kc} / \mathrm{s}, 100 \mathrm{mw}$ maximum at 100 ohms 
Distortion: approximate distortion in output (largely second harmonic)

\begin{tabular}{|c|c|c|}
\hline Class A: & $\begin{array}{l}\text { no load } \\
100-0 \mathrm{hm} \text { load }\end{array}$ & $\begin{array}{l}-60 \mathrm{db} \\
-40 \mathrm{db}\end{array}$ \\
\hline lass C: & $\begin{array}{l}\text { no load } \\
\text { 100-ohm load }\end{array}$ & $\begin{array}{l}-45 \\
-25\end{array}$ \\
\hline
\end{tabular}

c. Parts list

Parts values not given in the schematic diagram, Fig. 28, are as follows:

T-1 through T-5; 100-kc transformers, Aladdin Radio Industries part No. S-6568 with secondaries added over primary windings, consisting of 30 turns of $7 / 41 \mathrm{litz}$ wire. Primary inductance in shield can 11.1 mh. Dual ceramic-mounted, air-dielectric tuning condensers 90 to $135 \mu \mu f$ each, connected in parallel.

d. Illustrations

Fig. 27. Layout drawing of distribution amplifier; $100 \mathrm{kc} / \mathrm{s}$

Fig. 28. Circuit schematic of distribution amplifier; $100 \mathrm{kc} / \mathrm{s}$

Fig. 29. Photograph of distribution amplifier; $100 \mathrm{kc} / \mathrm{s}$ (top-front view)

Fig. 30. Photograph of distribution amplifier; $100 \mathrm{kc} / \mathrm{s}$ (bottom view) 6. Adjustable Frequezcy Oscillator; 500 to $600 \mathrm{kc} / \mathrm{s}$

a. Description

This oscillator is used, in conjunction with the decade-frequency generator and the frequency multiplier and dual frequency converter units, to give continuous frequencies of 2.0 to $2.8 \mathrm{kc} / \mathrm{s}$ of higher stability and finer control. for use with the main converter and multipliers.

The oscillator is a Lemina Laboratories type 103, to which has been 8dded a highly filtesed, regulated power supply and two radio-frequency output stages. The oscillator circuit in the Lampkin unit is essentially unchanged. A cathode-coupled buffer stage drives the 100-ohm output stage directiy and is coupled through a low-pass filter to the 500-ohm output stage. Output from the 500-ohm stage is used as a source of excitation for the frequency conterter and must, therefore, be very free of harmonic components. The 100.0hm output stage may be switched to a position giving high harmonic output for frequency monitoring purposes. By this means, the 500 to $600-k 0$ oscillator may be monitored on the same 2.0 to $2.4 \mathrm{kc}$ band used for one of the other oscillators. This gives the same number of calibration poists on 231 of the oscillators and higher degree of monitoring accurecy for the 500 to $600-k 0$ unit.

The scrsw-adjustment type of calibration-eorrection condenser has been replaced with a dial-operated trimmer which also serves as a fine-range tuning condenser where extrome precision is roquirod. 


\section{b. Operation and service instruetions}

The band.-pass output transformors reace the harmonio output and allow low-impedanse coupling to the converter unit. Theso double-tuned transformers are over-couplod and loadod so as to give essontially flat responso throughout the operating band. Adjustment of the trimmers is most easily carried out by usine the proper load realstor ( 100 or 500 ohms) and vacuum-tube voltmeter on the output, setting the oscillator to $515 \mathrm{kc} / \mathrm{s}$ and adjusting both trimmers for maximum output, reposting the adjustrmats soror times. A final check at each end of the band, and roadjustment if nocessary, should result in the output being flat within I db throughout the bond.

The 1000-ohm pi-section grid filter is so adjustod that the m-derived half-sections offer maximun attenuation to the second harmonic at different points in the operating range. The oparating parametars of the asK7 ampl1fier stage are chosen for minimum harmonic output.

The 6AC7 amplifier stage operates at a higher input leval and a highpass network supplies adequate hamonic output for monitoring the frequency at any multiple value up to the tenth harmonic.

The fine-tuning or calibration-correction condenser covers a range of \pm 3 main dial divisions, or approximately $\pm 50 \mathrm{c} / \mathrm{s}$ at $500 \mathrm{kc} / \mathrm{s}$.

Operating characteristios are as follow:

Power input: $110 \mathrm{7}, 60$ s. at 4.5 watts.

R-f output: (1) 500 to $600 \mathrm{kc} / \mathrm{s}, 30 \mathrm{mw}$ at 200 to $500 \mathrm{ohms}$, second harmonic. $-70 \mathrm{db}$, other harmonics $-100 \mathrm{db}$.

(2) 500 to $600 \mathrm{kc} / \mathrm{s}, 100 \mathrm{mw}$ at 50 to 100 ohrs, or harmonics 28 high as 10th。

Dscillator constricy: Shortutime rariations (3-minute period) less than 1 part in 2 million.

Dial backlash: less than 1 small dial division.

c. Parts list

Parts values not shown in the sircuit schematic, Fig. 32, are as follows:

$\mathrm{T}-1, \mathrm{~T}-2$ : Bandmpass output transformers, 500 to $600 \mathrm{kc} / \mathrm{s}$

pri: 185 turns 7/41 litz wire wound on $1 / 2^{\text {t }} \times 1 / 2^{\prime \prime}$ powdered-iron core, inductance $0.85 \mathrm{mh}$.

pri loading: 25,000-ohm $1 / 2$ watt resistor

pri tuning: adjustabio air-trimner, 5 to $55 \mu$, fixed silvered mica

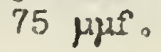

soc: similar to primary, except loading resistor 50,000 ohms $1 / \hat{s}$ watt tertiary: 25 turas $7 / 41$ litz wire would orer low-potential end of secondary. 
spacing: botween primary and secondary core edges $1 / 8$ ".

Pi-notwork filter:

L-4: 110 turns $7 / 41$ litz wire wound on $1 / 2^{\prime \prime} \times 1 / 2^{\mu}$ powdered-iron core, inductance $360 \mu \mathrm{h}$.

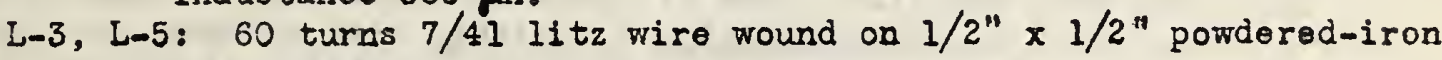
core, inductance $110 \mu \mathrm{h}$.

C $-2, C-3: 290 \mu \mu f$, silvered mica

C-1: $220 \mu \mu f$, silvered mica

C-4: $170 \mu$ uf, silvered mica

d. Illustrations

Fig. 31. Layout drawing of adjustablo-frequency oscillator; 500 to $600 \mathrm{kc} / \mathrm{s}$.

Fig. 32. Circuit schematic of adjustable-frequency oscillator; 500 to $500 \mathrm{kc} / \mathrm{s}$.

Fig. 33. Photograph of adjustable-frequency oscillator; 500 to 600 $\mathrm{kc} / \mathrm{s}$. (front view).

Fig. 34. Photograph of adjustable-frequency oscillator: 500 to 600 $\mathrm{kc} / \mathrm{s}$ (top $\nabla$ iew).

Fig. 35. Photograph of adjustable-frequency oscillator; 500 to 600 $\mathrm{kc} / \mathrm{s}$ (bottom view).

7. Frequency wultiplier and Dual Frequency Converter; outputs 1500 to 3000 $\mathrm{kc} / \mathrm{s}, 1000$ to $2000 \mathrm{kc} / \mathrm{s}, 2000$ to $3000 \mathrm{kc} / \mathrm{s}$

a. Description

This unit provides a means of using the output of the decade frequency generator and the low-frequency adjustable oscillator to obtain marker frequencies and high-precision complete coverage in the microwave spectrum. In this function, its output is used with the main converter-multiplier equipment in place of the regular 2.0 to 2.8 -ilc oscillators.

These three auxiliary units may also be used direotly or through harmonic generators as a frequency standard in the low, medium or high frequency range.

The unit contains three tunable channels covering the ranges as given. The circuits of the three stages are identical with the exception of the input coupling arrangements and the inductance values of the filter transformers. The second and third channels, normally used as frequency converters, may also be used as frequency multipliers by supplying the proper frequencies at the left-hand input jacks.

As shown in the schematio diagram, Fig. 37, the first tube (6AC7) in each channel operates as a multiplier or converter. An input of 3 to 6 volts is supplied to the No. 1 grid in both cases. In the converter stages, 
the lower frequency, which might have harmonics that fall in the desired output range, is supplied to the cathode at the low level of 0.1 to 0.2 volt to suppress the generation of harnonics in the converter tube.

The first 6SK7 amplifier tube is operated under class c conditions with the rectified grid current supplying a variable bias to both the first and second tubes, thus supplying an automatic gain control action. Coil windings are used which have considerably higher $Q$ at the low-frequency end of the operating band, thus giving a fairly constant impedance and uniform voltage gain throughout the band. The 6SK7 output stage operates olass A at about 0.1 watt to minimizo the generation of harmonics.

Very complete shielding and decoupling networks reduce the interference between the three channels to negligible amount.

b. Operation and service instructions

The adjustable oscillator should normally be used with the third channel as this reduces by one the number of controls that must be kept in tuno as the frequency is varied. If an output froquency is required, on which harmonic cross-over interference is experienced, the oscillator may be used with the center channel and the interference thus oliminated by propor choice of the input frequencies to the converters. No harmonic interference is experienced when fixed frequencies only are used in the converters.

In tuning the converter channels one should be certain that the desired output freguency is selectod, as the fundamental or hamonics of the frequencies applied to the left-hand jacks may bo obtained if thoy fall within the tuning ranges.

At sorne points in the tuning ranges a slight double peaking effect may be noticed due to mistracking or to a slight coupling backlash. Final tuning adjustment of the converter stages may be made for the clearest sigmal on the analyzer screen.

For meny of the fixed frequency marker points only the frequency multiplier channel need be used. All of the fixed frequency points from 2.0 to $2.8 \mathrm{kc} / \mathrm{s}$ may be obtained by using the multiplier and only one converter channel. Harmonics as high as the tenth may be obtained from the multiplier channol at full power output.

Alignment is carried out by adjusting the trimner condensers mountad in the transfomers. Only those trimmers with one end of the slot notched are used (maximum capacity occurs when the notch is toward center of transformer). The multiplier and first converter channel are aligned for maximum output at the high-frequency end with the dials set at 100. The second converter channel is similarly aligned with the dial set to 80 for the high-frequency end of the band. Each channel should be checked for proper range coverago and uniformity of gain and slight roadjustments made if necessery. 
Oparating characteristics are as follows:

Power input: $110 \nabla ., 60 \mathrm{c}$. at 70 watts

$R-f$ input: untuned inputs, voltage range 3 to 6 volts.

$\mathrm{R}-\mathrm{f}$ outputs: 1500 to $3000 \mathrm{kc} / \mathrm{s}, 1000$ to $2000 \mathrm{kc} / \mathrm{s}, 2000$ to $3000 \mathrm{kc} / \mathrm{s}$ at 100 ohms, 0.1 watt.

Output purity: Harmonics in output
2nd
3 rd and 4 th
-40 to $-60 \mathrm{db}$
5 th and higher
-50 to $-70 \mathrm{db}$
-80 to $-100 \mathrm{db}$

Harmonic cross-over interference:

from 4 th harmonic of oscillator

$-55 \mathrm{db}$

from 5 th and higher harmonios

$-80 \mathrm{db}$

Harmonic interference between channels (channel No. 1 at $1000 \mathrm{kc} / \mathrm{s}$ and channel No. 2 at $2000 \mathrm{kc} / \mathrm{s}$ )

$-50 \mathrm{db}$

$$
\begin{aligned}
& \text { Gamnei voltage } \mathrm{c} \text { :in: No. I (multiplier) } 55 \mathrm{db} \\
& \text { No. } 2 \text { (first, converter) } 45 \mathrm{db} \\
& \text { No. } 3 \text { (socond convorter) } 35 \mathrm{db}
\end{aligned}
$$

c. Parts list

Condenser and resistor data are given in the schematic diagram, Fig. 37 .

runable filter-transformer data are given in the following table:

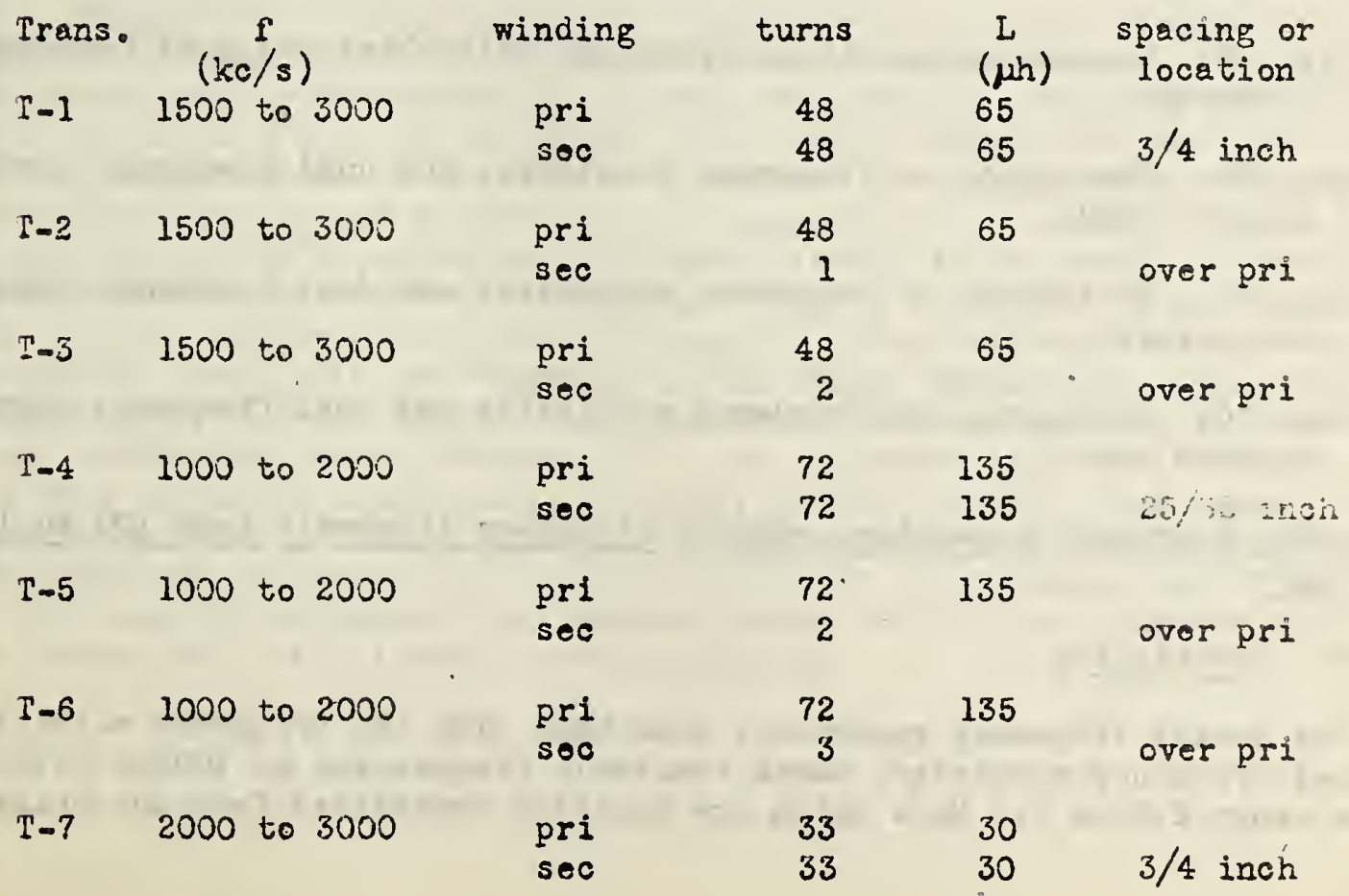




$\begin{array}{cccccc}\text { Irans. } & \begin{array}{c}f \\ (\mathrm{kc} / \mathrm{s})\end{array} & \text { winding } & \text { turns } & \begin{array}{c}L \\ (\mu h)\end{array} & \begin{array}{c}\text { spacing or } \\ \text { location }\end{array} \\ \text { T-8 } & 2000 \text { to } 3000 & \begin{array}{c}\text { pri } \\ \text { sec }\end{array} & 33 & 1 & \text { over pri } \\ \text { T-9 } & 2000 \text { to } 3000 & \text { pri } & 33 & 30 & \\ & & \text { sec } & 11 / 2 & & \text { over pri }\end{array}$

General coil data

On all of the above transformers the colls are wound on $1 / 2^{\prime \prime} \times 1 / 2^{\prime \prime}$ powdered-iron cores (Aladdin Fadio Industries, part No, 10-101). On the first transformer in each channel, separate cores are used for primary and secondary windings with spacing between core edges as given. On the other transformers primary and secondary windings are on the same cores. Tuned wirdings are of $7 / 41$ litz wire, wound with a cam throw of 0.43 inch; low impedance windings are of $10 / 41$ litz wire.

Trimmer condensers in the first two channels are Sickles Co. No. SL-3219, 3 to $25 \mu \mu f$, and in the third channel Sickles Co. No. SD-3157, 5 to $55 \mu \mu f$. Tuning condensers are Hammarlund No. MCD-140-M, 8 to $145 \mu$ f each section, two two-gang units being used in each channel. thick.

Shield cans are aluminum, Sickles Co., size $4^{\prime \prime} \times 2^{\prime \prime} \times 1-7 / 16^{\prime \prime} \times 0.32^{n}$

\section{d. Illustrations}

Fig. 36. Layout drawing of frequency multiplier and dual frequency converter; outputs 1500 to $3000 \mathrm{kc} / \mathrm{s}, 1000$ to $2000 \mathrm{kc} / \mathrm{s}, 2000$ to $3000 \mathrm{kc} / \mathrm{s}$.

Fig. 37. Circuit sohematic of frequenoy multiplier and dual frequency converter.

Fig. 38. Photograph of frequency multiplier and dual frequency converter (front view).

Fig. 39. Photograph of frequency multiplier and dual frequency converter (top view).

Fig. 40. Photograph of frequency multiplier and dual frequency oonverter (bottom view).

8. Decade Frequency Cenerator; outputs at 100-kc intervals from 100 to 1000 $\mathrm{ko/8}$

\section{a. Description}

The decade frequenoy generator, when used with the frequency multiplior and dual frequency converter, makes avallable frequencies at $100-k c$ intervals in the range 2.0 to $2.8 \mathrm{Mc} / \mathrm{s}$ which are entirely controlled from the primary 
standard of frequency. These frequencies may be used to generate marker frequencies throughout the microwave spectrum by use of the main converter and multiplier equipment. Complete coverage, at a highor stability and higher control precision, may also be obtained by using the $500-600 \mathrm{kc}$ oscillator with this equipment.

The decade frequency generator will furnish, simultaneously, harmonics of $100 \mathrm{kc} / \mathrm{s}$ in the decade rango of 100 to $1000 \mathrm{kc} / \mathrm{s}$, at a power output of 0.1 watt each. Output impedance is nominally 100 ohms although performance is satisfactory between 50 ohms and open-circuit conditions. Seprrate switchos and output jacks are provided so that any or a.ll of tho outputs may be oporated at will. These frequencies are obtained by passing the 100-ke input froquency through a pulse-forming circuit arrangement which generates sharp pulses of approximately 0.5 microsecond duration with a par power of about 1 watt. With this adjustment the harmonic content of the pulso output is approximately inversely proportional to the harmonic order. Tunod filters select and equalize the various harmonies. A separate type 6SK7 amplifier tube with single-tuned transformer coupling is used for each output frequency. Theso tubes are operated as class A amplifiers with voltage and loed values chosen to minimizo harmonic output.

A separate report, "Decade frequenoy generator", R213.1 b. Feb. 25, 1946 , gives detailed design and operational data for this unit.

\section{b. Operation and service instructions}

The unit is normally operated from a regulated a-c supply and will not give uniform output from tho various stages if the line voltage drops below about 105 volts. As in any multiplier, phase shifts causing frequency modulation in higher froquency stages may result if the unit is operated from unregulated supply roltage.

Realigament should soldom be required as all filter cirouits are tuned with air-trimmer or silvered mica condensers. If necessary, the following procedure should be used fer allowing the unit to stabilize for $1 / 2$ hour. PluE in 100-kc input and align the pulse input transformer and the 100-ko output transformor. 100-ohm load resistor and vacuum-tube voltmetor should be used on the outputs during alignment with trimmer adjustments progressing from harmonic bus to output circuit in sequence. A wide-band oscilloscope is useful for observing the pulse wave-form on the harmonic bus and the ratios of the output stages by obtaining Lissajou figures. It should be noted that the trimmers in the output transformers are wired in parallel for greater range, also, the 300 to $1000-k c$ grid input transformers each contain an unused trimmer. All used trimmers heve been scribed at correct ilignment points and should not deviate groatly from these points. Particular care should be observed on the input trimmers connecting to the harmonic bus as these will tune to several of the frequencies in most cases. After complete adjustment for maximum output all of the trimmers should be rechecked with a.ll of the outputs operating. 
Operating characteristlos of the decade-frequency generator are as follows :

Power input: 110 v., 60 ०. at 75 watts

R-f input: $110 \mathrm{kc} / \mathrm{s}, 0.1$ watt at 100 ohms

R-f output: 100 to $1000 \mathrm{kc} / \mathrm{s}$ at 100 -kc intervals, 0.1 watt each at 100 ohms

For one output only operating -- 100-oh load, 4.5 to 5.5 volts no load, 6 to 9 volts

For all outputs operating -- 100-ohm load, 3.2 to 3.7 volts no load, 4.1 to 6.8 volts.

Spurious frequenoies:

$1000 \mathrm{kc} / \mathrm{s}$, side-frequencios $f \pm 100 \mathrm{kc} / \mathrm{s}$

$f \pm 200 \mathrm{kc} / \mathrm{s}$

$900 \mathrm{kc} / \mathrm{s}, \mathrm{side}-\mathrm{frequencles}$

800 to $200 \mathrm{kc} / \mathrm{s}$, s1de-

froquencies

1000 to $200 \mathrm{kc} / \mathrm{s}$, harmonles

$100 \mathrm{kc} / \mathrm{s}$, harmonics $\mathrm{f} \pm 100 \mathrm{kc} / \mathrm{s}$

$\mathrm{f} \pm 200 \mathrm{kc} / \mathrm{s}$

$\mathrm{f} \pm 100 \mathrm{kc} / \mathrm{s}$

$\mathrm{f} \pm 200 \mathrm{kc} / \mathrm{s}$

$f \times 2$

$f \times 3$

$f \times 4$

$f \times 2$

$f \times 3$ $\mathrm{db}$ down

100-ohm losd

65

80

no load

75

100

90

100

100

60

65

80

50

60
65

70

80

70

85

85

100

100

60

hoove are minimum values and are approximately the same for all or only one output stage operating.

\section{Parts list}

Condenser and resistor data are given in the schematio diagram, Fig. 42. Resonant filter tranformer data are given in the following table.

\begin{tabular}{|c|c|c|c|c|c|c|c|}
\hline Trans. & $(\mathrm{kc} / \mathrm{s})$ & uso & winding & turns & $\begin{array}{c}L \\
(\mu h)\end{array}$ & $\begin{array}{l}\text { par, cond. } \\
(\mu \mu f)\end{array}$ & $\begin{array}{l}\text { spacing } \\
\text { (inches) }\end{array}$ \\
\hline$T-1$ & 100 & input & $\begin{array}{l}\text { pri } \\
\text { sec }\end{array}$ & $\begin{array}{l}500 \text { (esti- } \\
\text { mated) } \\
\text { none }\end{array}$ & 11,100 & 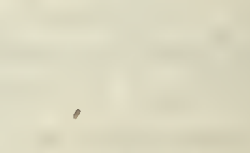 & \\
\hline$T-2$ & 100 & plate & $\begin{array}{l}\text { pri } \\
\text { soc }\end{array}$ & $\begin{array}{r}250 \\
25\end{array}$ & 1,700 & 1400 & 0 \\
\hline$T-3$ & 200 & grid & $\begin{array}{l}\text { pr } 1 \\
\text { soc }\end{array}$ & $\begin{array}{l}400 \\
400\end{array}$ & $\begin{array}{l}4,100 \\
4,100\end{array}$ & $\begin{array}{l}125 \\
125\end{array}$ & 1 \\
\hline
\end{tabular}




\begin{tabular}{|c|c|c|c|c|c|c|c|}
\hline Frans & $\cdot\left[\begin{array}{l}f \\
(k c / s)\end{array}\right.$ & use w & rinding & turns & $\stackrel{I}{(2 / 2)}$ & $\begin{array}{c}\text { par. aond } \\
(\mu \mu f)^{-}\end{array}$ & $\begin{array}{l}\text { d. spacing } \\
\text { (inchos) }\end{array}$ \\
\hline$T-4$ & 200 & plate & $\begin{array}{l}\text { pri } \\
\text { sec }\end{array}$ & $\begin{array}{r}114 \\
16\end{array}$ & 420 & 1430 & 0 \\
\hline$T-5$ & 300 & grid & $\begin{array}{l}p r i \\
\text { sec }\end{array}$ & $\begin{array}{l}400 \\
400\end{array}$ & $\begin{array}{l}4,150 \\
4,150\end{array}$ & 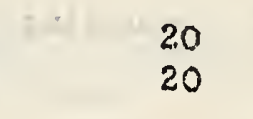 & 1 \\
\hline$T-6$ & 300 & plate & $\begin{array}{l}\text { pri } \\
\text { sec }\end{array}$ & $\begin{array}{l}92 \\
14\end{array}$ & 950 & 950 & 0 \\
\hline$T-7$ & 400 & coupling & $\begin{array}{l}\text { pri } \\
\text { soo }\end{array}$ & $\begin{array}{l}400 \\
250\end{array}$ & $\begin{array}{l}4,150 \\
1,800\end{array}$ & 50 & $3 / 4$ \\
\hline$T-8$ & 400 & grid & $\begin{array}{l}\text { pri } \\
\text { soo }\end{array}$ & $\begin{array}{r}50 \\
200\end{array}$ & $\begin{array}{r}80 \\
1,130\end{array}$ & 100 & $1 / 2$ \\
\hline$T-9$ & 400 & plate & $\underset{\text { seo }}{\mathrm{pri}}$ & $\begin{array}{l}76 \\
12\end{array}$ & 190 & 750 & 0 \\
\hline$T-10$ & 500 & coupling & $\begin{array}{l}\text { pri } \\
\text { sec }\end{array}$ & $\begin{array}{l}400 \\
200\end{array}$ & $\begin{array}{l}4,150 \\
1,130\end{array}$ & 50 & $3 / 4$ \\
\hline$T-11$ & 500 & grid & $\begin{array}{l}\text { pri } \\
\text { sec }\end{array}$ & $\begin{array}{r}40 \\
160\end{array}$ & $\begin{array}{r}54 \\
725\end{array}$ & 100 & $1 / 2$ \\
\hline$T-12$ & 500 & plato & $\begin{array}{l}\text { pri } \\
\text { seo }\end{array}$ & $\begin{array}{l}64 \\
11\end{array}$ & 152 & 600 & 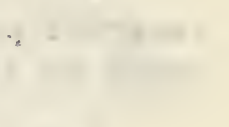 \\
\hline$T-13$ & 600 & coupling & $\begin{array}{l}\text { pri } \\
\text { sec }\end{array}$ & $\begin{array}{l}350 \\
150\end{array}$ & $\begin{array}{r}3,170 \\
670\end{array}$ & 70 & $3 / 4$ \\
\hline$T-14$ & 600 & grid & pri & $\begin{array}{r}35 \\
135\end{array}$ & $\begin{array}{r}42 \\
510\end{array}$ & 70 & $1 / 2$ \\
\hline$T-15$ & 600 & plate & $\begin{array}{l}\text { pri } \\
\text { sec }\end{array}$ & $\begin{array}{l}56 \\
10\end{array}$ & 116 & 550 & 0 \\
\hline$T-16$ & 700 & coupling & $\begin{array}{l}\text { pri } \\
\text { seo }\end{array}$ & $\begin{array}{l}300 \\
125\end{array}$ & $\begin{array}{r}2400 \\
510\end{array}$ & 70 & $3 / 4$ \\
\hline$T-17$ & 700 & grid & $\begin{array}{l}\text { pri } \\
\text { soo }\end{array}$ & $\begin{array}{r}30 \\
115\end{array}$ & $\begin{array}{r}32 \\
370\end{array}$ & 70 & $3 / 8$ \\
\hline$T-18$ & 700 & plate & $\begin{array}{l}\text { pri } \\
\text { sec }\end{array}$ & $\begin{array}{r}50 \\
9\end{array}$ & 90 & 500 & 0 \\
\hline $\mathrm{T}-19$ & 800 & coupling & $\begin{array}{l}\text { pri } \\
\text { sec }\end{array}$ & $\begin{array}{l}250 \\
100\end{array}$ & $\begin{array}{r}1,800 \\
310\end{array}$ & 70 & $3 / 4$ \\
\hline$T-20$ & 800 & grid & $\begin{array}{l}\text { pri } \\
\text { sec }\end{array}$ & $\begin{array}{r}25 \\
100\end{array}$ & $\begin{array}{r}25 \\
310\end{array}$ & 70 & $1 / 4$ \\
\hline
\end{tabular}




\begin{tabular}{|c|c|c|c|c|c|c|c|}
\hline Trans. & $\frac{f}{(k c / s)}$ & use & winding & turns & $\begin{array}{c}\mathrm{L} \\
(\mu h)\end{array}$ & $\begin{array}{l}\text { per. cond. } \\
(\mu \mu f)\end{array}$ & $\begin{array}{c}\text { ipacing } \\
\text { (inches) }\end{array}$ \\
\hline$T-21$ & 800 & plate & $\begin{array}{l}\text { pri } \\
\text { sec }\end{array}$ & $\begin{array}{r}44 \\
8\end{array}$ & 74 & 450 & 0 \\
\hline$T-22$ & 900 & coupling & $\begin{array}{l}\text { pri } \\
\text { sec }\end{array}$ & $\begin{array}{r}225 \\
75\end{array}$ & $\begin{array}{r}1,425 \\
180\end{array}$ & 130 & $5 / 8$ \\
\hline$T-23$ & 900 & grid & $\begin{array}{l}\text { pri } \\
\text { seo }\end{array}$ & $\begin{array}{l}22 \\
86\end{array}$ & $\begin{array}{r}22 \\
220\end{array}$ & 70 & $1 / 8$ \\
\hline$T-24$ & 900 & plato & $\begin{array}{l}\text { pri } \\
\text { seo }\end{array}$ & $\begin{array}{r}42 \\
7\end{array}$ & 65 & 400 & \\
\hline$T-26$ & 1000 & coupling & $\begin{array}{l}\text { pri } \\
\text { sec }\end{array}$ & $\begin{array}{r}200 \\
50\end{array}$ & $\begin{array}{r}1,130 \\
80\end{array}$ & 230 & $5 / 8$ \\
\hline$T-26$ & 1000 & grid & $\begin{array}{l}\text { pri } \\
\text { sec }\end{array}$ & $\begin{array}{l}20 \\
75\end{array}$ & $\begin{array}{r}18 \\
180\end{array}$ & 100 & $1 / 8$ \\
\hline $\mathrm{T}-27$ & 1000 & plato & $\begin{array}{l}\text { pri } \\
\text { sec }\end{array}$ & $\begin{array}{r}40 \\
6\end{array}$ & 60 & 350 & 0 \\
\hline
\end{tabular}

General coil data

On all of the above transformers prlmary and secondary windings aro on separate powdered-iron cores. Spacing betweon primary and secondary core odges is given.

Core material: R-f powdered-iron, cylindrioal $1 / 2^{\prime \prime} \times 1 / 2^{\prime \prime}$ with $3 / 16^{\circ}$ dia. hole (Mladdin Radio Industrios, part No. 10-101).

Wire Coil windings are of 7-8trand No. 41 litz wire with the exception of the plate transformer secondaries which are of $10 / 41 \mathrm{litz}$ wire. Findings are universal type, with a 5/16" throw. Two layers of scotch elootrical tape are placed between cores and windings and finished windings are coated with polys tyreno cement.

Trimmer condensers: Dual air-dielectric, ceramic-mounted trimmer condensers (F. W. Sickle8 Co. No. SD-3157), 5 to $55 \mu$ feach, are used on all transformers exoept the 100-ke input transformer which is an Aladdin Radio Industries S-6568, having trimmers of 85 to $125 \mu \mu f$ each.

Shunting condensers: Whero additional capaoity is required, silvered mica condensers are shunted across the variable air-trimmers.

Coil mounting: The coils are mounted on the tuning condensers by moans of threaded bakelite rods of the proper length through the holes in the oore material and with bakelite spacers whero indioatod. A threaded bakelite washer is usod as a rotaining nut. 
Output leads: The connections botween the output transformers and the panel jacks are made with flexiblo concontric conductors with the shiolds grounded at the jacks.

Shield cans: Aluminum shield cans are from F. W. Sickles Co., sizo $4^{\text {H }} \times 2^{\text {" }} \times 17 / 16^{\prime \prime} \times 0.032^{\text {" }}$ thick.

Inductance values: All inductance values are given as assembled for use with shield cans and primary and secondary cores in place.

d. Illustrations

Fig. 41. Layout drawing of decade frequency generator; outputs at 100-ke intervals from 100 to $1000 \mathrm{kc} / \mathrm{s}$.

Fig. 42. Circuit schematic of decade frequency generator

Fig. 43. Photograph of decade frequency generator (front vi ew).

Fig. 44. Photograph of decade frequency generator (top view).

Fig. 45. Photograph of decade frequency generator (bottom viow).

\section{Harmonic Series Generator}

\section{a. Description}

This unit contains three class $C$ amplifier stages, using 6AC7 tubes, and having a high degree of intermodulation through use of a common plato load resistor. The untunod inputs may bo supplied with frequoncies to give numerous check points in any desired region of the low, medium or high frequency spectrum. Normally, standard-frequency inputs of $100 \mathrm{kc} / \mathrm{s}$ and $10 \mathrm{kc} / \mathrm{s}$ are used in checking or monitoring the adjustable oscillators. An audio-frequency interpolation oscillator with a range of 0 to $5000 \mathrm{c} / \mathrm{s}$ is used for determination of values between these check points.

The third input channel may be operated at very low lovel at an audio frequency (usually $1000 \mathrm{c} / \mathrm{s}$ ) for very accurately zero-beating the oscillators to these check points for calibration purposes. As an alternate arrangement, the receiver "S" meter may be used as a very low beat indicator.

The unit also contains mixing controls for adjusting the relative levels of the standard and unknown froquencies at the receiver input.

b. Operation and sorvice instructions

In operation, the proper input and output connections are completed and the control dials sot for most sensitive conditions. Use of a fixod line insertion-type attenuator $(20 \mathrm{db})$ for reducing the output from the adjustablefrequency oscillators gives a soother adjustment of the mixing controls. 
Operating characteristics are as follows:

Power inputs 110 v. 60 c. at 35 watts

R-f input: nominally $100 \mathrm{kc} / \mathrm{s}, 10 \mathrm{kc} / \mathrm{s}$ and $1 \mathrm{kc} / \mathrm{s}$ at $500 \mathrm{ohms}, 0.1$ watt

R-f output: output sufficient for frequency measurements up to 100 th harmonic ( $10 \mathrm{Mo} / \mathrm{s}$ for $100 \mathrm{kc} / \mathrm{s}$ input)

c. Parts list

Values of all components are given in the sohomatic diagram, Fig. 46.

d. Illus trations

Pig. 46. Circuit schematic of harmonic series generetor.

Fig. 47. Photograph of harmonic series generator (top-front viow).

Fig. 48. Photograph of harmonic series generator (bottom viow).

10. Audio Frequency. Interpolation Oboillator

This unit is a General Radio type 617-C Interpolation Osoillator.

Operating characteristics are as follows:

Power input: $110 \nabla_{0}, 60$ c. at 20 watts

Amf output: 0 to $5000 \mathrm{c} / \mathrm{s}$ at 7 volts, 20,000 ohms

Accuracy $\pm 1 \mathrm{c} / \mathrm{s}$ when standardized at intervals of $100 \mathrm{o} / \mathrm{s}$.

11. Multi-Band Receiver and Monitoring Speaker

The receiver is a National Co. NC-200 RG rack-mounting typo; frequenoy range 490 to $30,000 \mathrm{kc} / \mathrm{s}$; complete with panel mounted speaker.

Power consumption is approximately 100 watts.

12. Wide-Band Oscilloscope

The oscilloscope is a 3 -inch, raok-mounted type manufactured by Research Construction Co., Cambridge, Mass.

13. Frequency Divider; $100 \mathrm{kc} / \mathrm{s}$ to $10 \mathrm{kc} / \mathrm{s}$ to $1 \mathrm{ko} / \mathrm{s}$ to $0.1 \mathrm{ko} / \mathrm{s}$.

This unit is a Hewlett Packard 100-A Low Frequenoy Standard. The 100-ke crystal supplied with the unit was removed and the osoillator tubo converted to a 100-kc buffer amplifer by supplying a standard-frequenoy voltage from one of the distribution amplifier outputs to the grid of this tube. This input is connected through the torminals on the reas of the unit normally used for 100-ko output. Output from the distribution amplifior is adjus tod to the 
center of the range which gives a stable 10 to 1 division. The other divider stages should require no adjustment. The unit was remored from the wooden cas $\theta$ and supplied with a bottom cover and a rentilated dust cover.

\section{Acknowledgments}

Grateful acknowledgment is given to Messrs. V. E. Heaton and $R$. $H$ 。 McCracken for their assistance in the design and construction of the oquipment.

Thanks are also due Messrs. F. J. Gaffney, L. B. Young, P. A, Hower and N. C. Colby of the MIT Radiation Laboratory for their help.

Soptember 1946. 



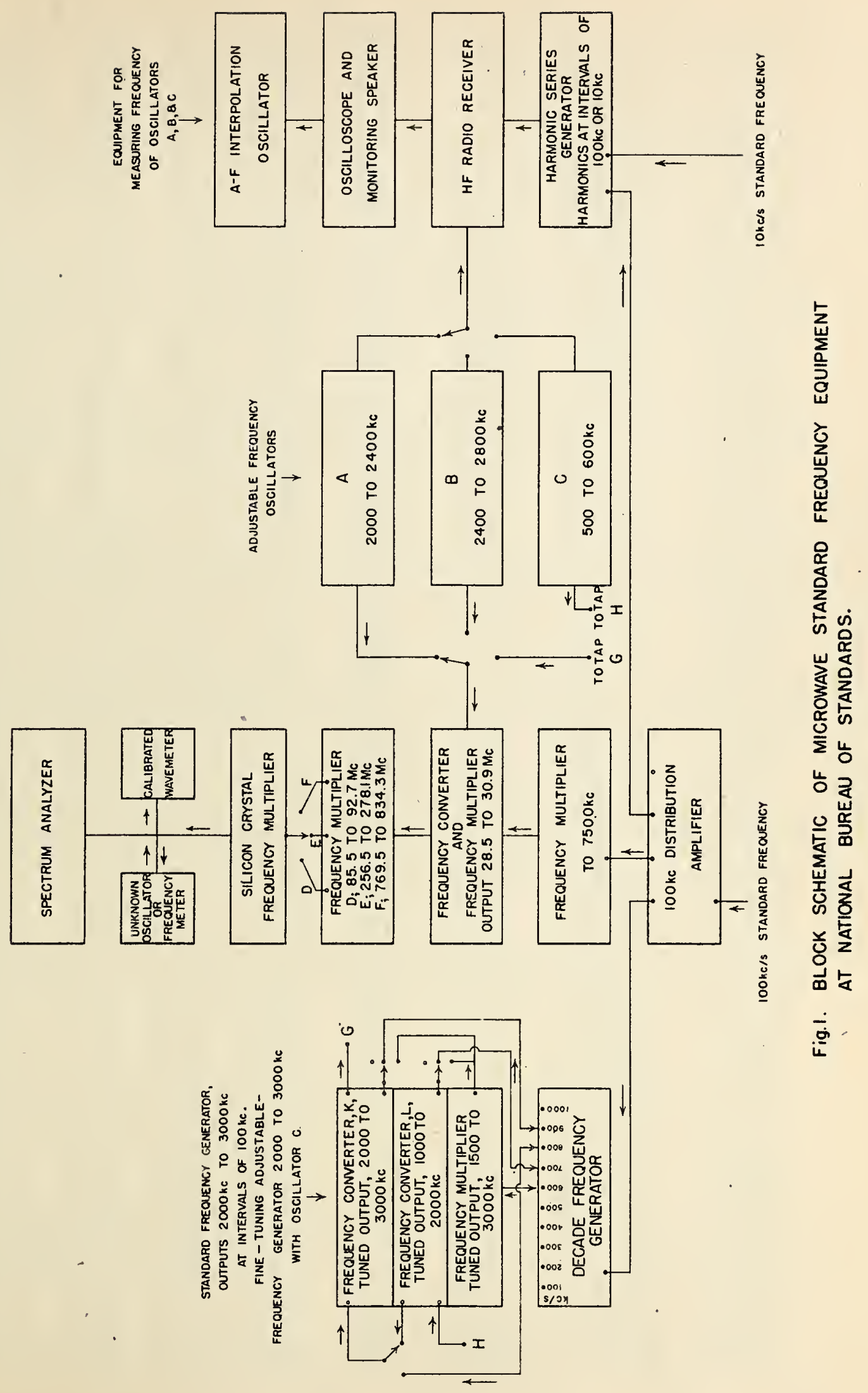





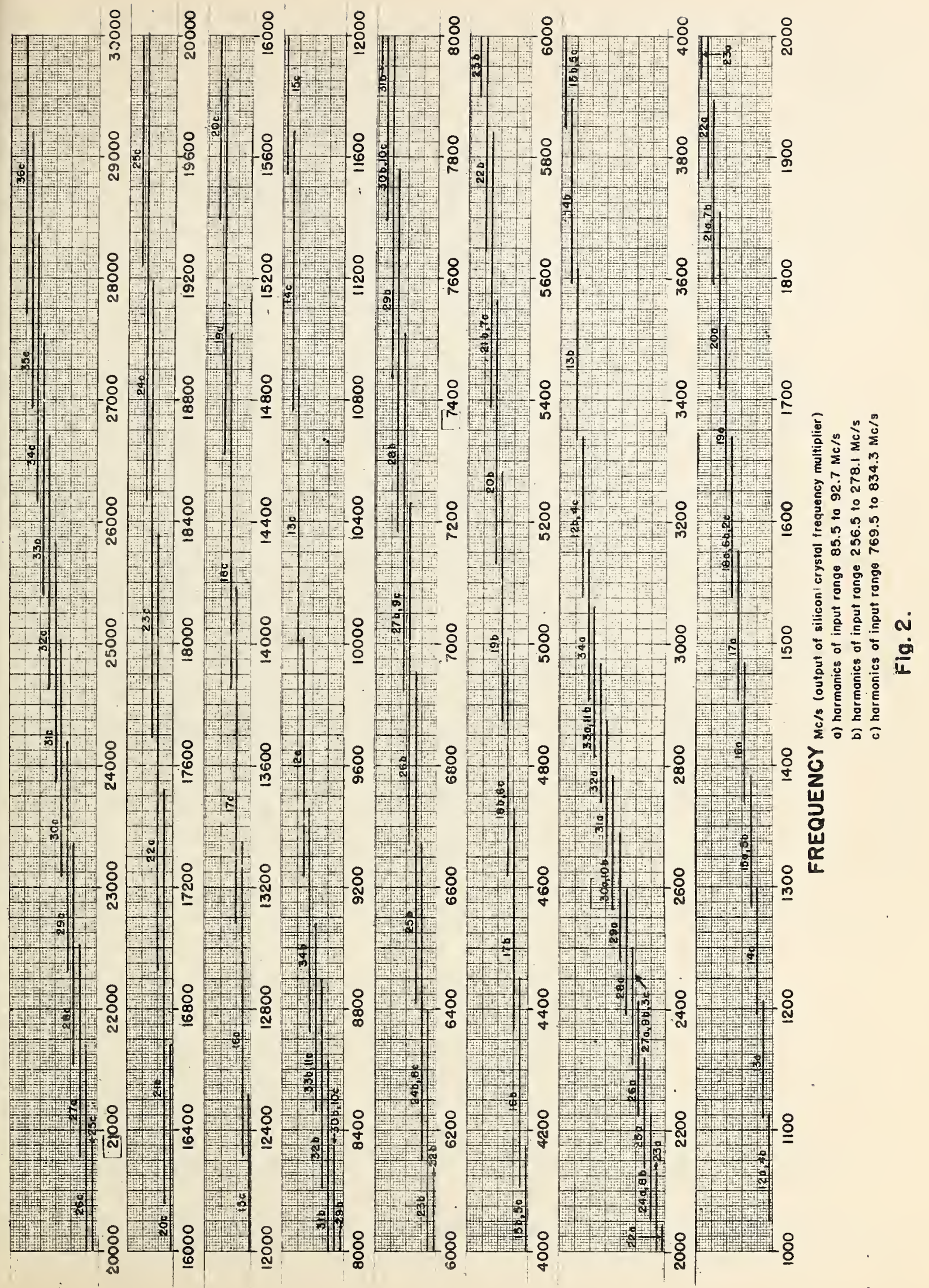





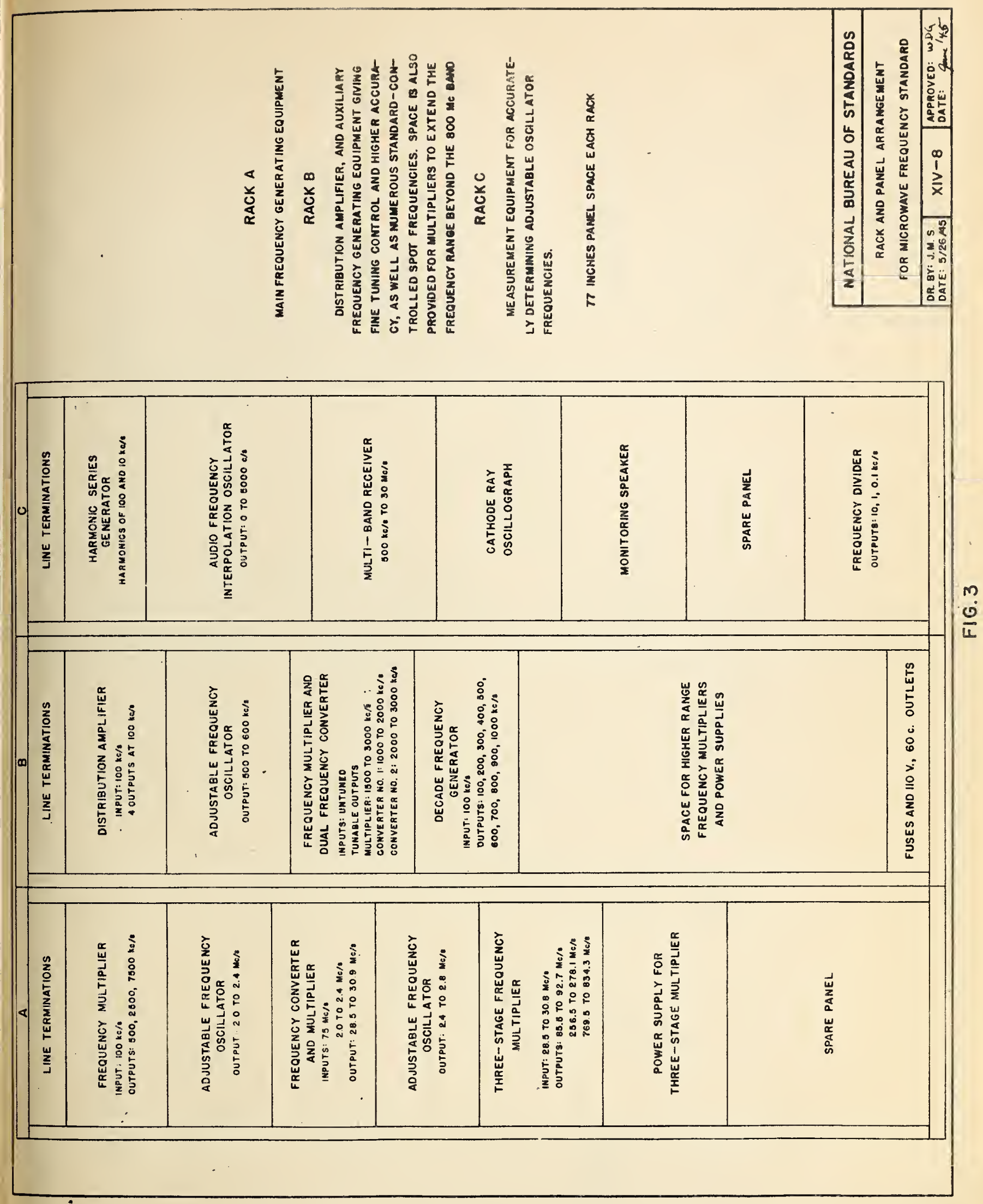




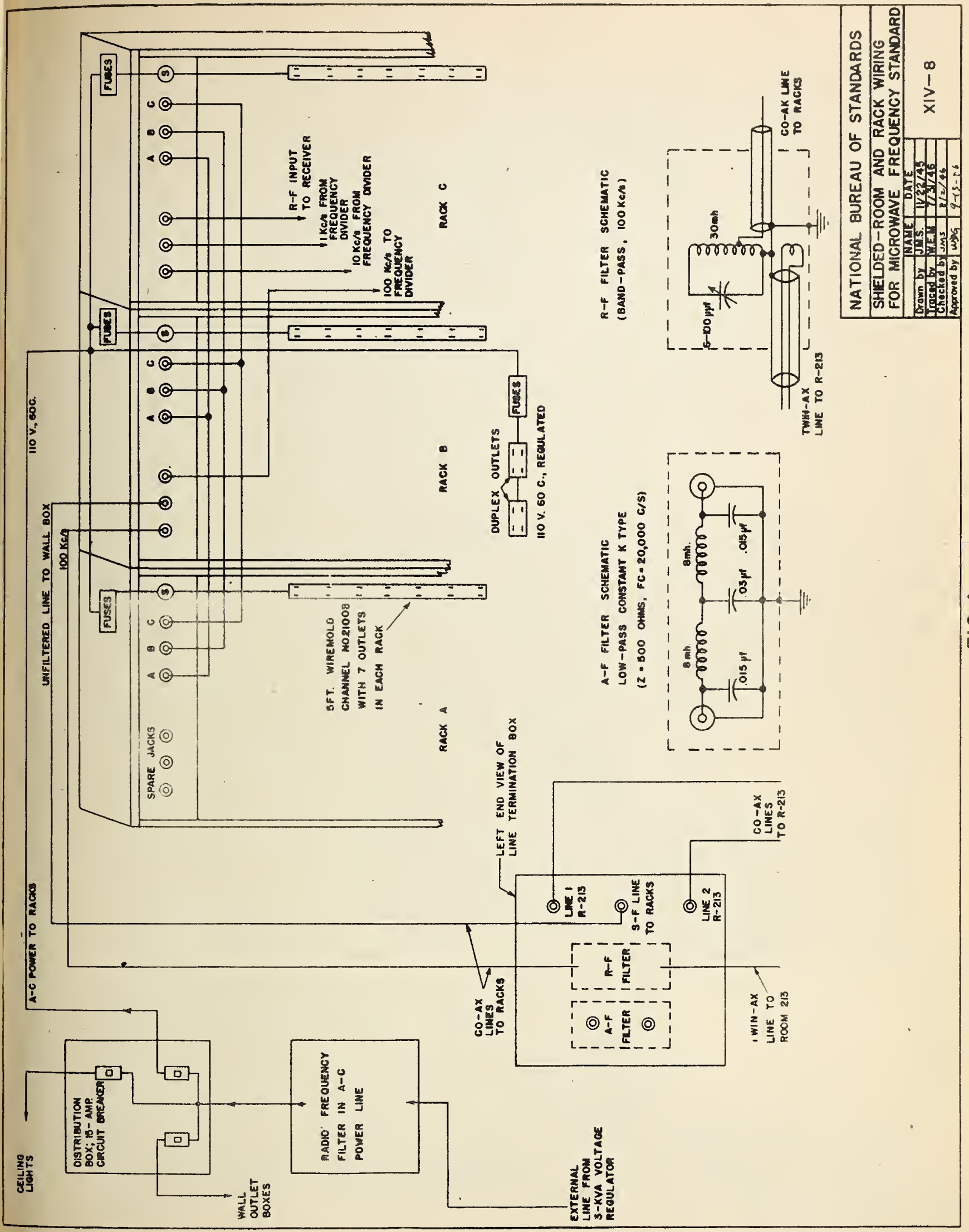





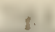

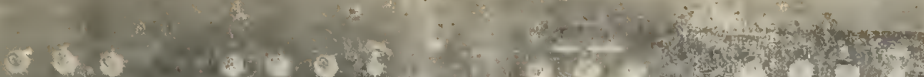

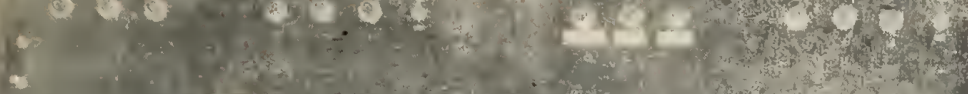

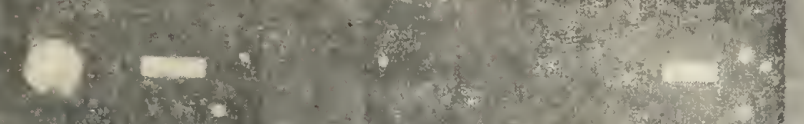

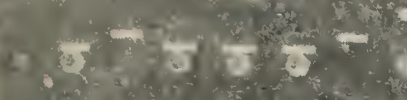

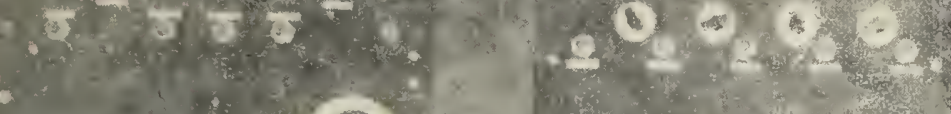

$-0$

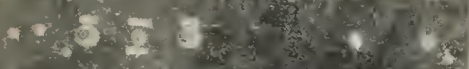

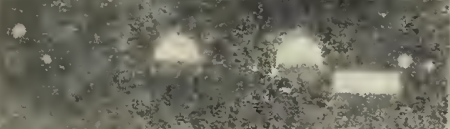

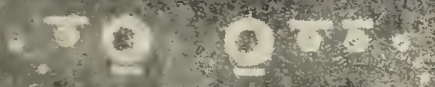

$x^{2}+x^{2}$

2. 1.

$x+5 \times 5 \%$

40

C 60

$+\frac{1}{2}$

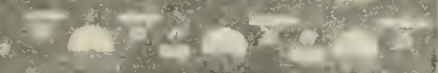

- 4 .

$-2$

$\therefore \cdot 9 \cdot 0$.
- 0

$\operatorname{lom}^{2}+x^{2}+x^{2}$

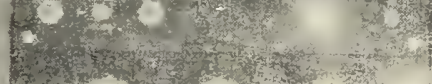

Fit. $, 1,1$ - $C(5)+3)$ a d a d ons

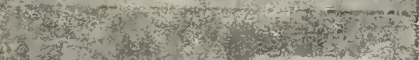

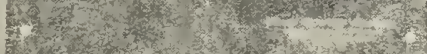

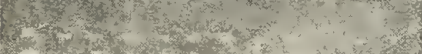

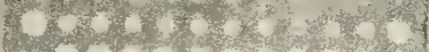
$-2 x+2 x+30$

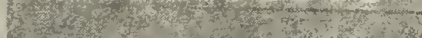

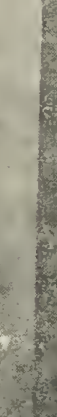

$(-\infty$,

d.

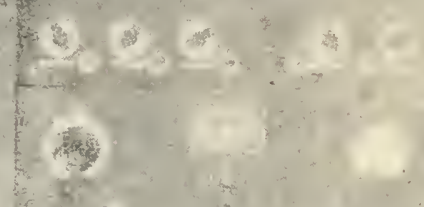

$t^{2}$
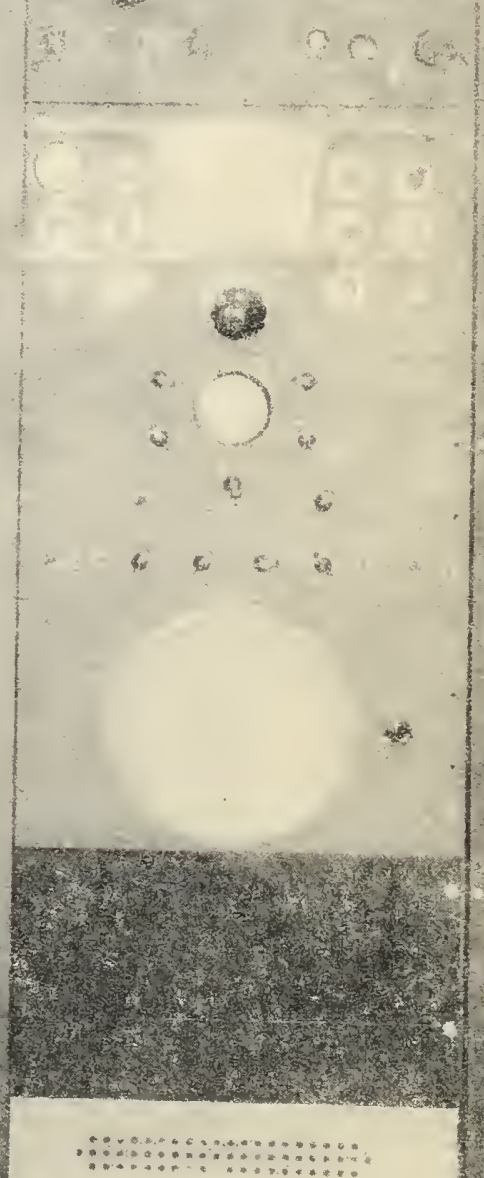

(⿻) 


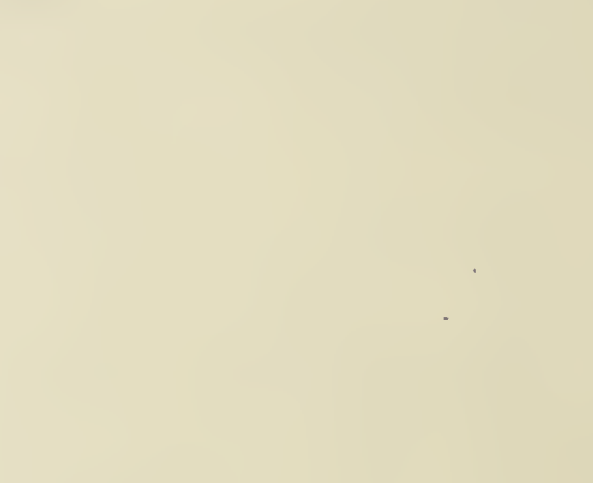




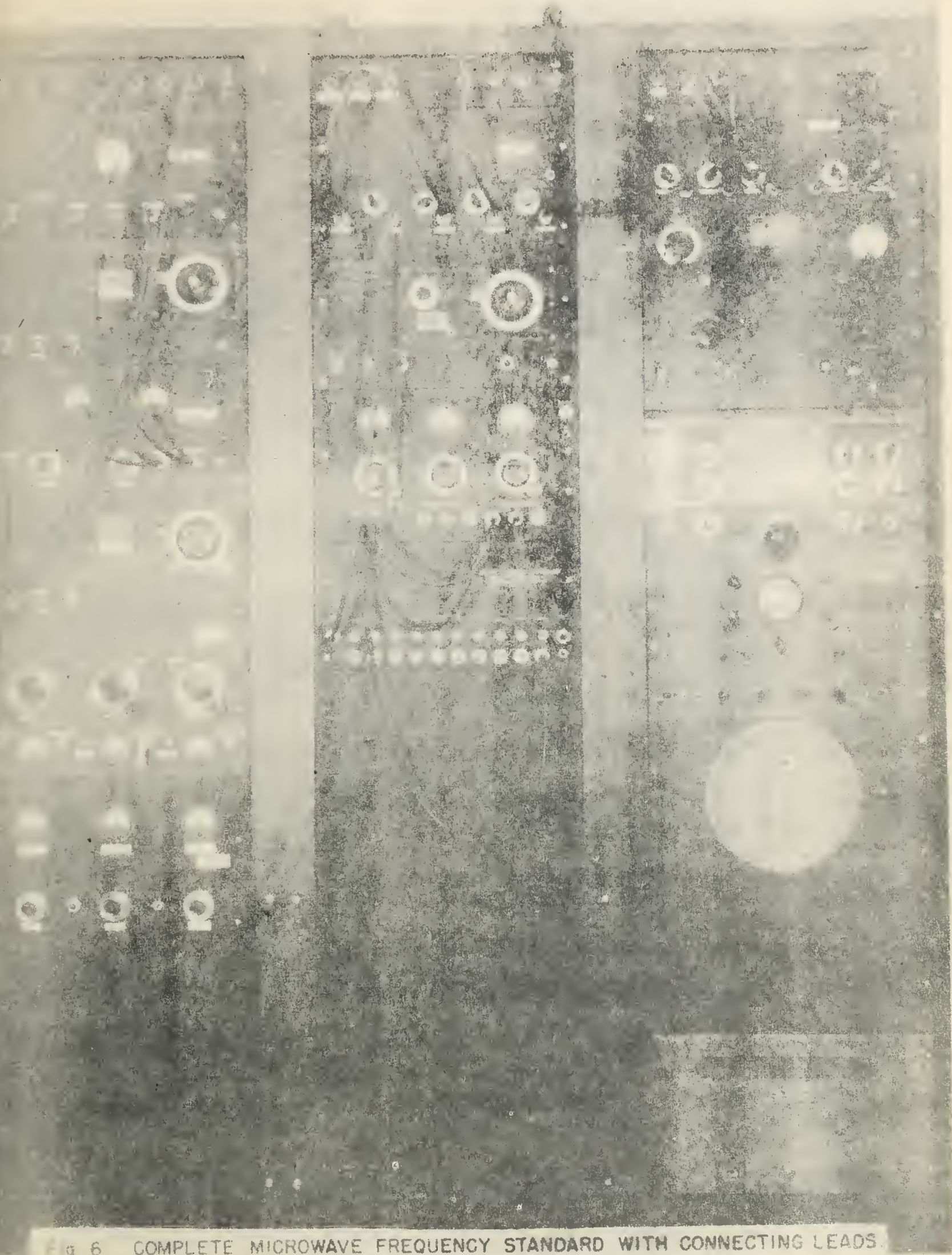





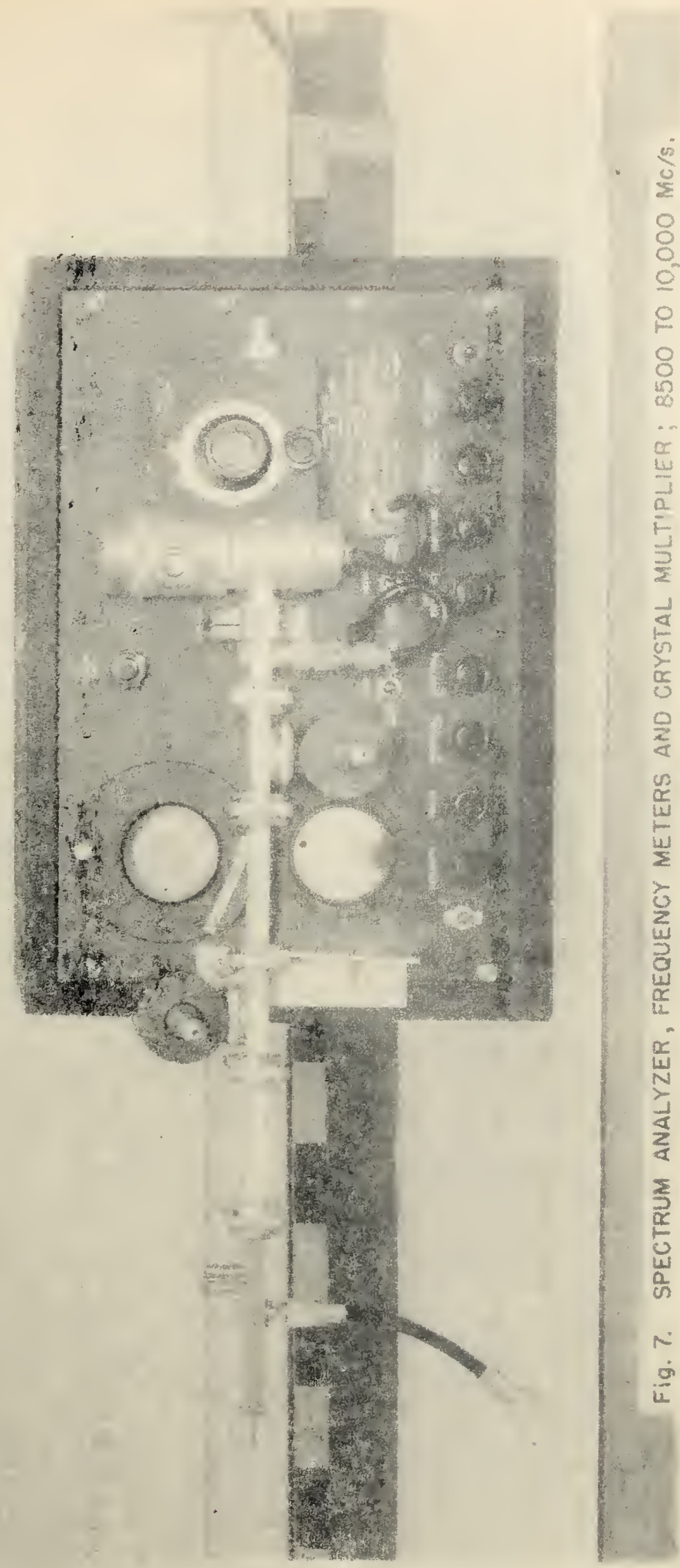




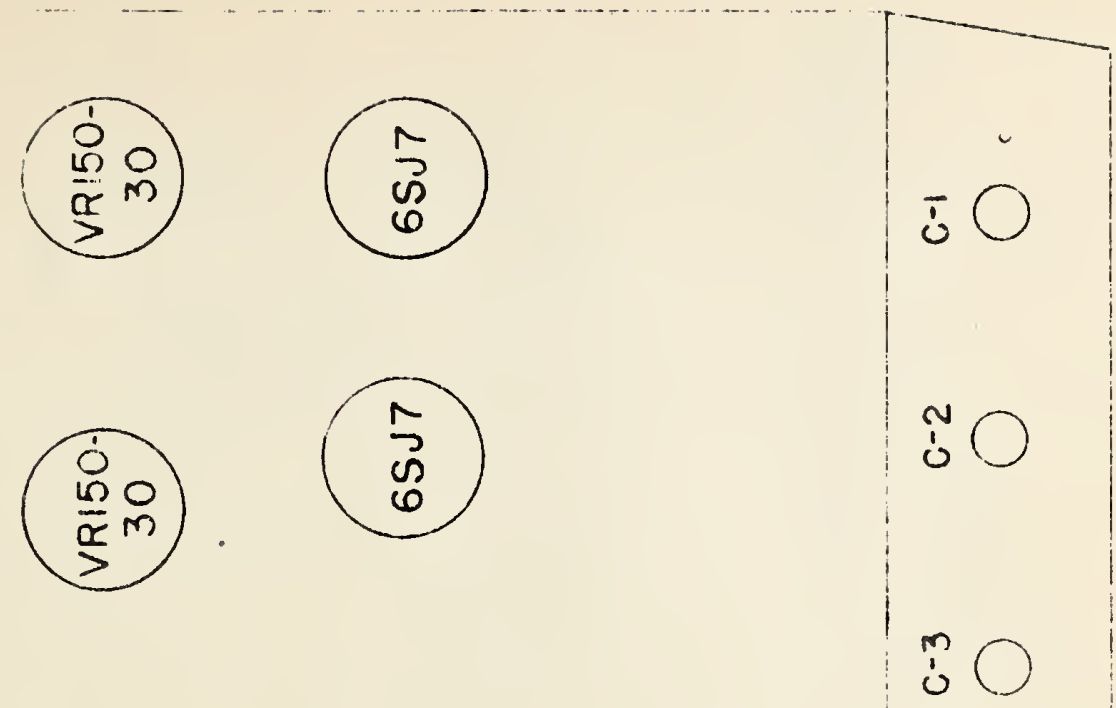

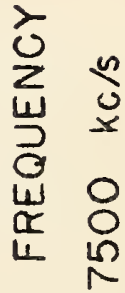
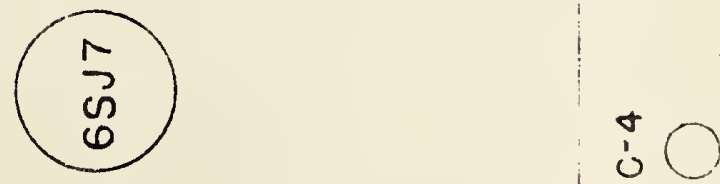

岁 0 意

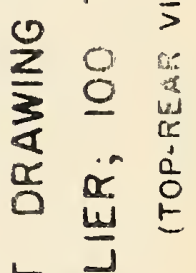
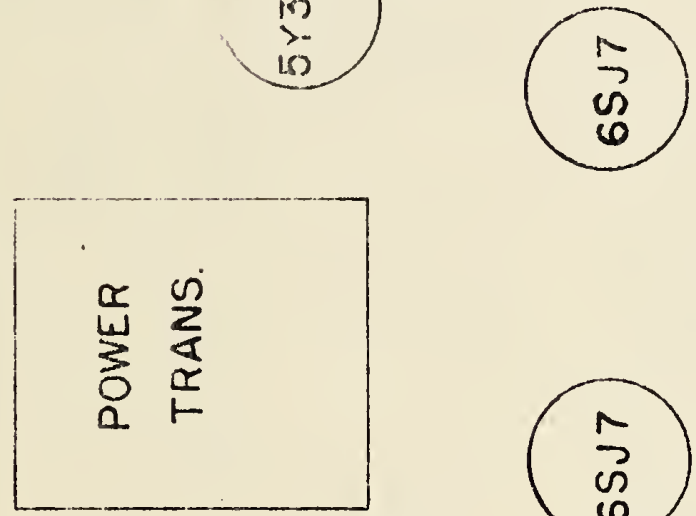

$\stackrel{\text { : } O}{0}$

$5 \frac{a}{5}$

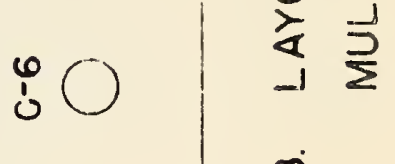

$n$
0
0

$\infty$

io

in
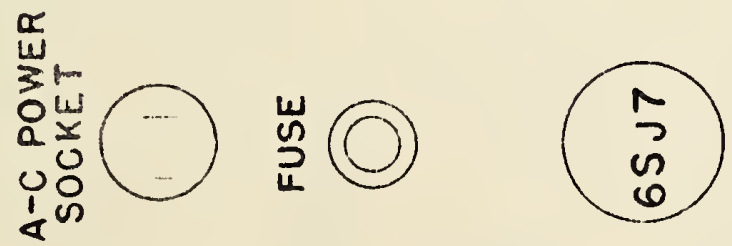

i 



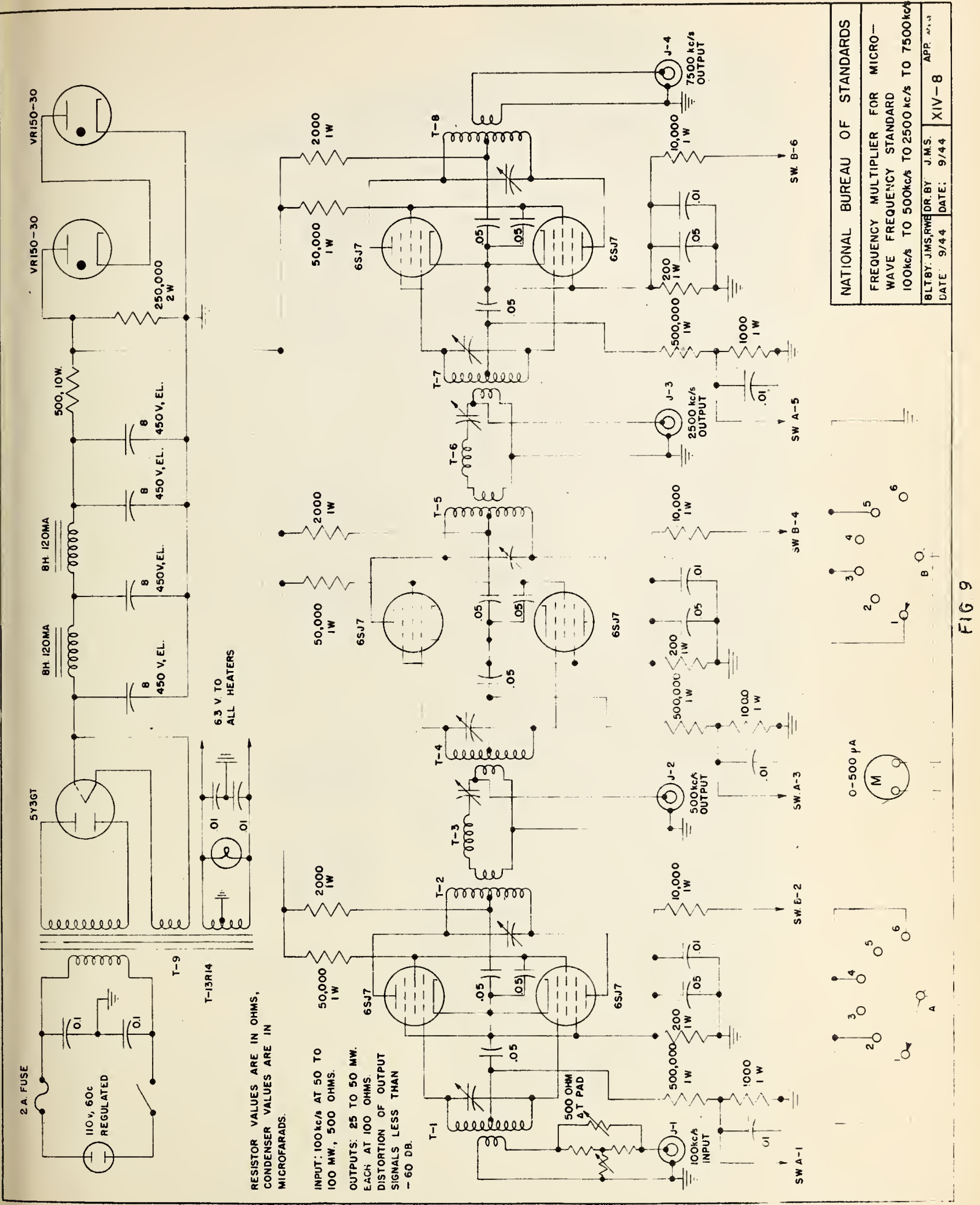





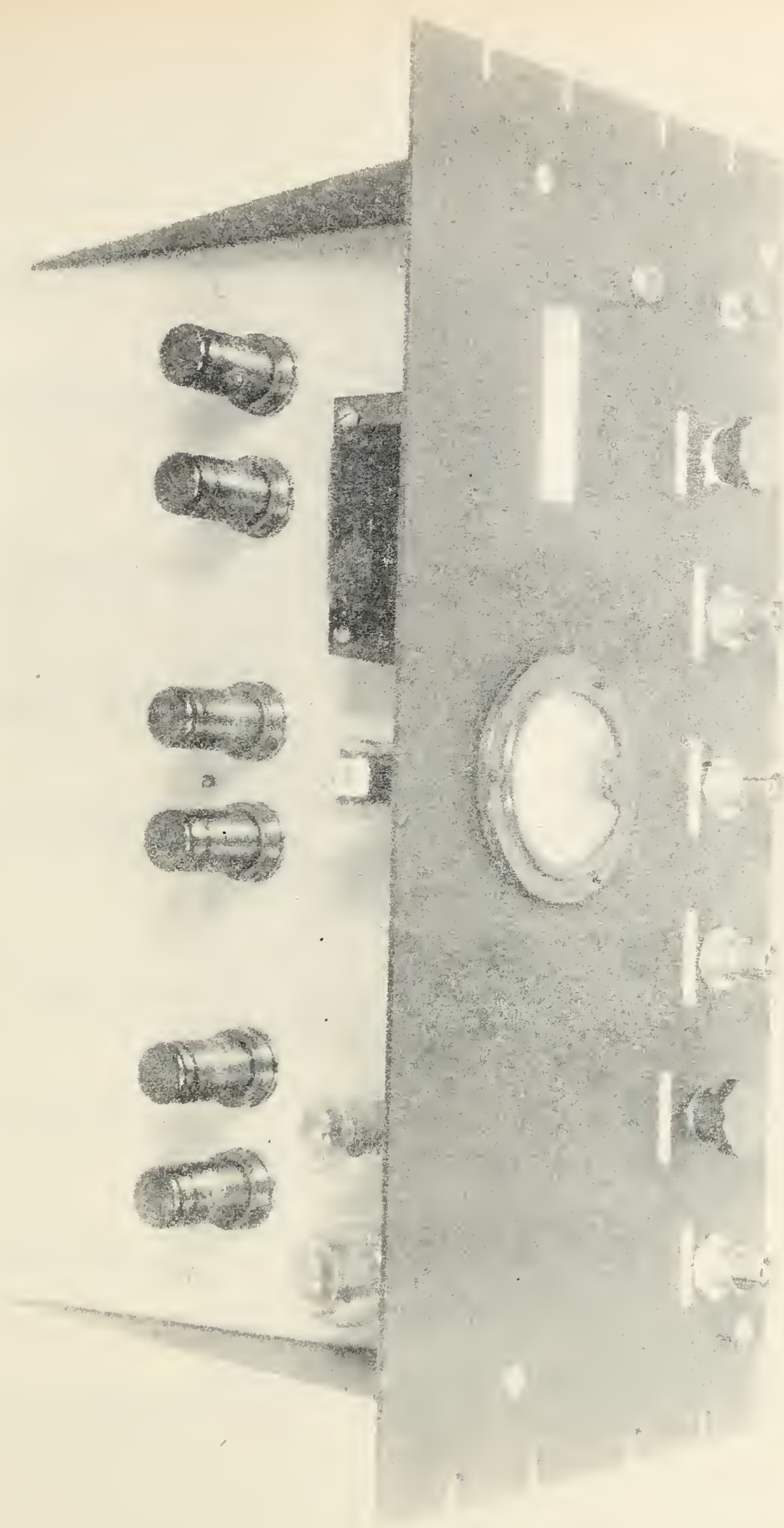





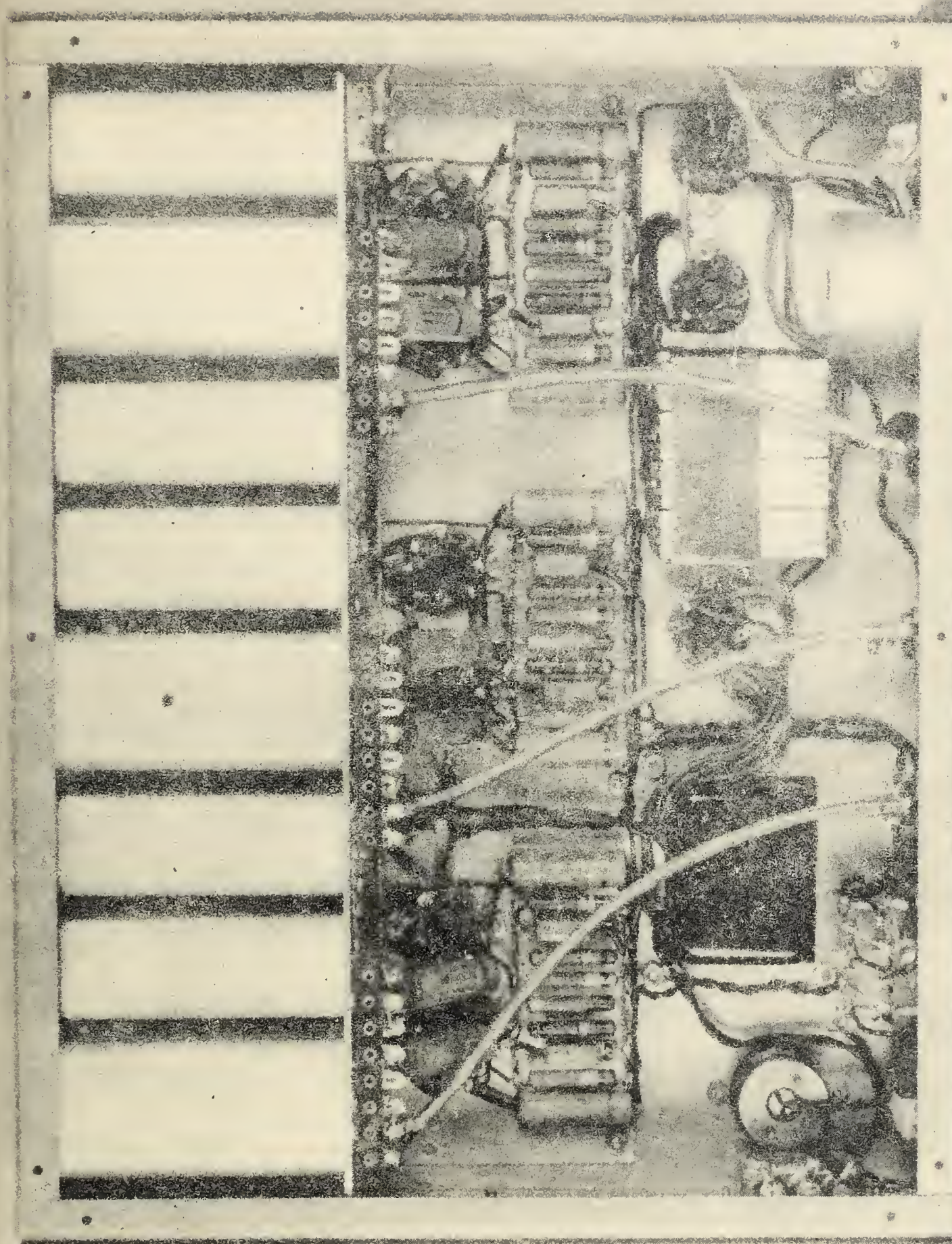





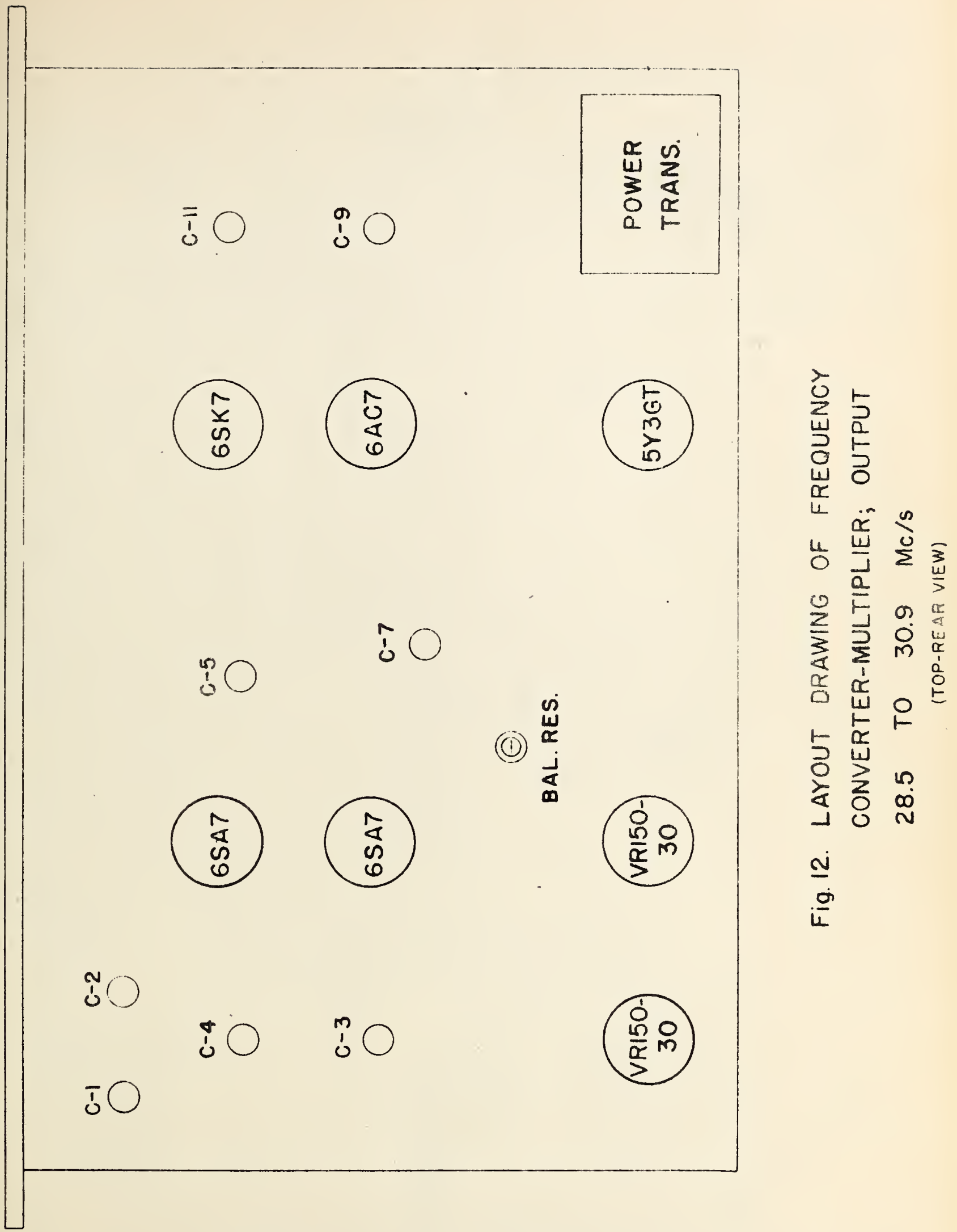





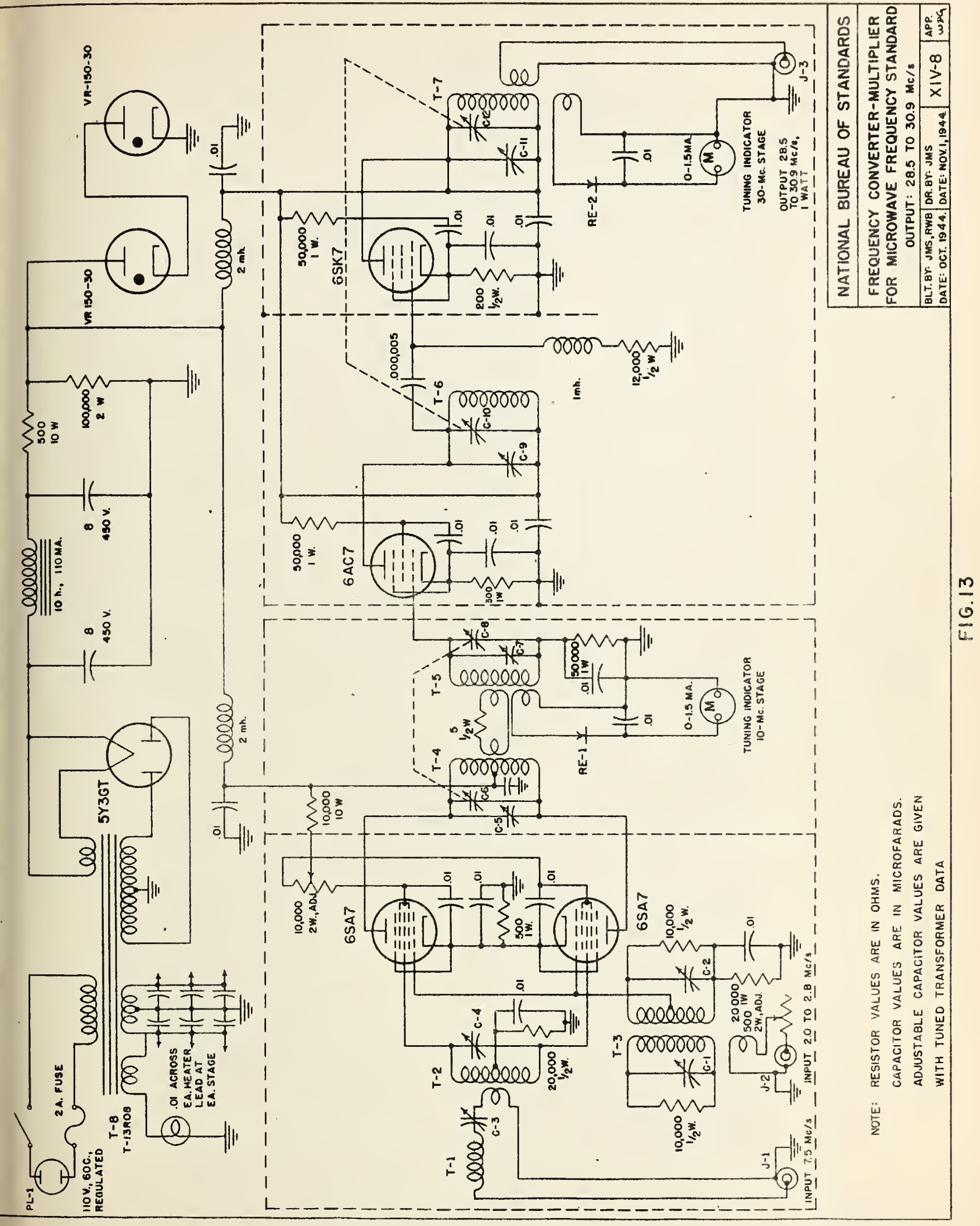





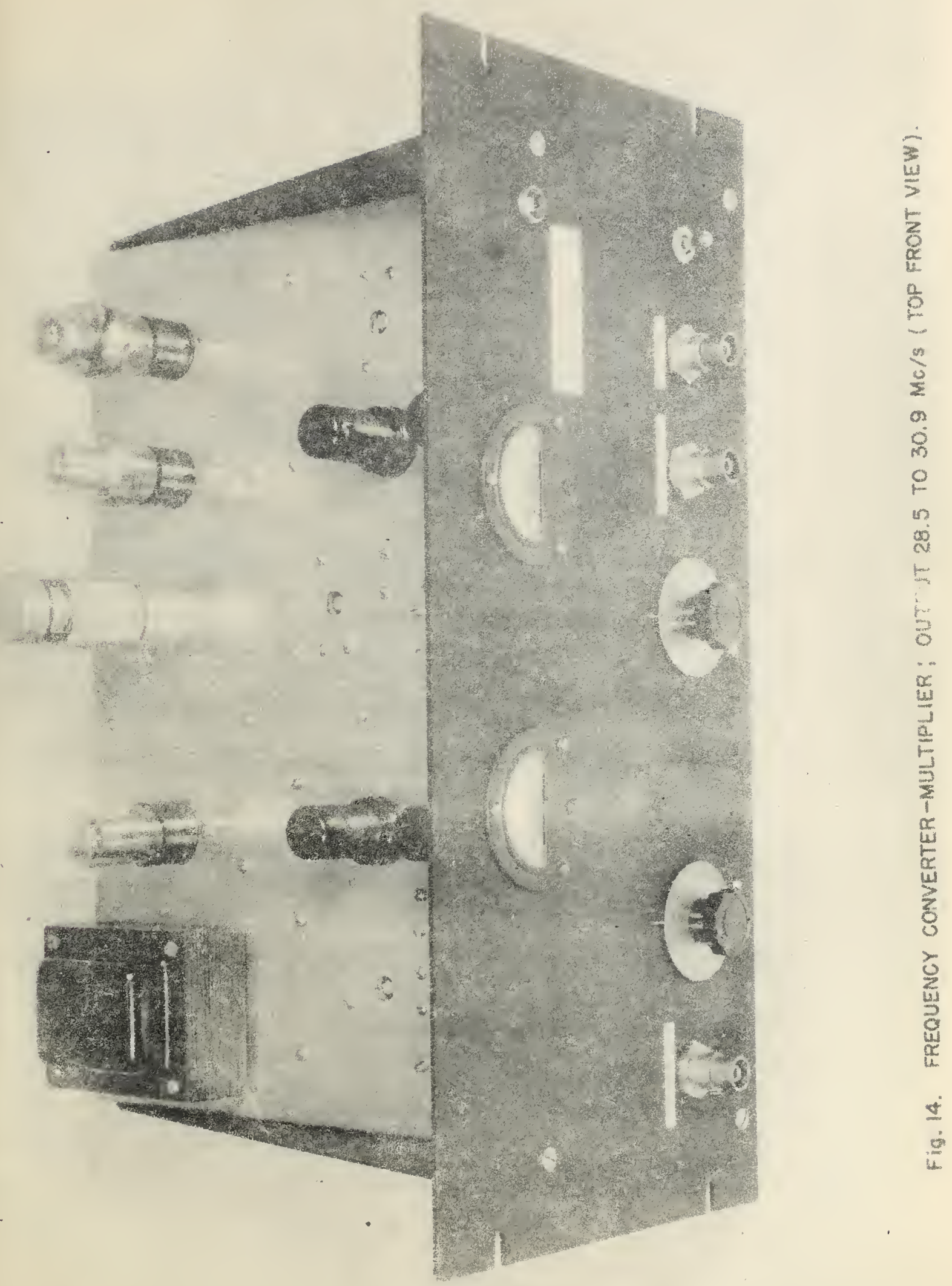




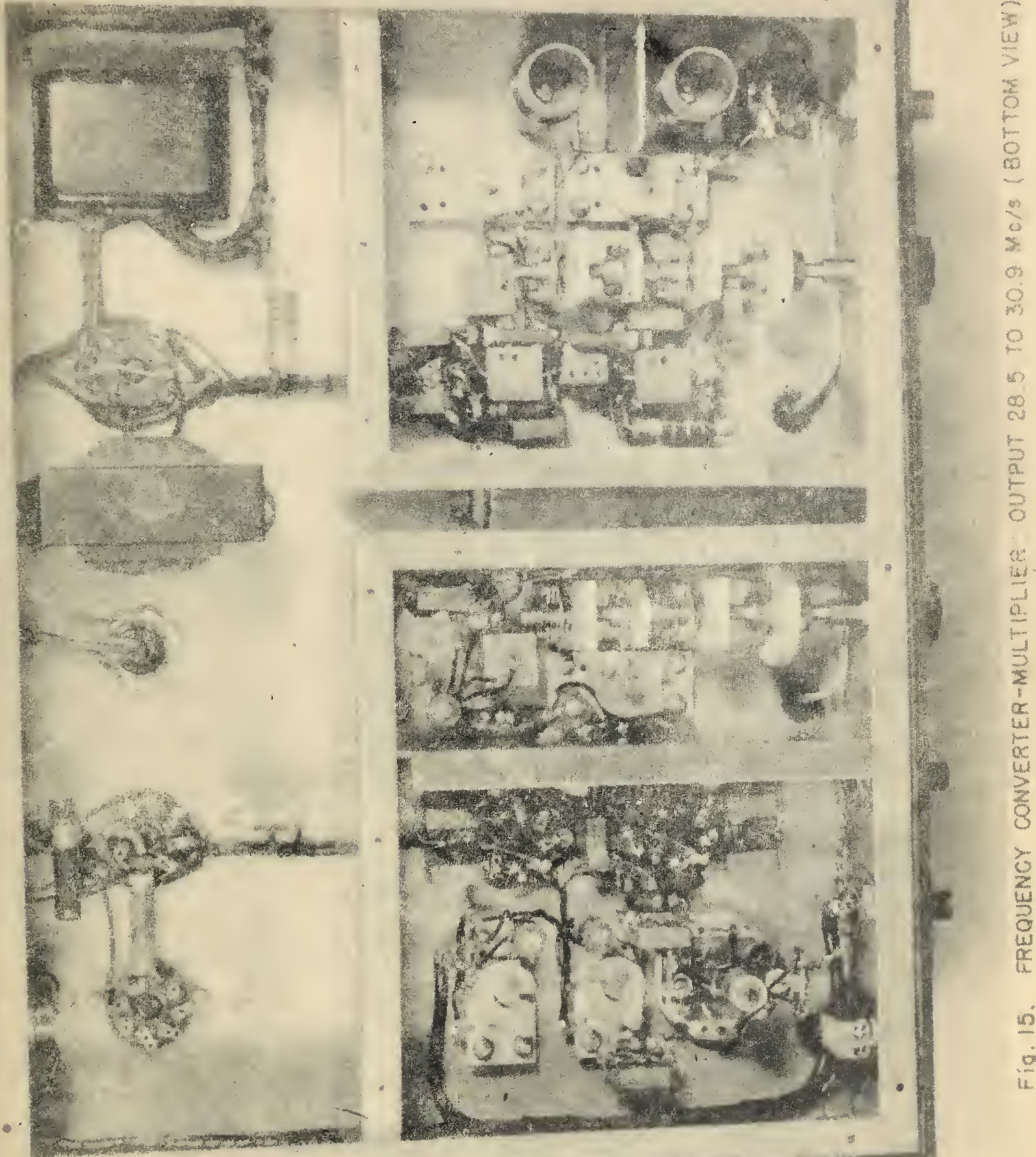

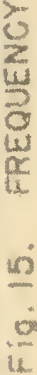





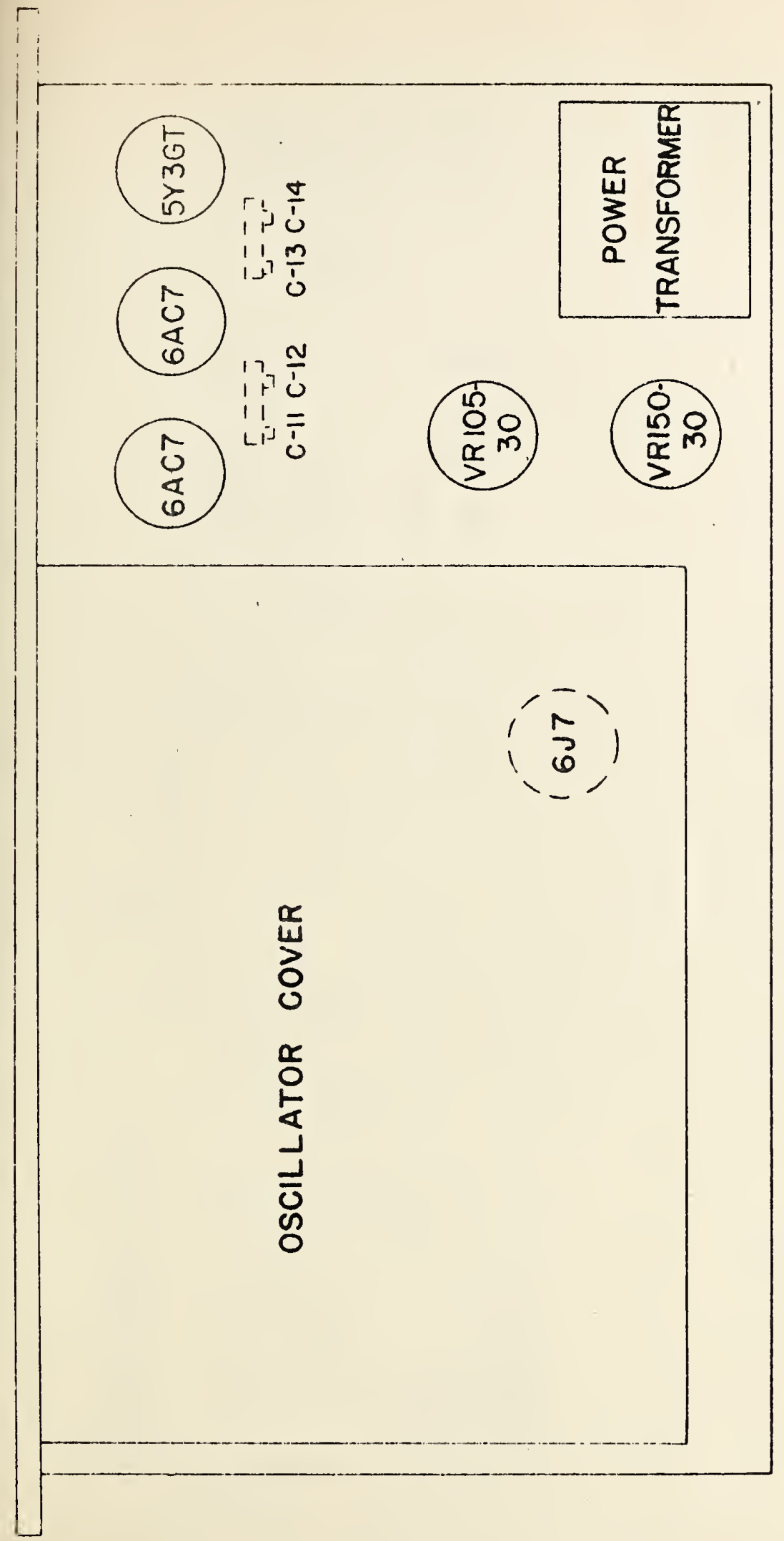

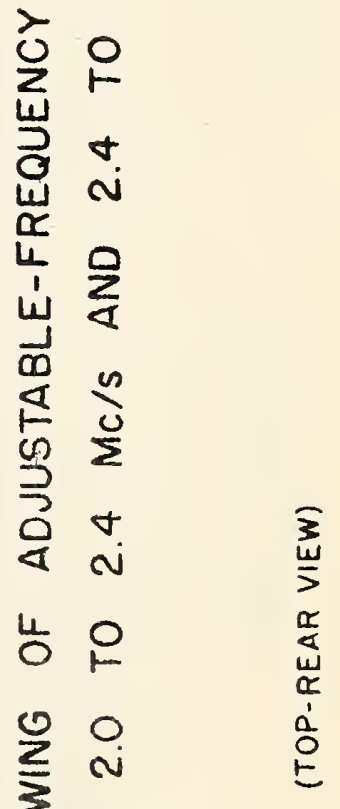

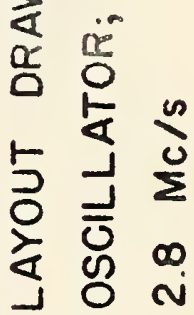

6

iิ 



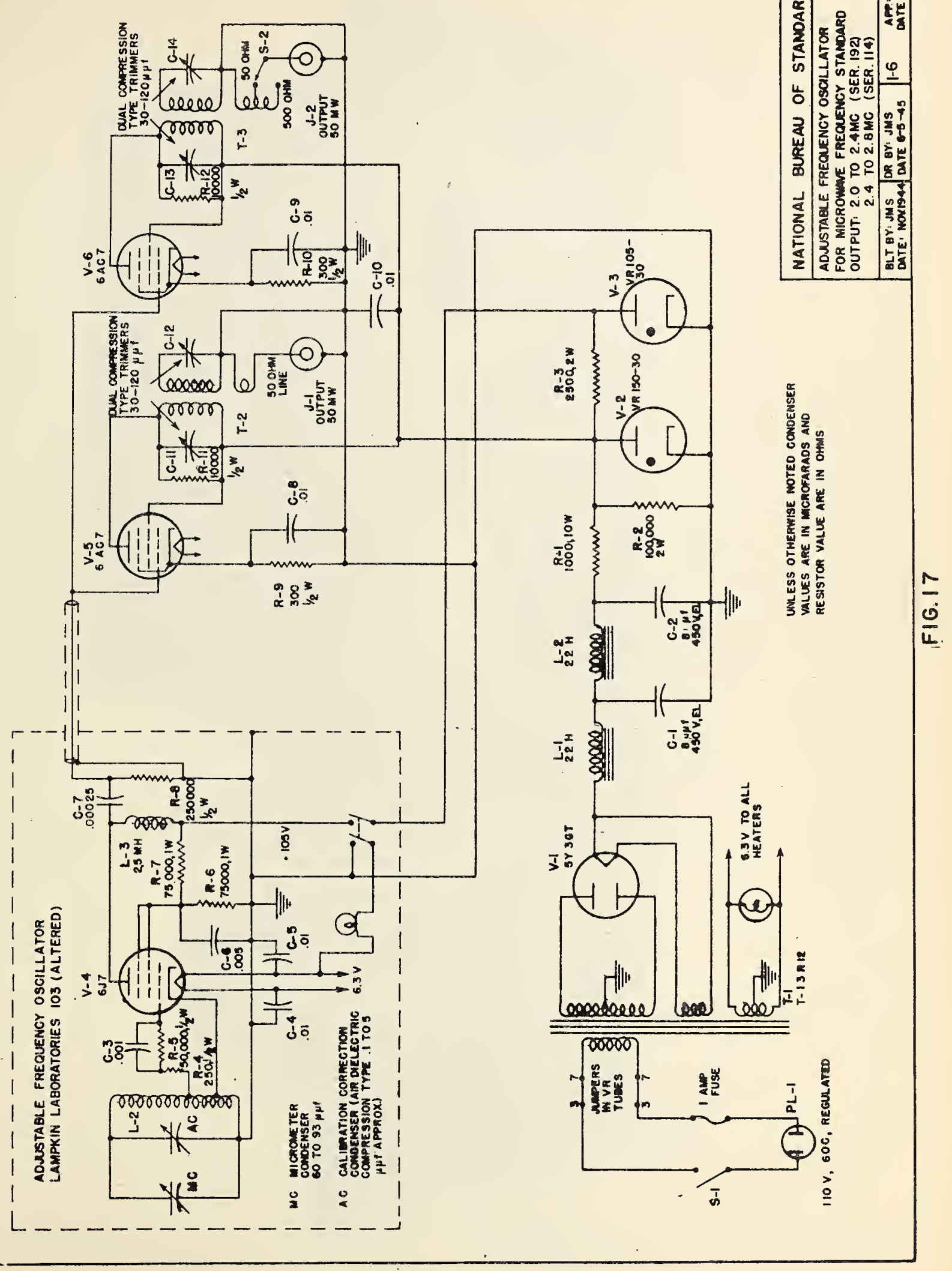





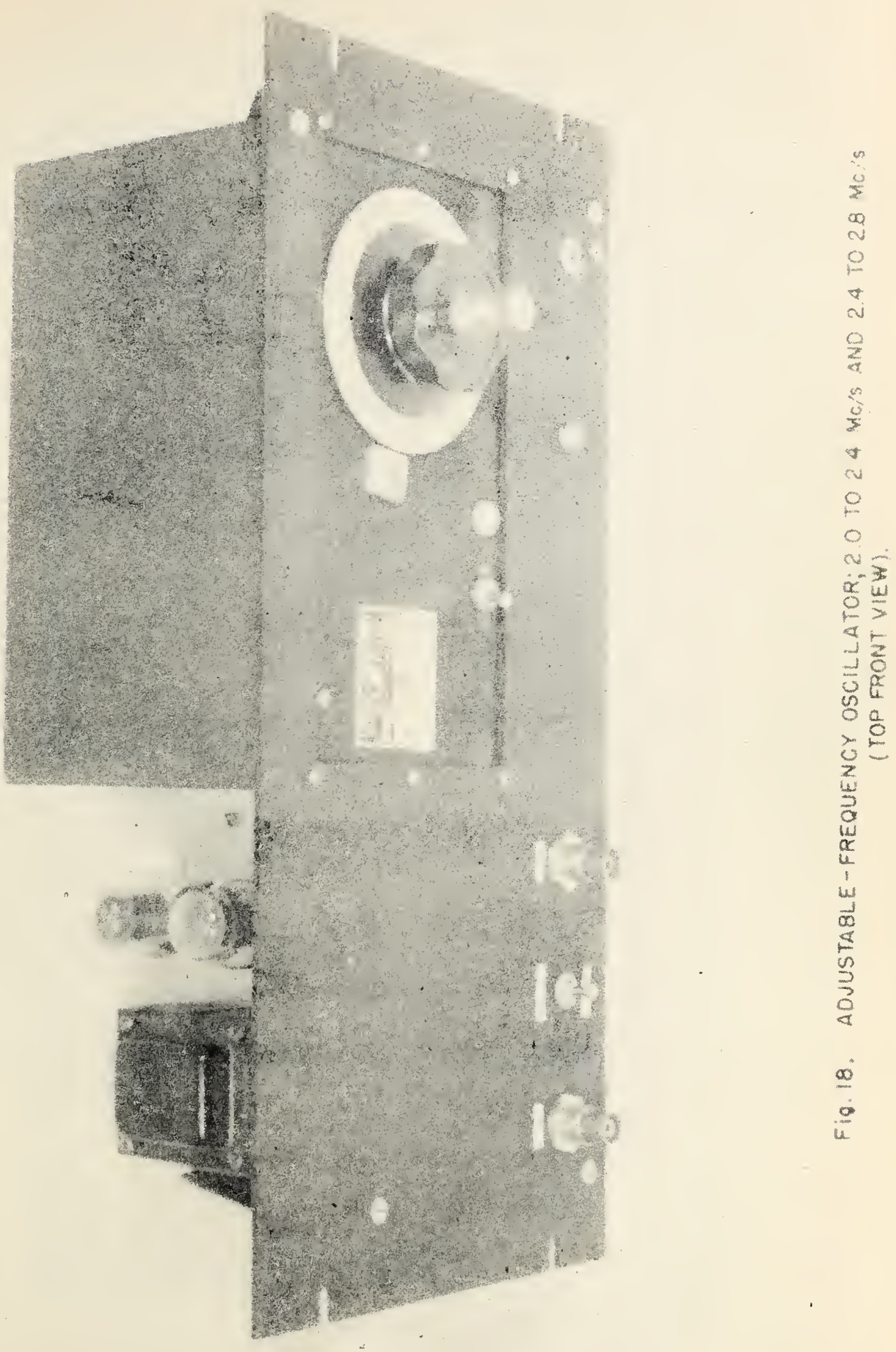





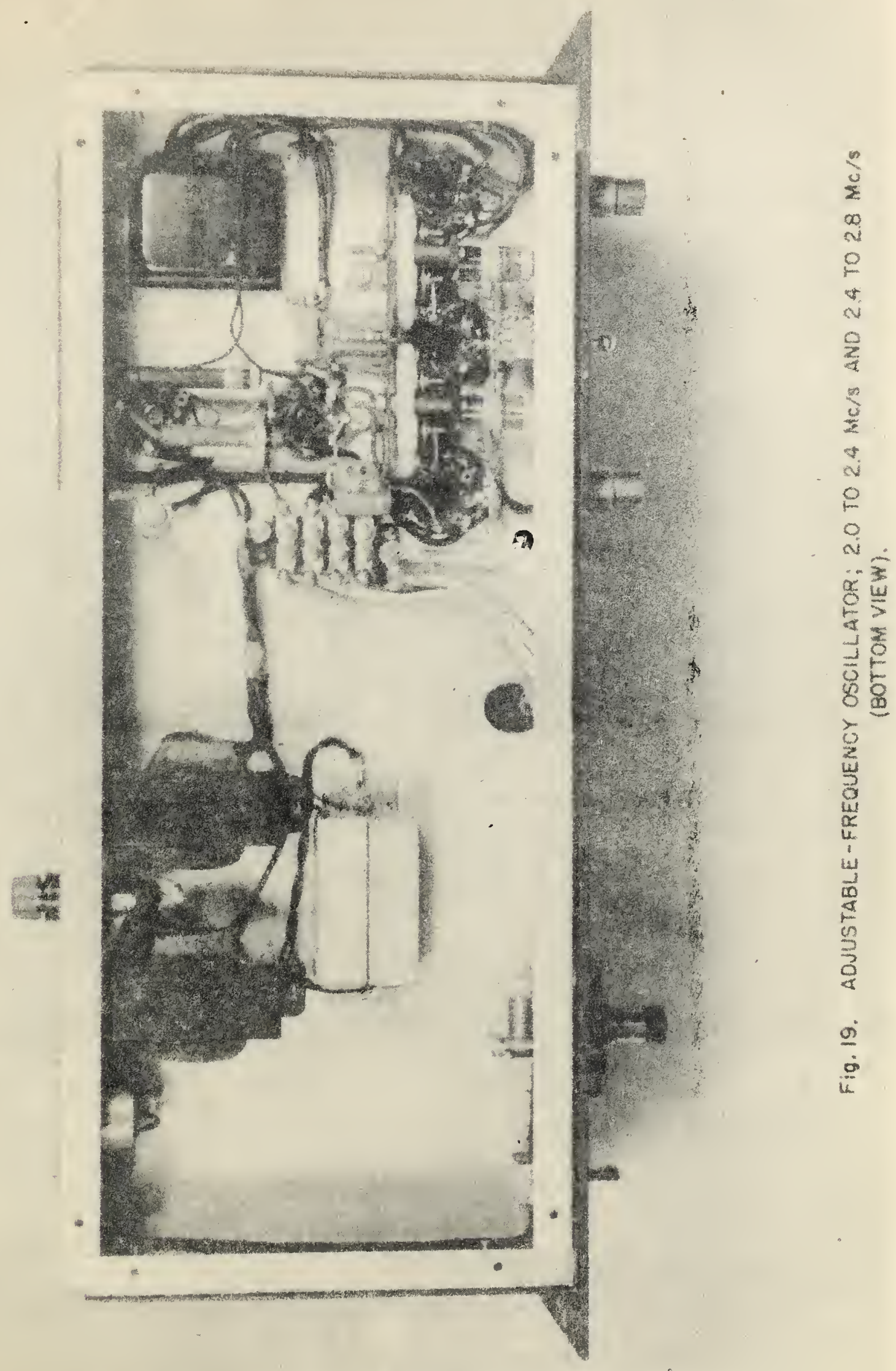





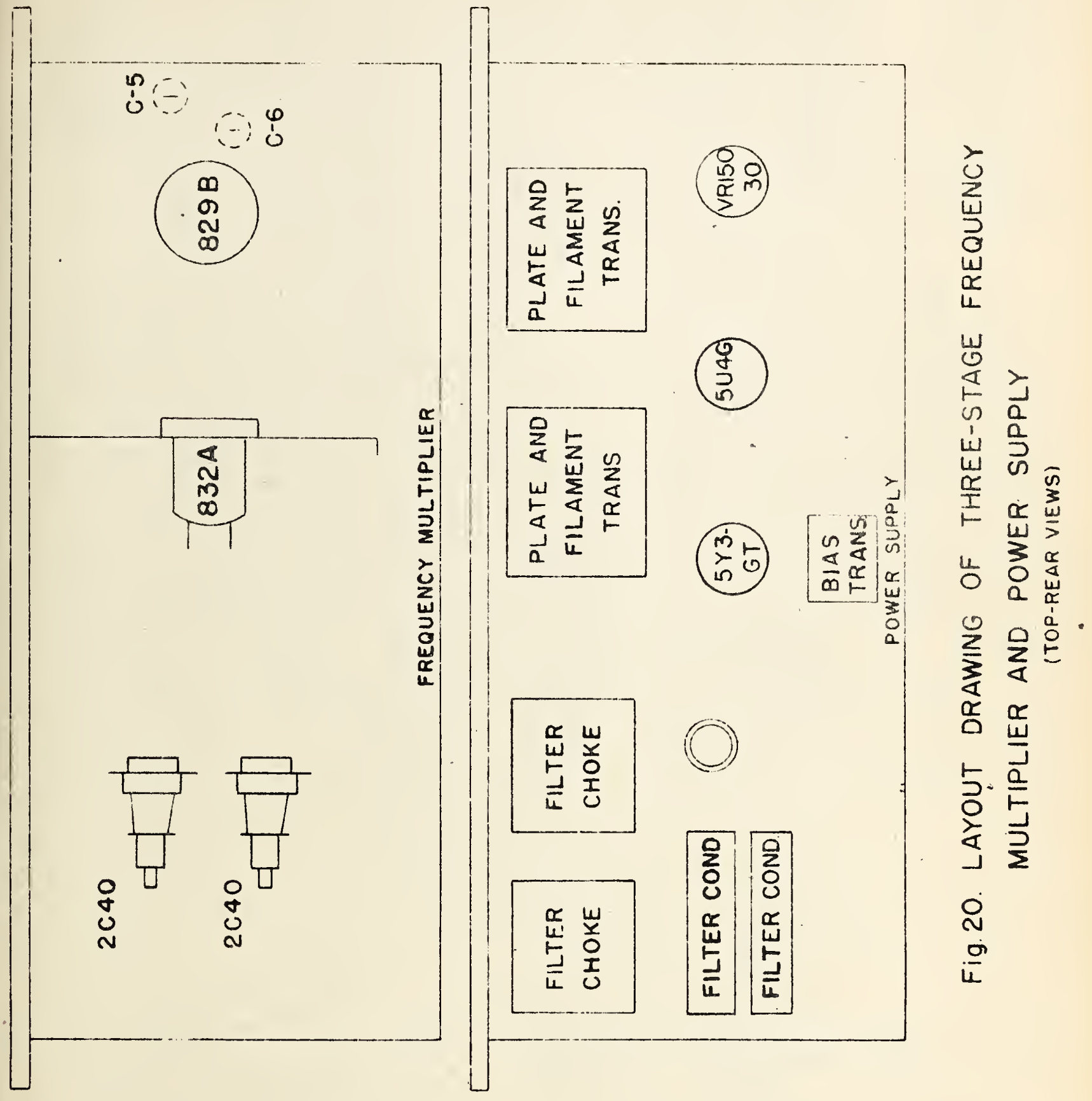




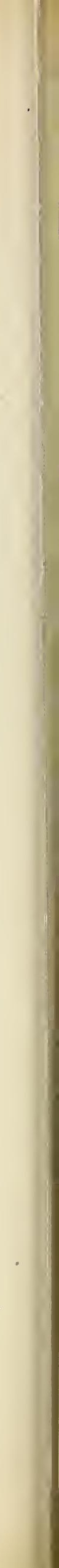




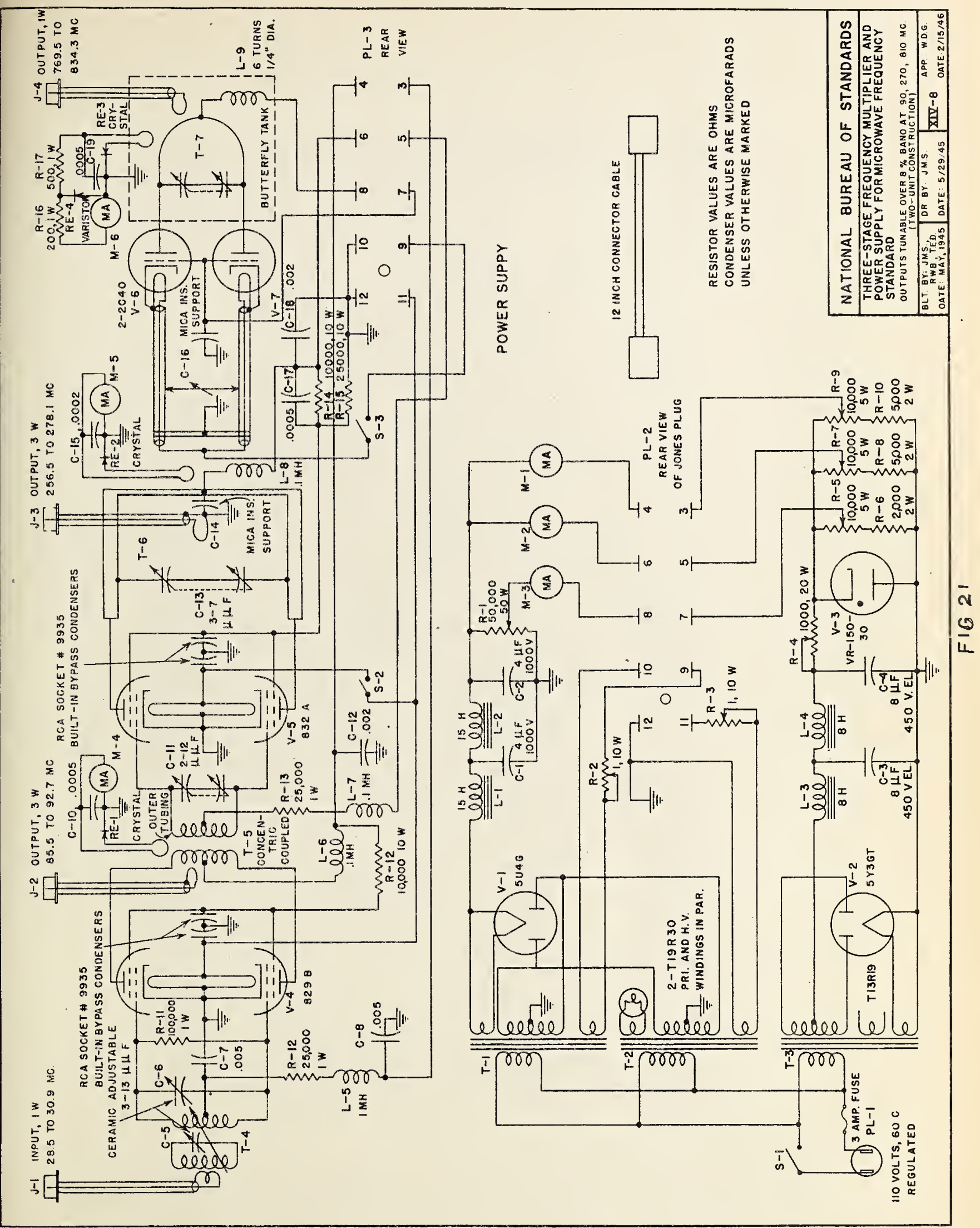





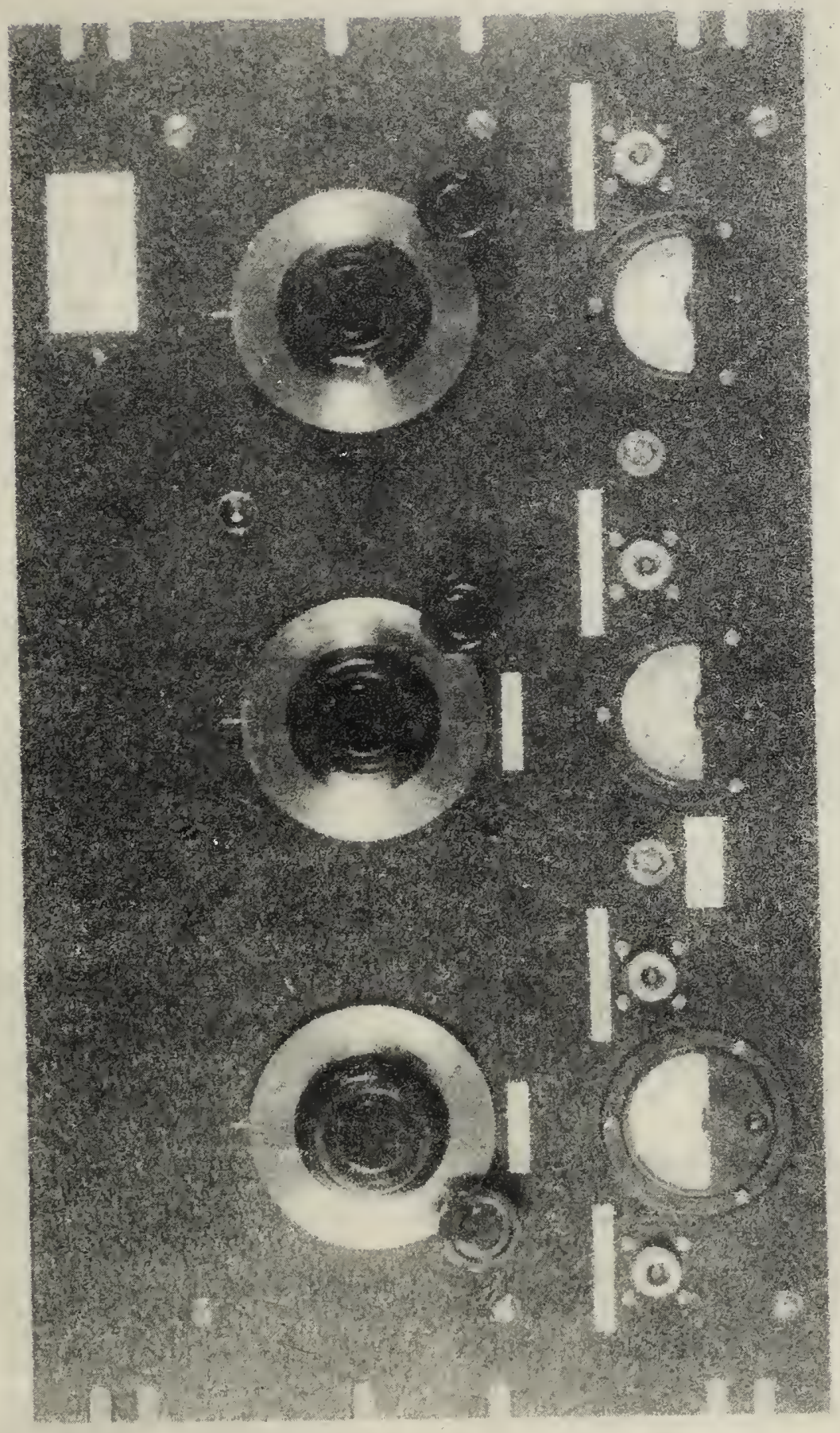

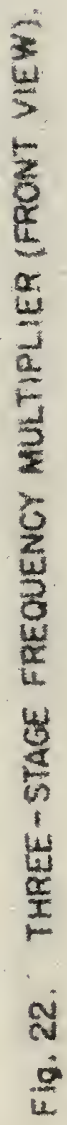




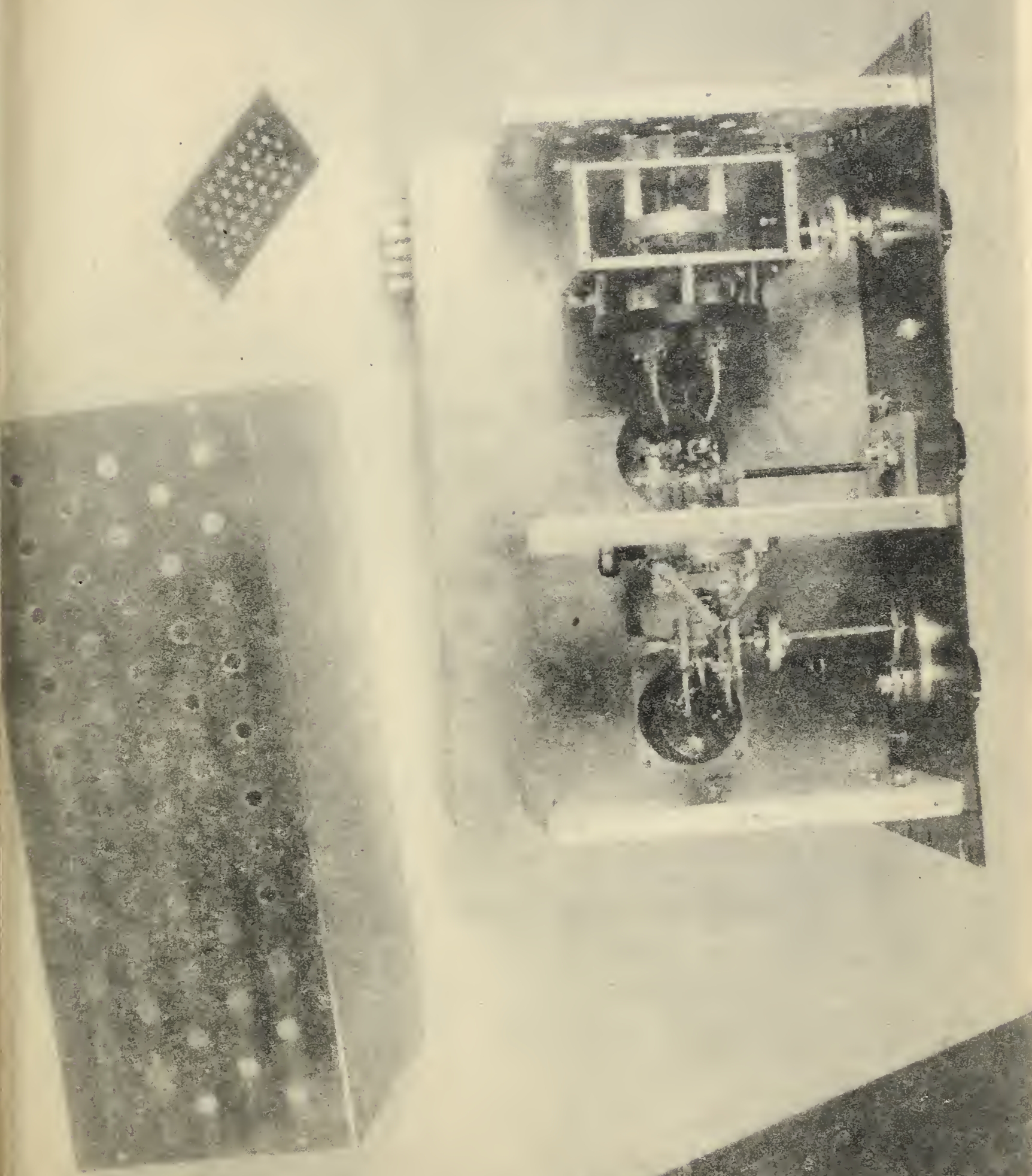

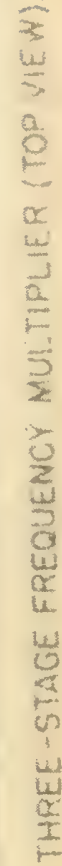

?

우 



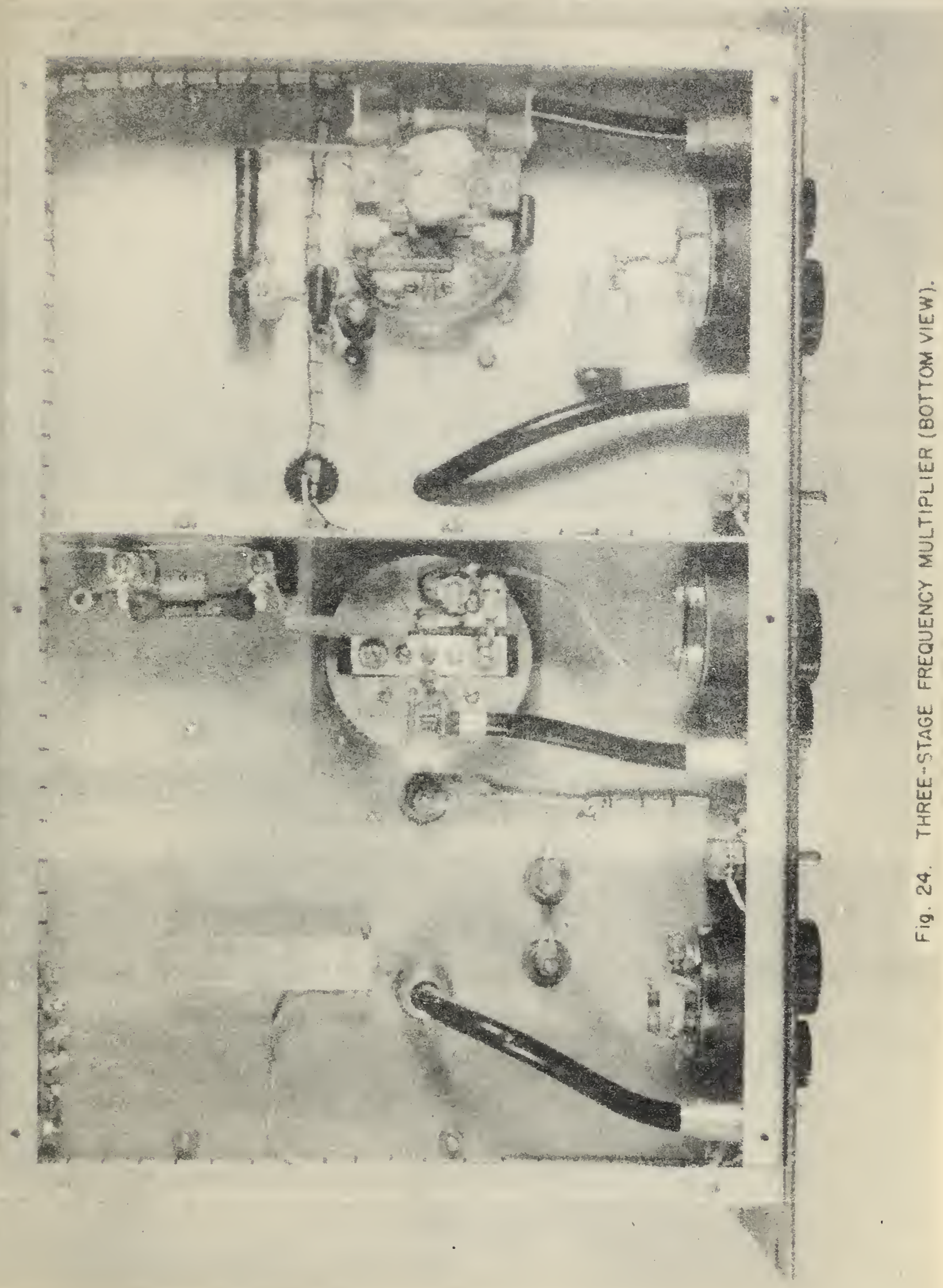





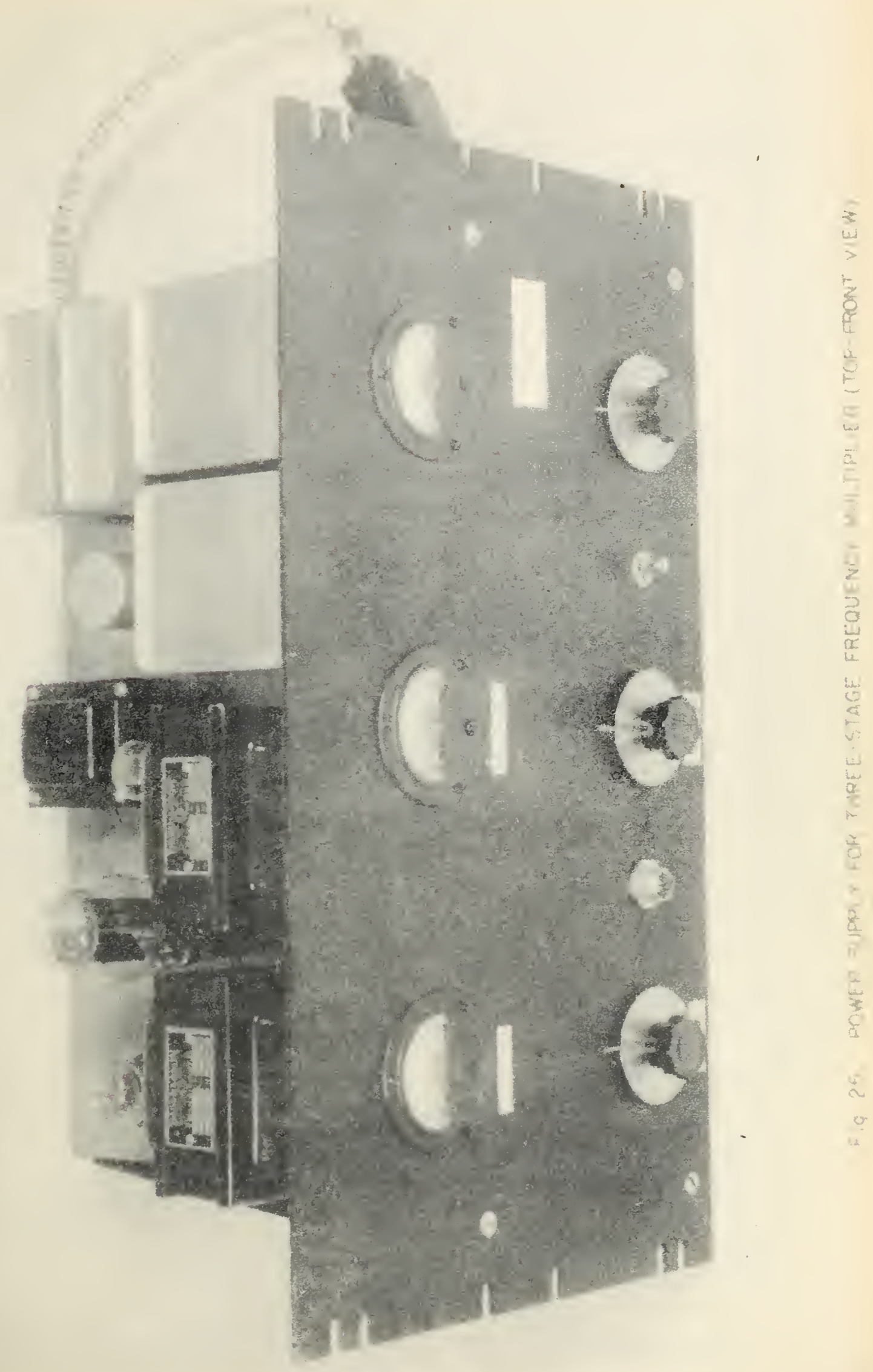





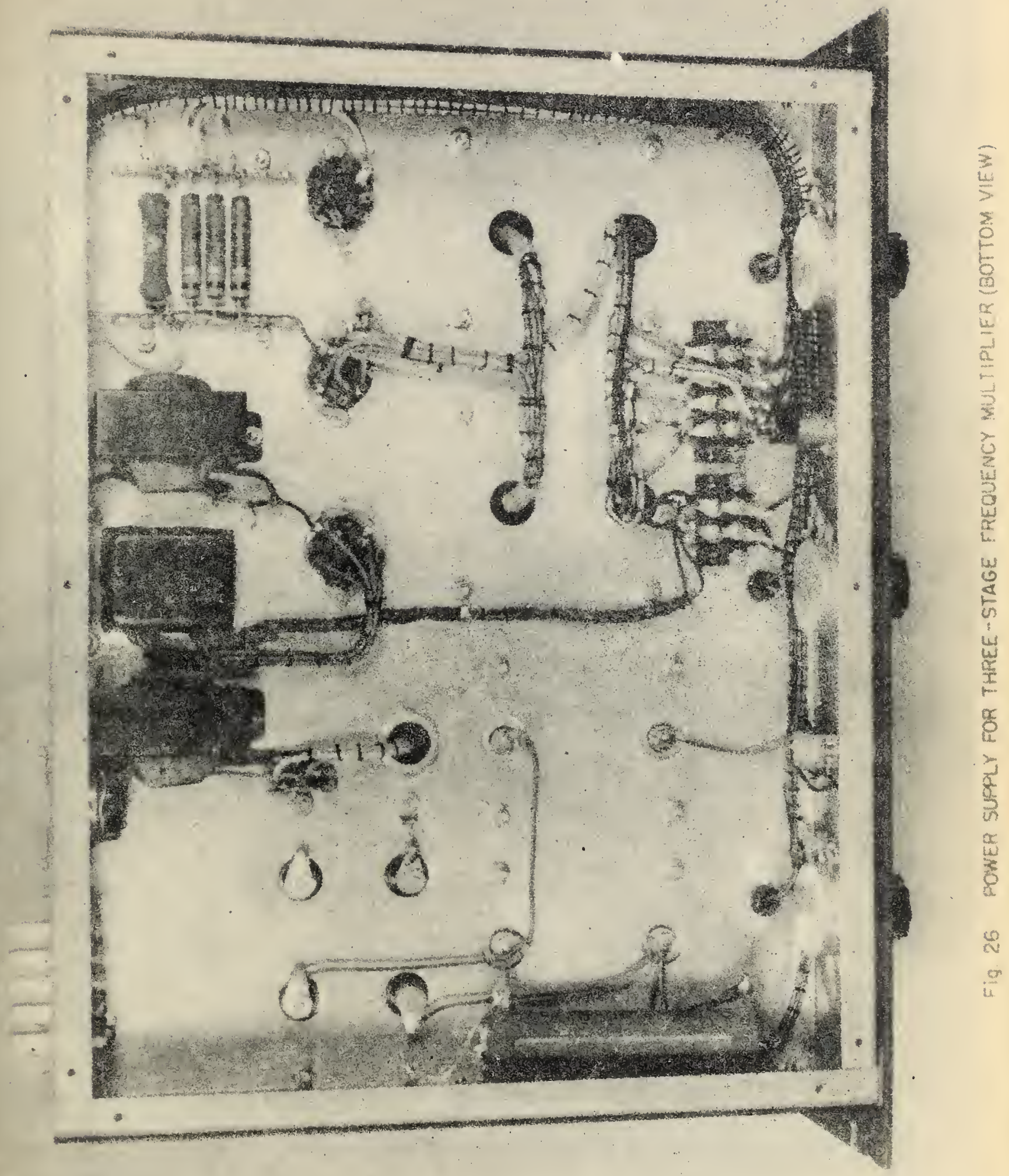





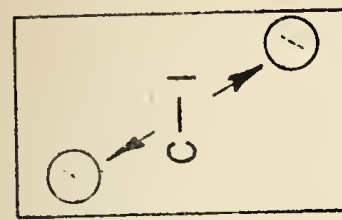

(95:앙

또요

모요

0
0
0
0

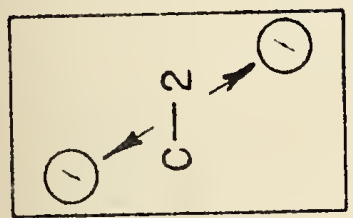

0
0
0
0

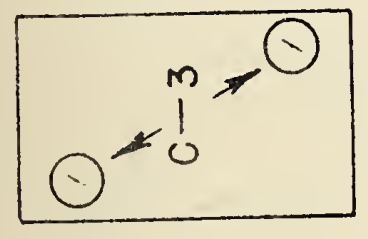

0
0
0
0
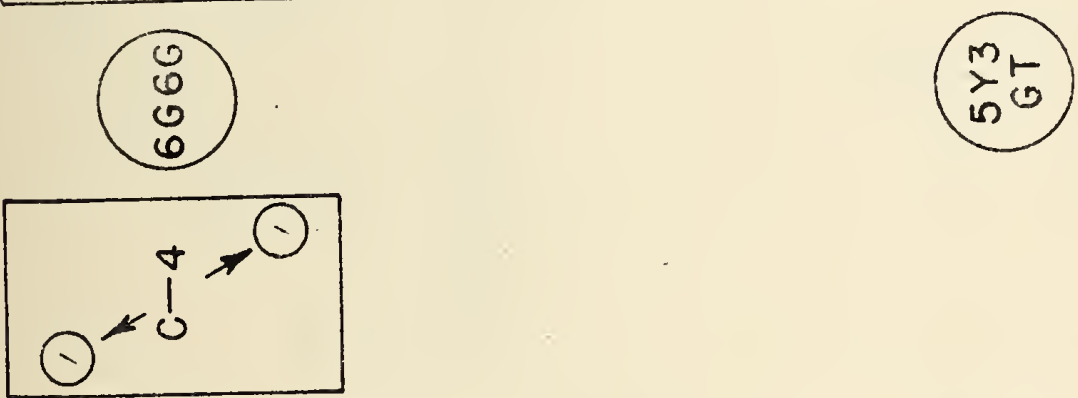

$\frac{2}{\frac{2}{5}}$

$\frac{1}{0}$

O

L $\frac{\alpha}{6}$

0

$\geq$

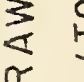

a i

○

10

2

\lrcorner$\ddot{\alpha}$

W

$N \leq$

$\frac{0}{u} \sum_{L}^{n}$ 

5
5
5
5
5
0
0

$\overbrace{i}^{+1} 2\}$
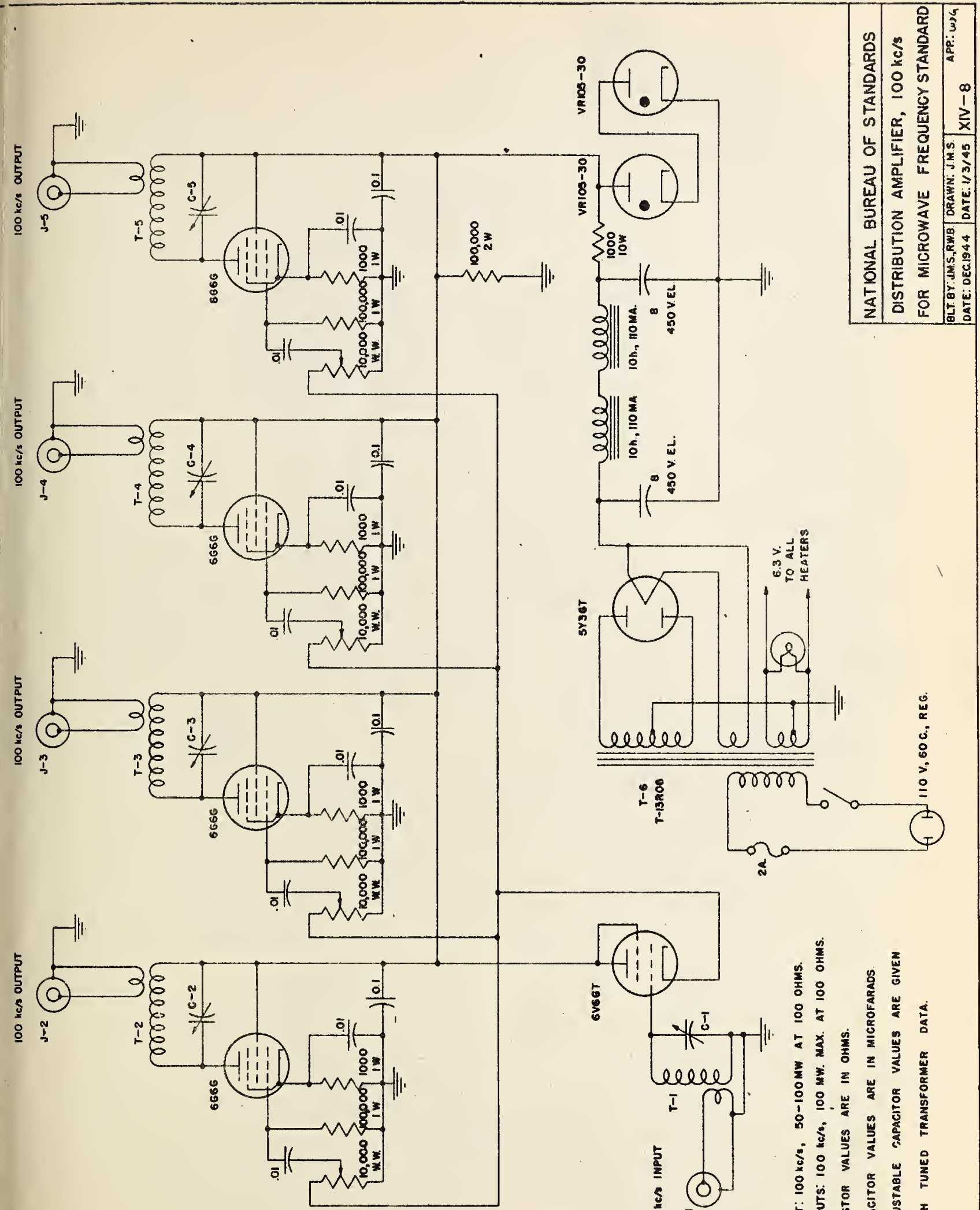

車i
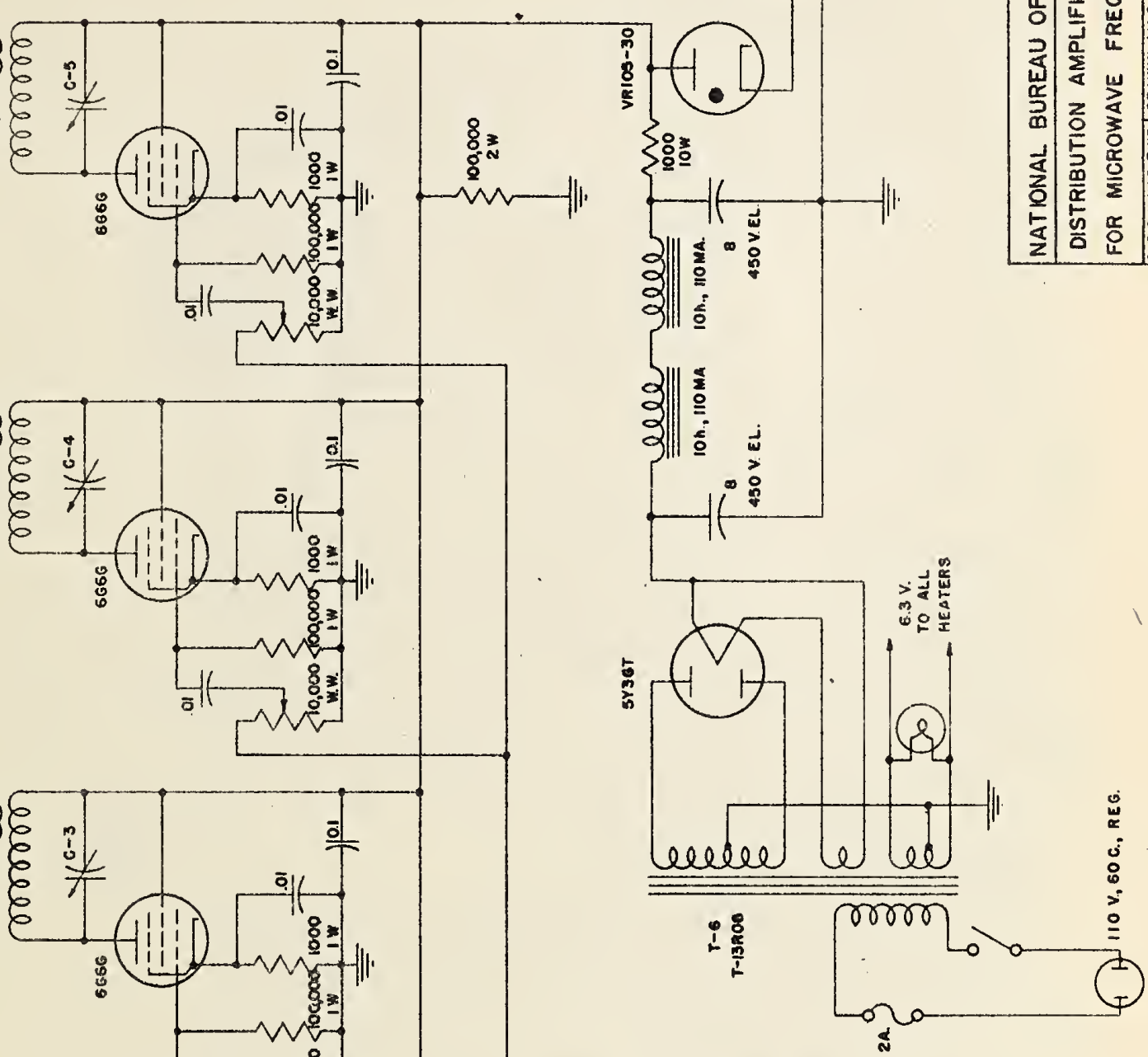

$\infty$
$N$
0
$u$ 



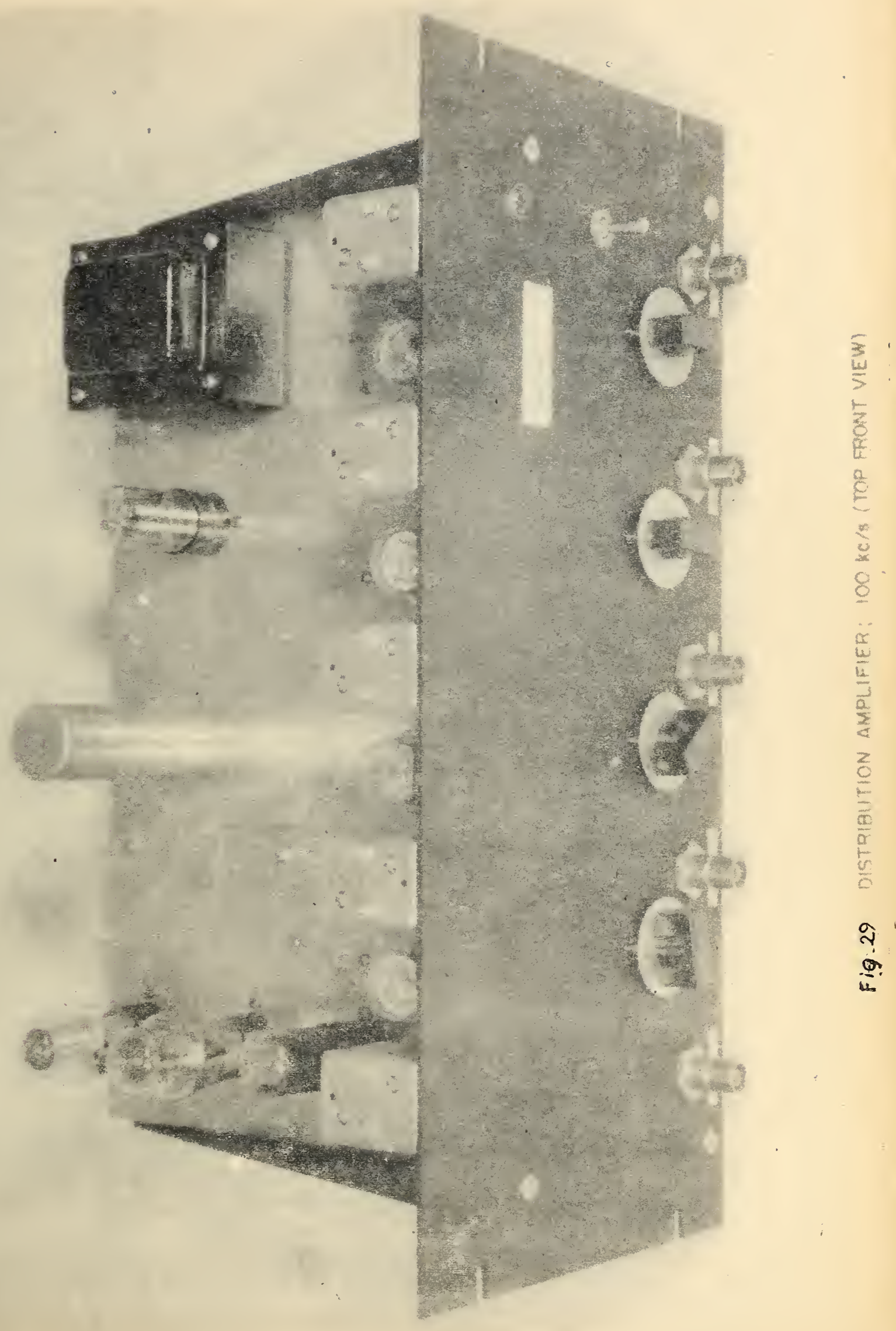





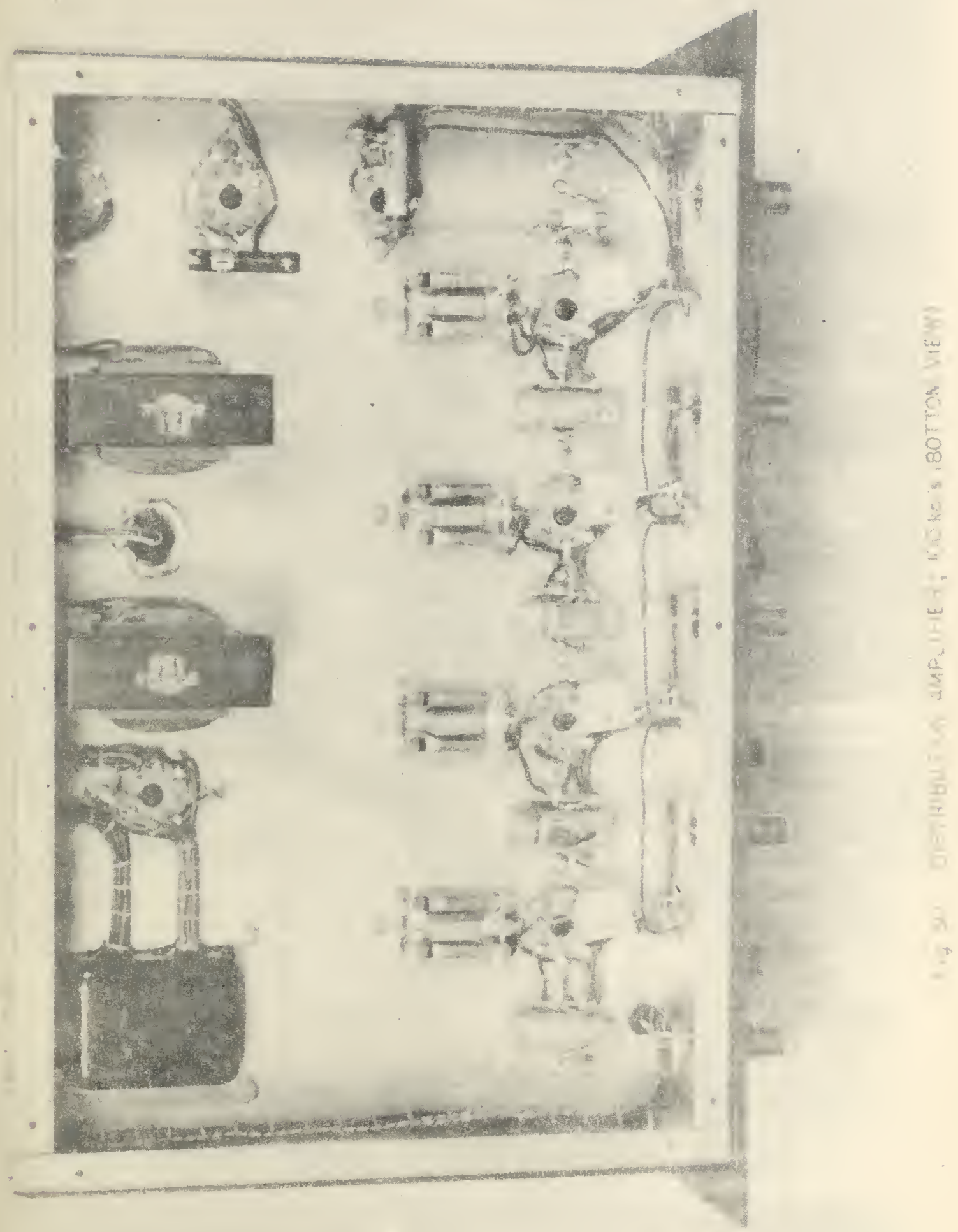




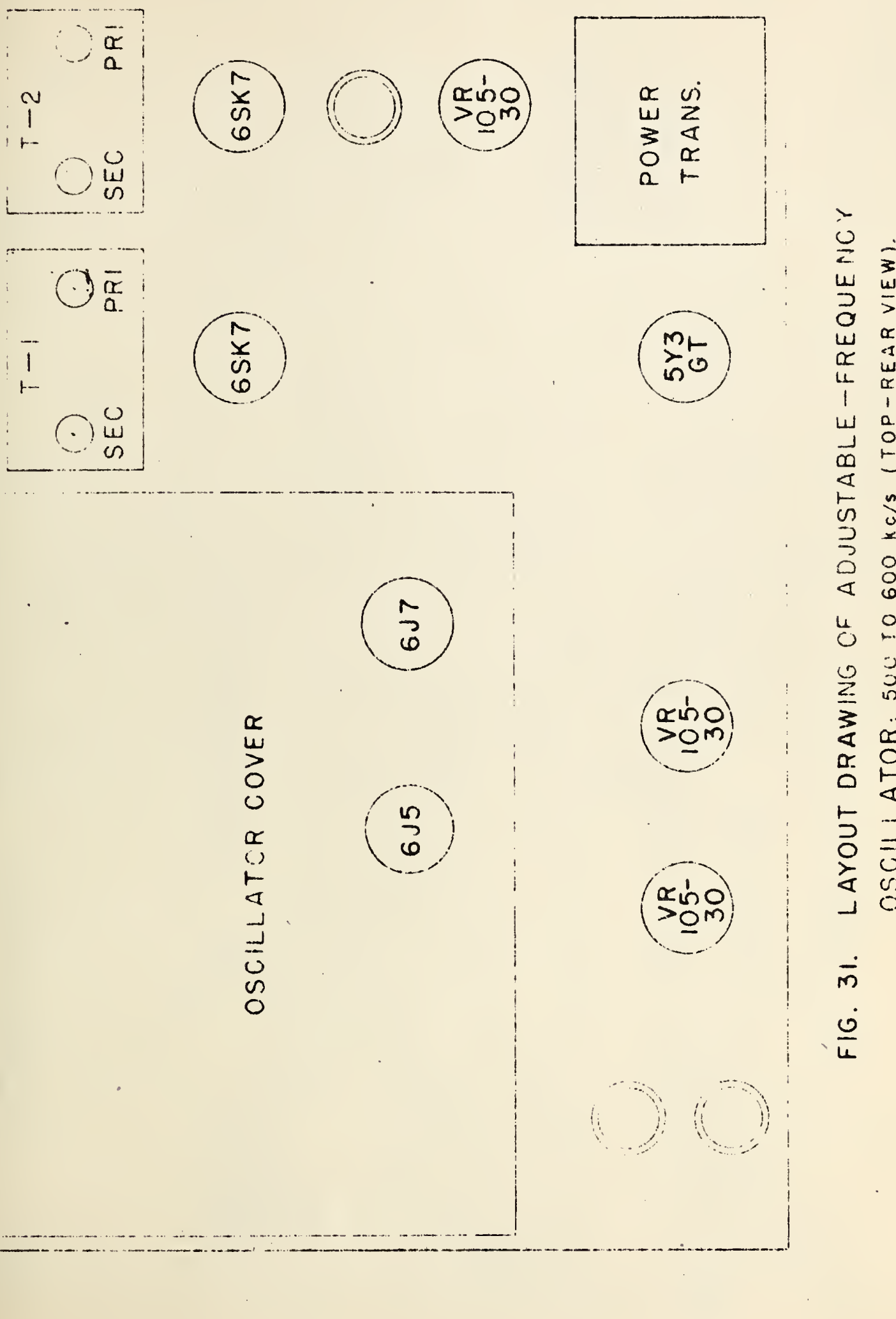

40

$\begin{array}{ll}0 & 3 \\ 2 & 0 \\ 3 & 0 \\ \vdots & 0 \\ 0 & 0 \\ 0 & 4\end{array}$

$\begin{array}{ll}5 & 1 \\ 2 & = \\ 0 & 0 \\ \frac{1}{4} & 0 \\ 1 & 0\end{array}$

$\dot{m}$

$\frac{0}{4}$ 



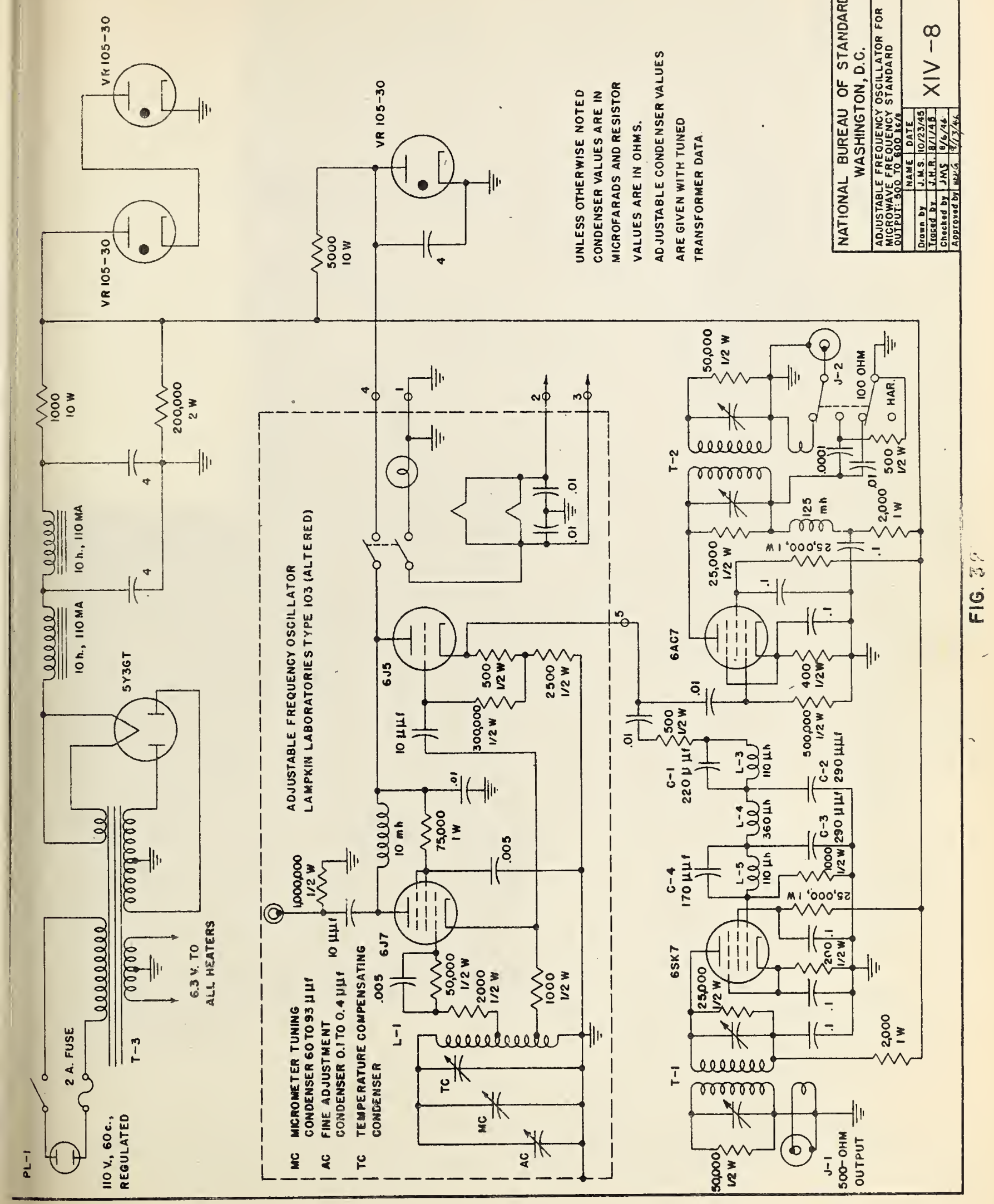


FIG. 33 mISSING 


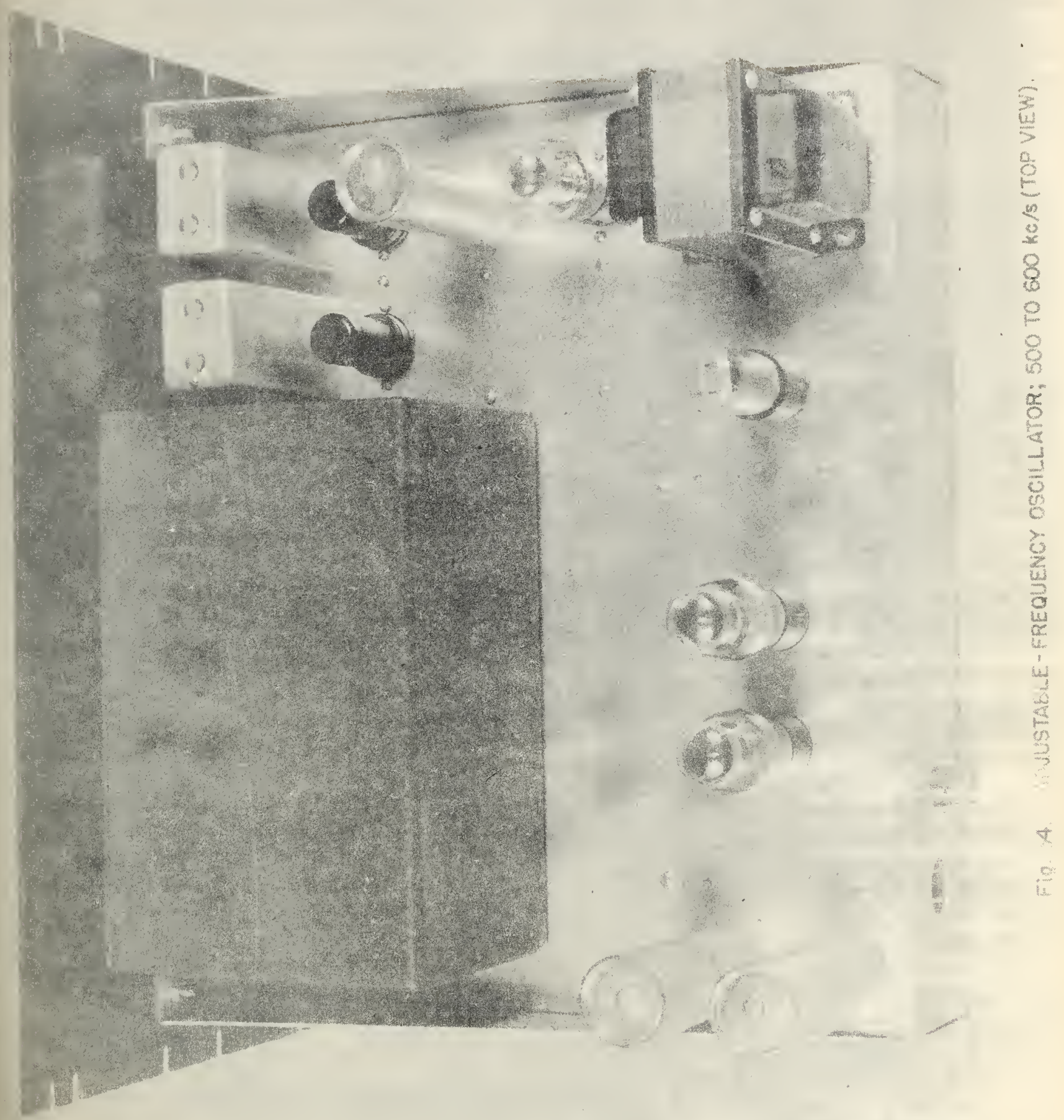





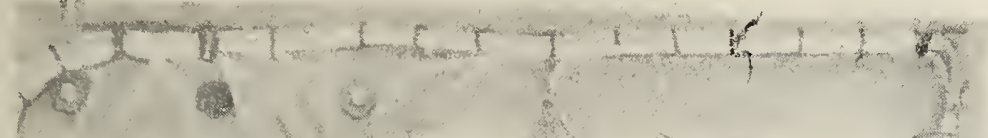

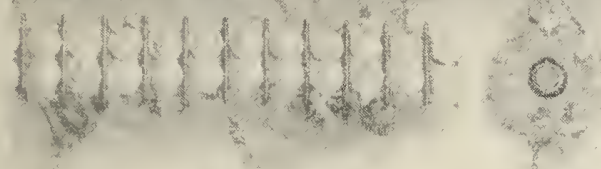

1 4 -

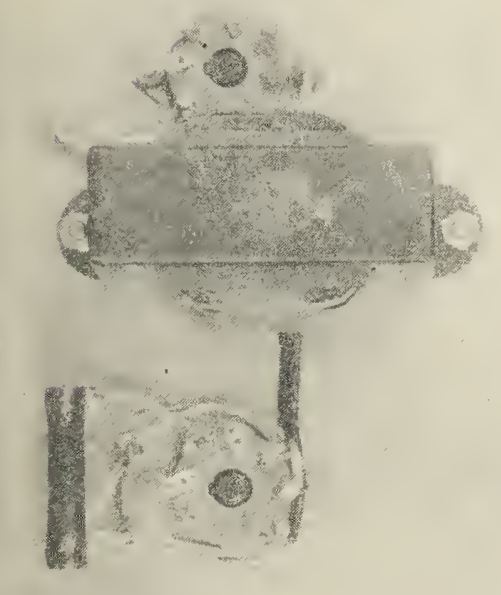

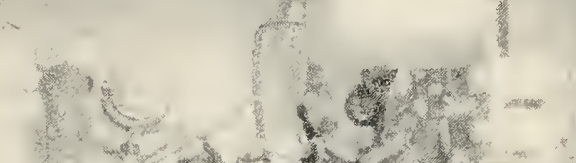

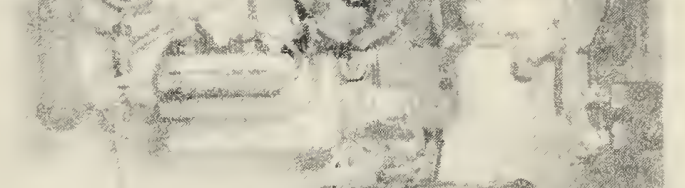

the

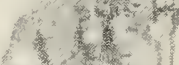
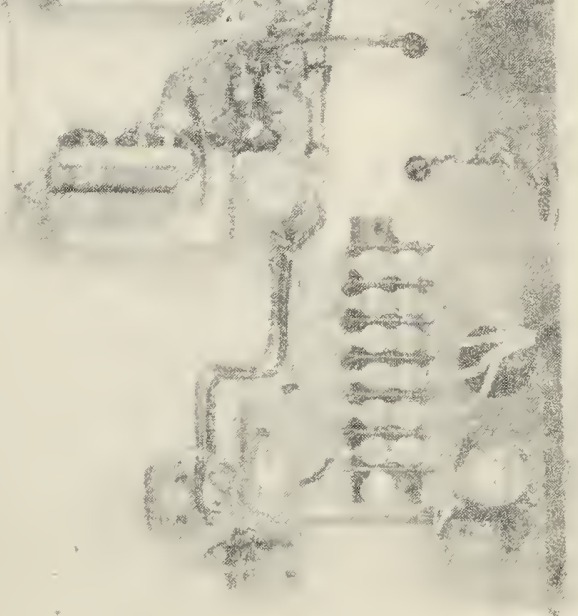

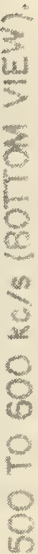

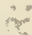

$\frac{8}{4}$

(it)
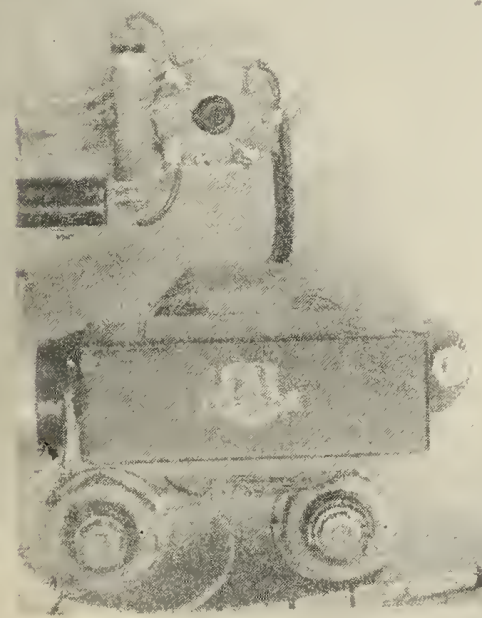


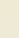




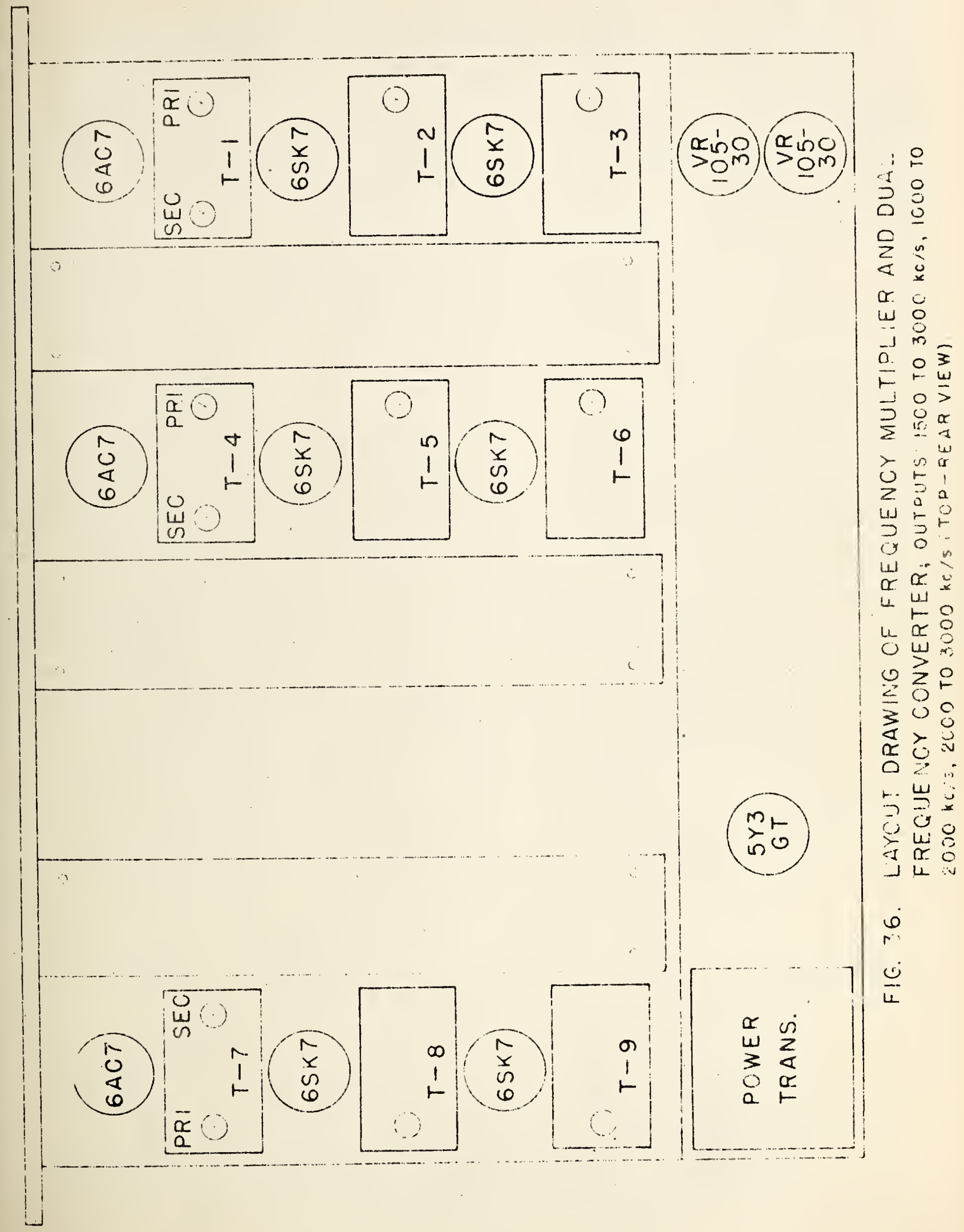



(4) 告- $11.8=5$ 萡

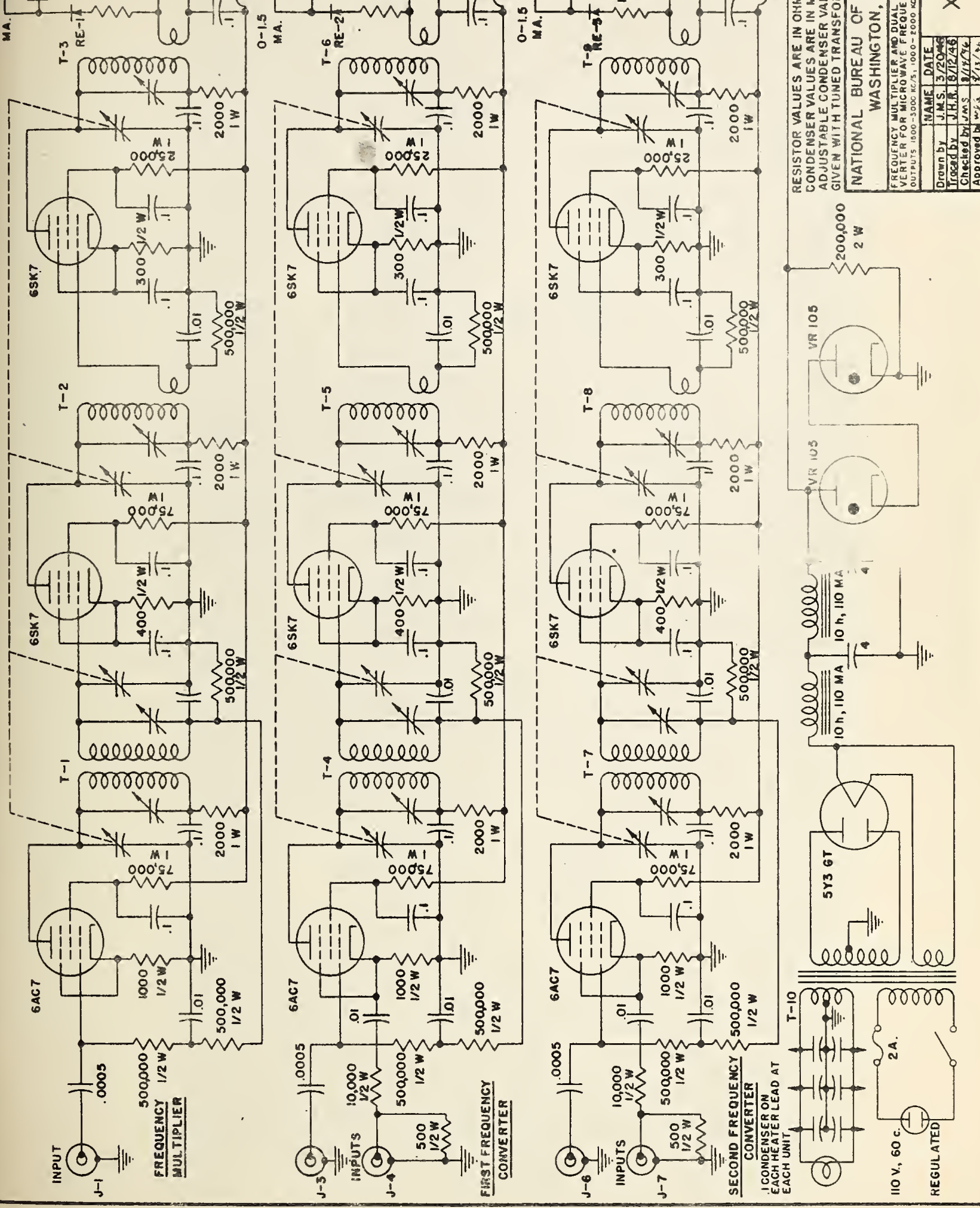




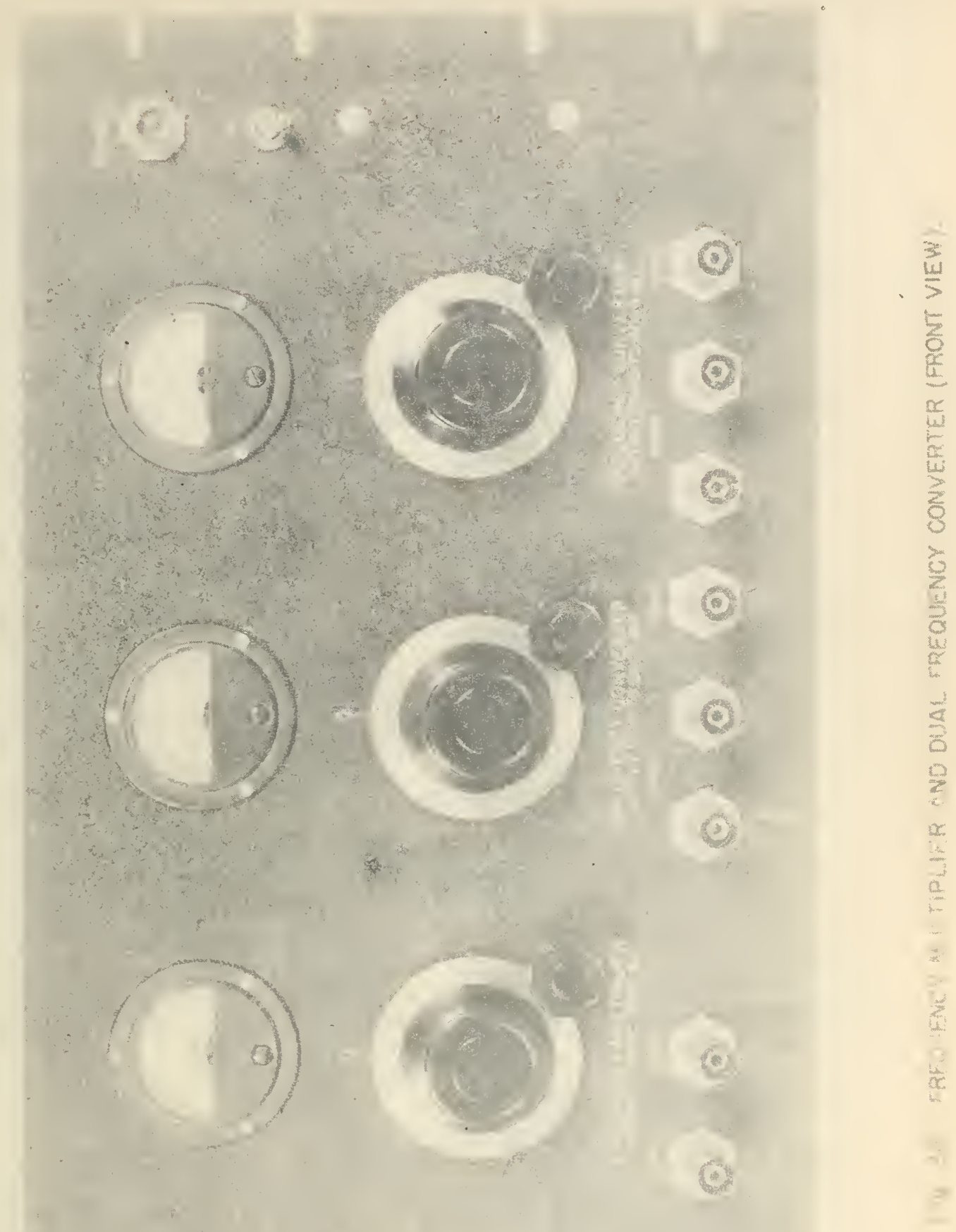



v.

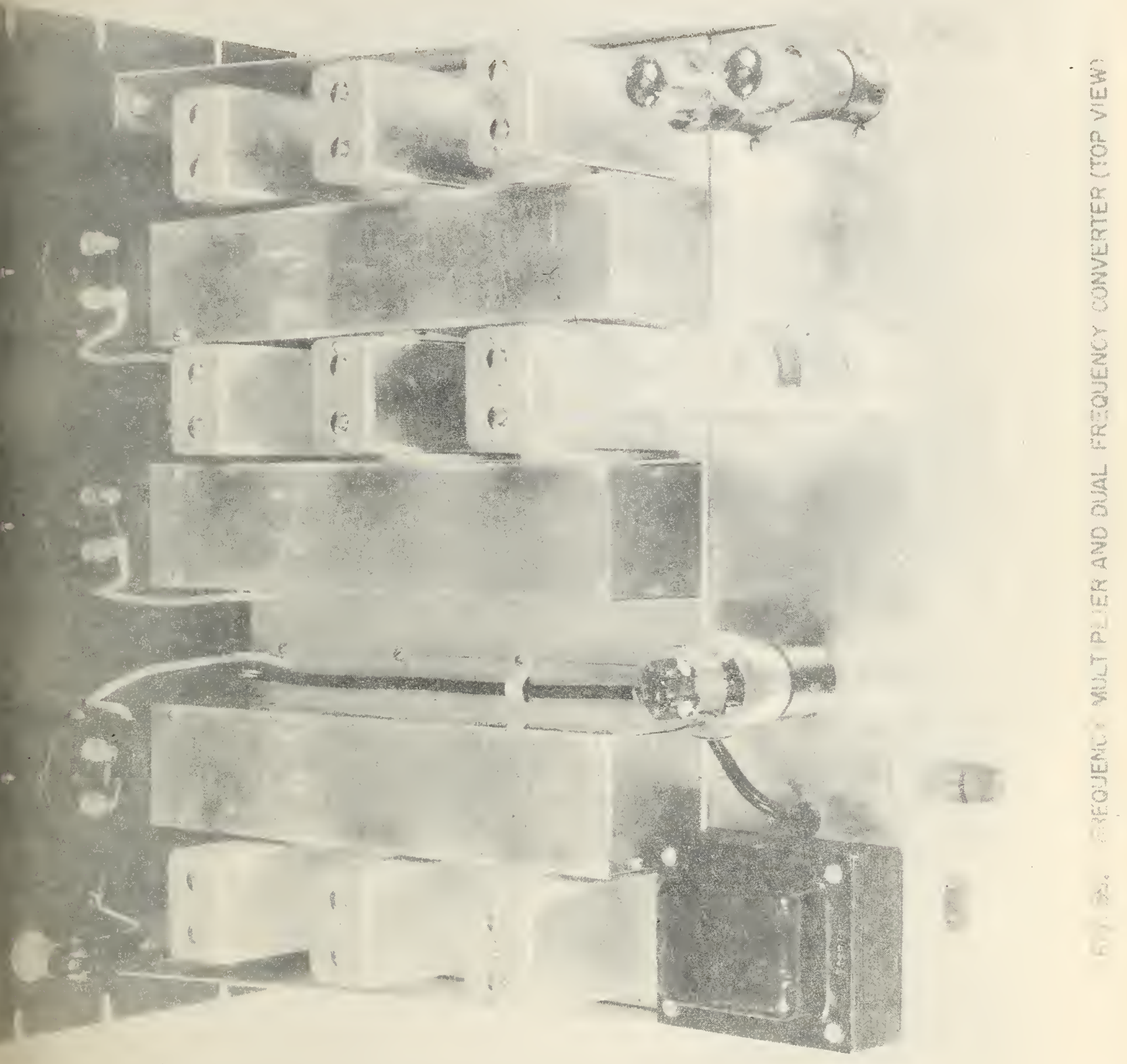





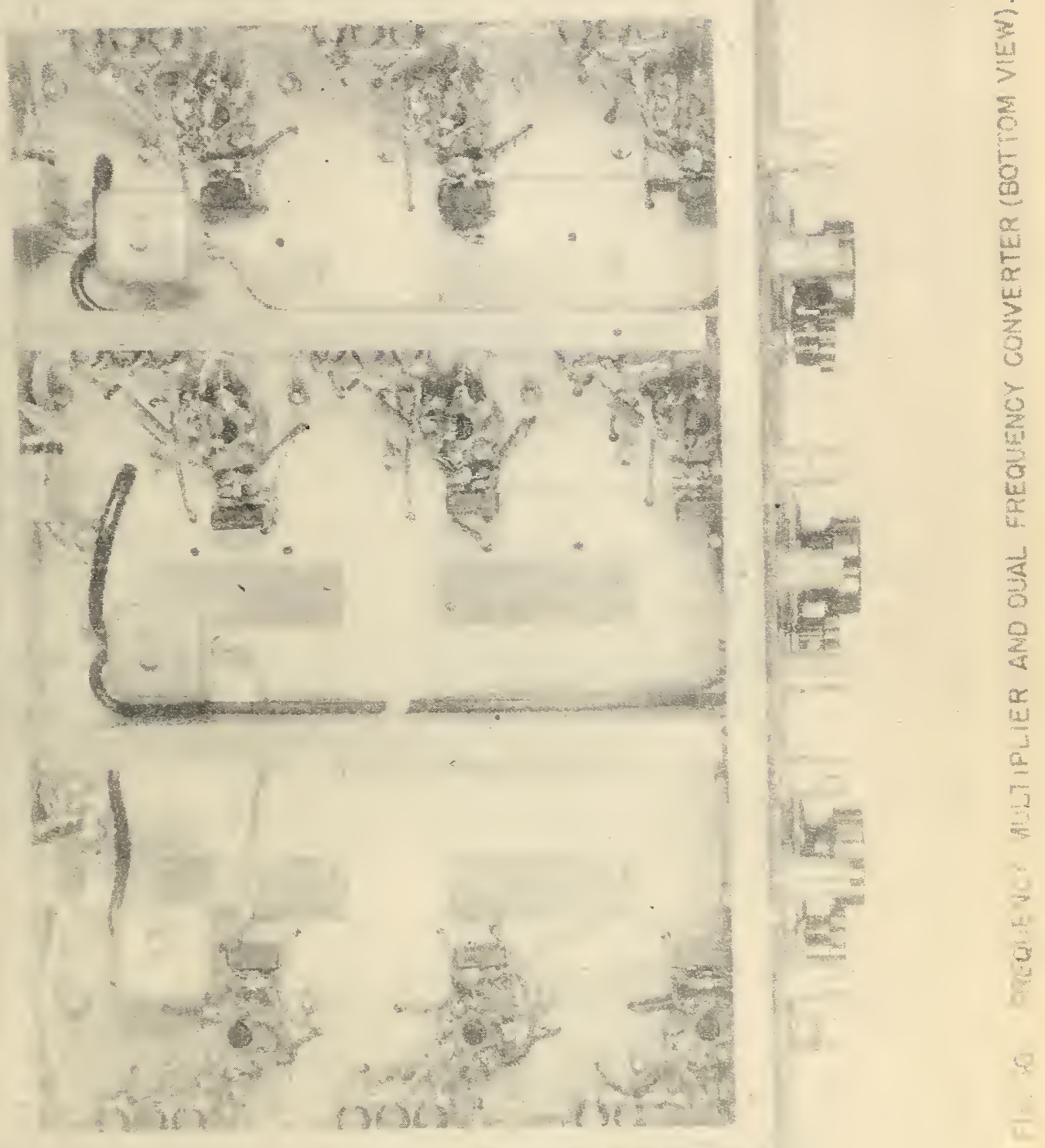




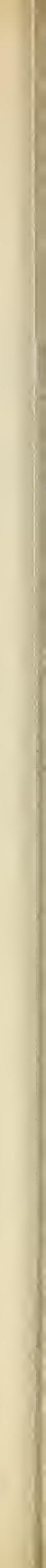




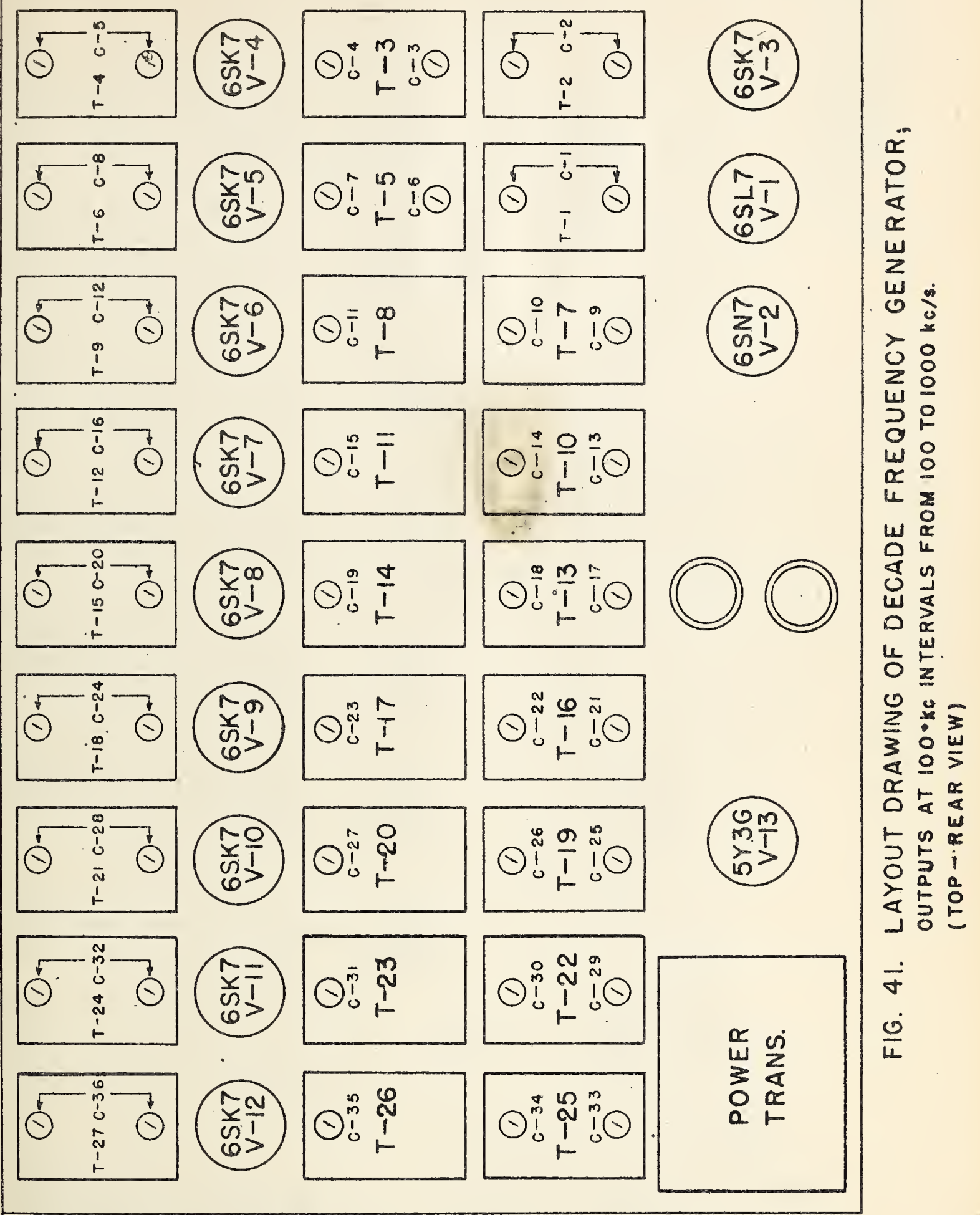





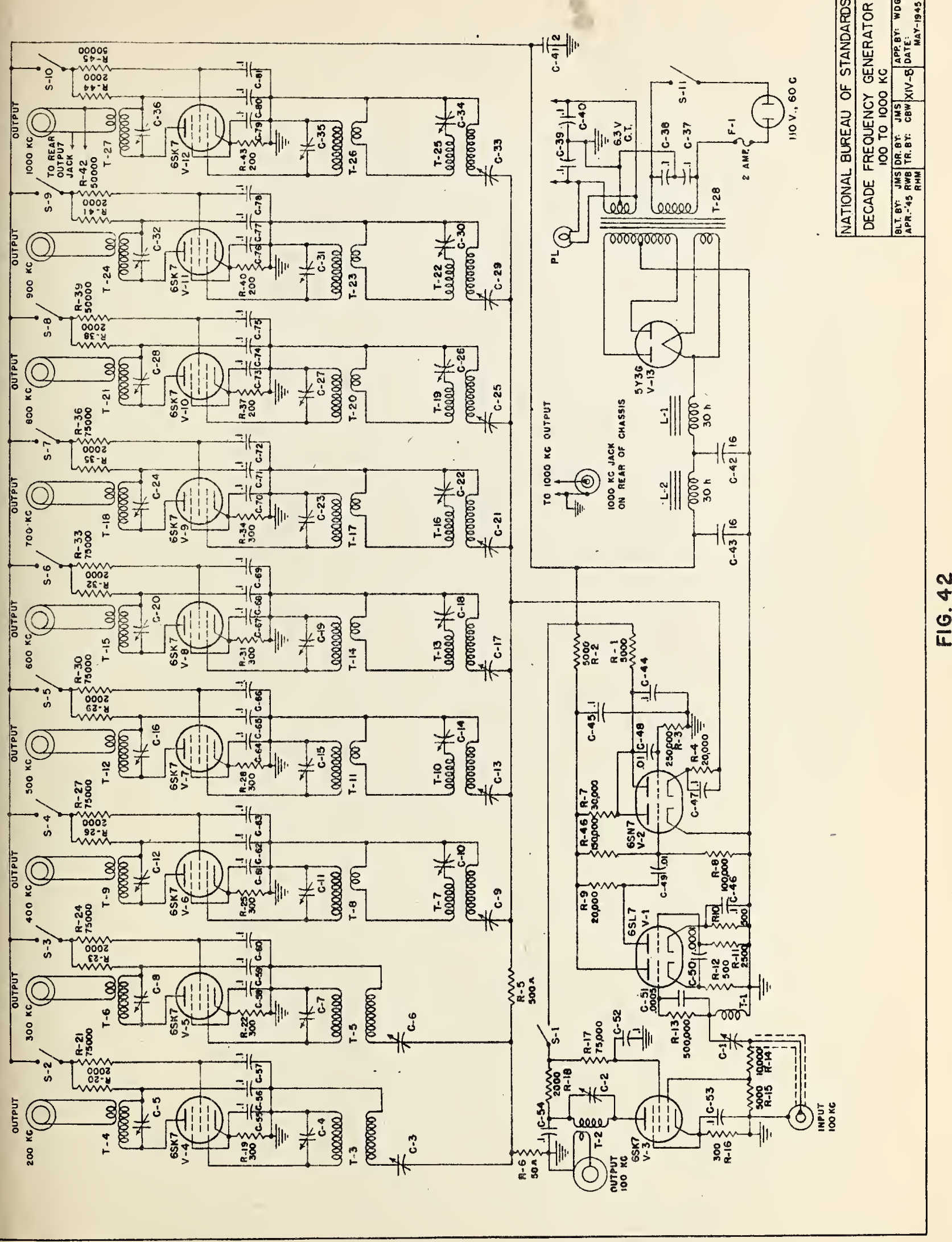





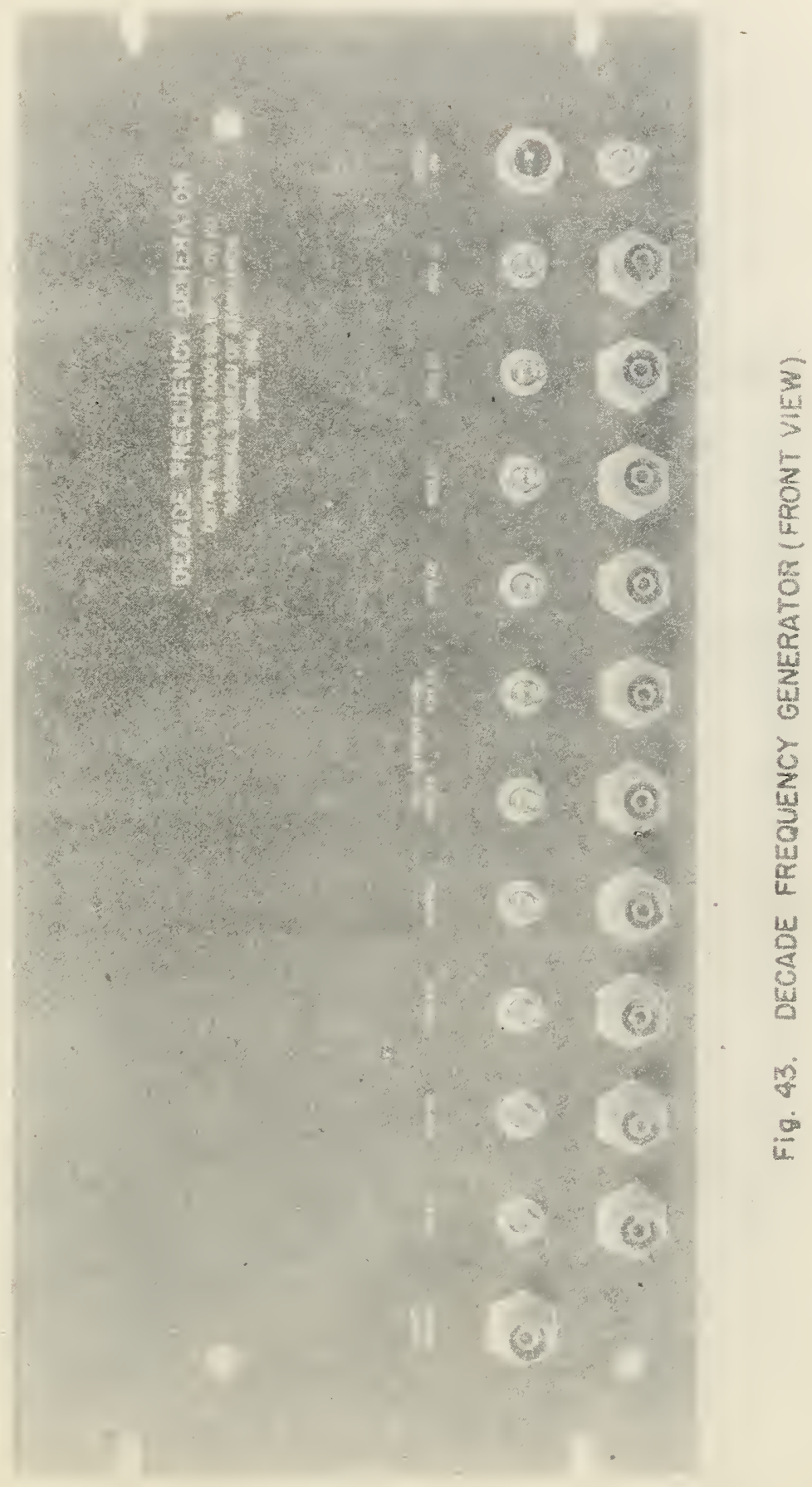





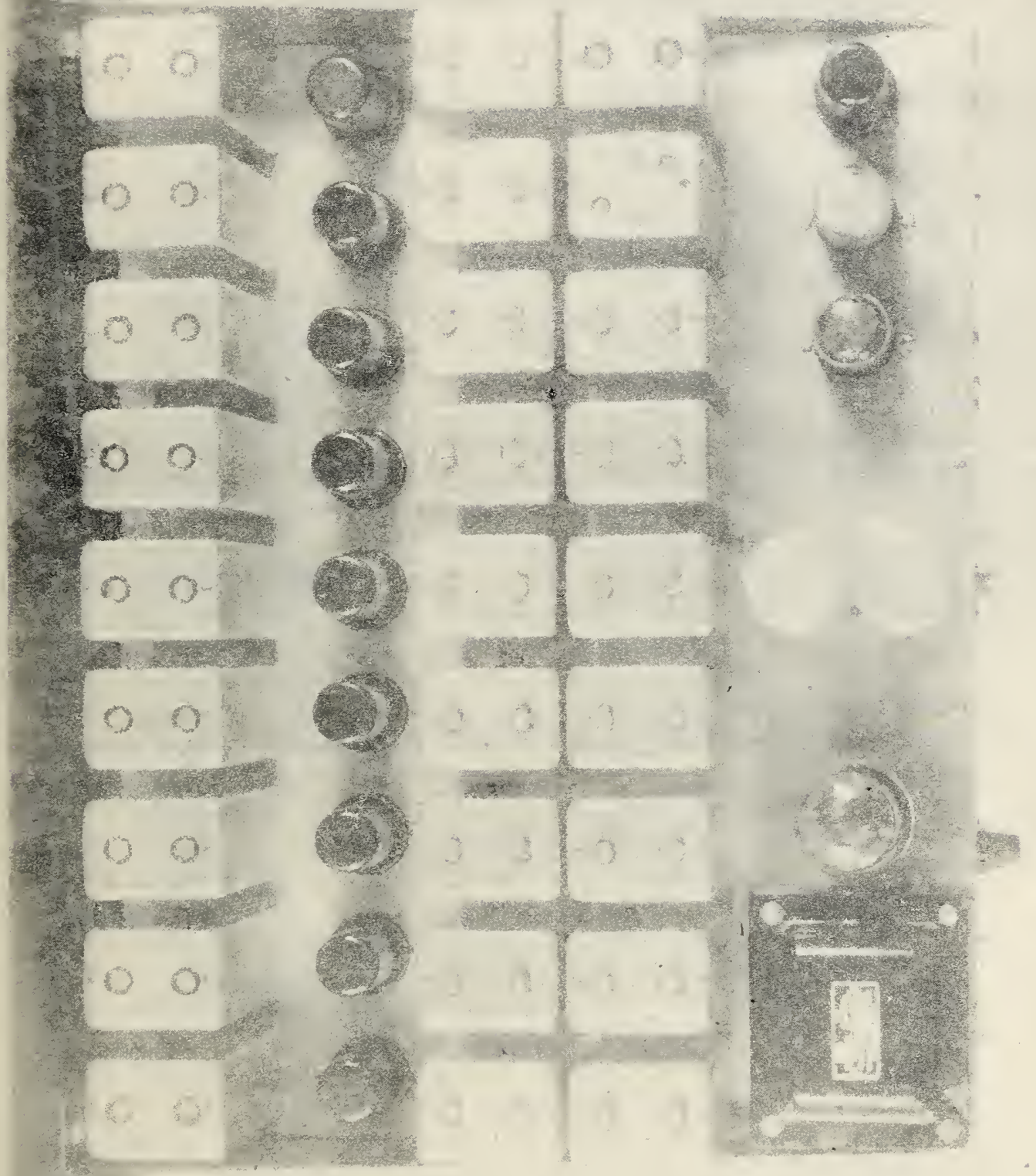

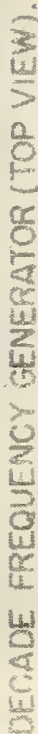

8 



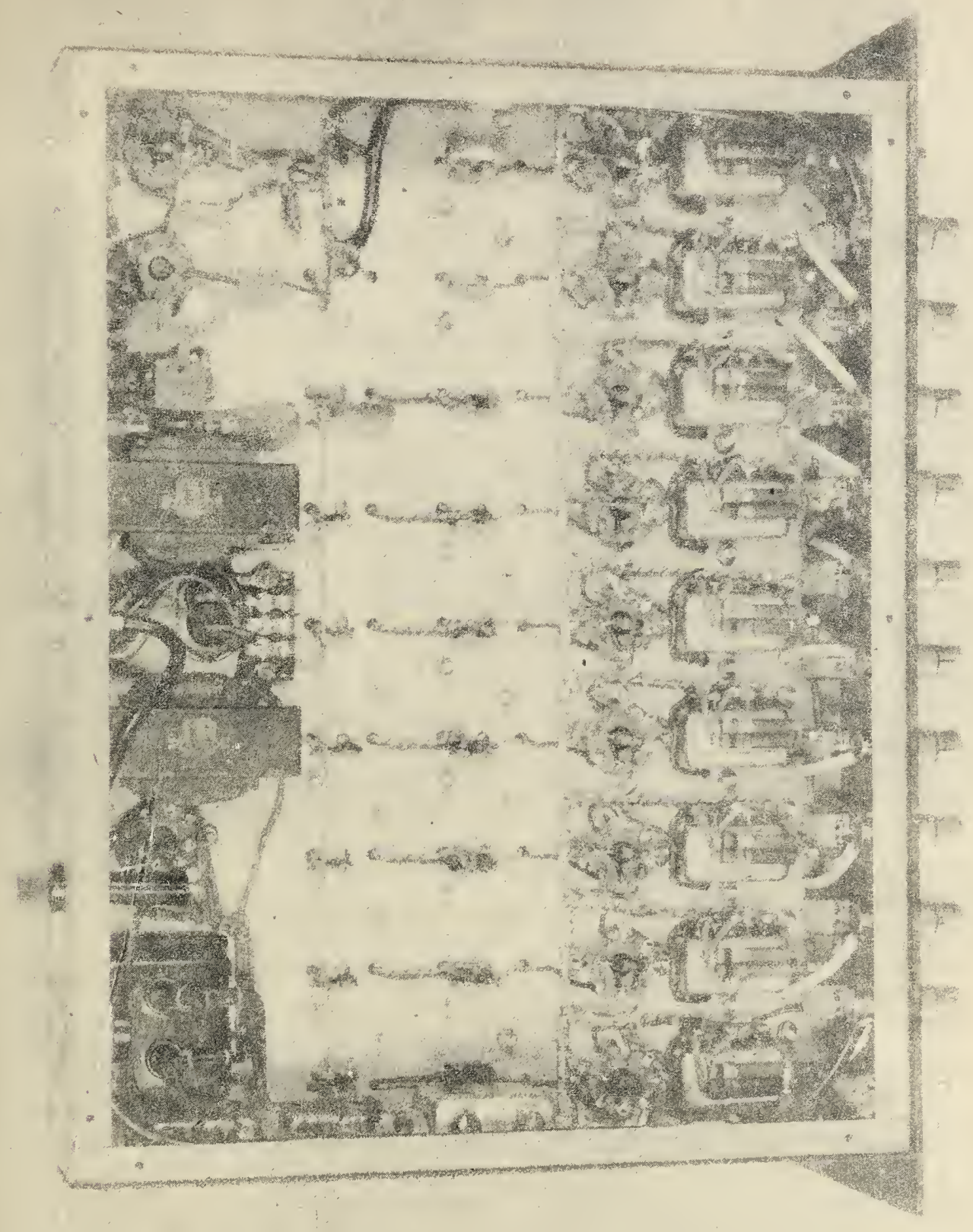

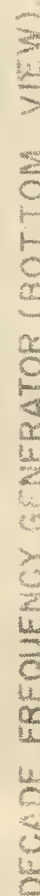

8 



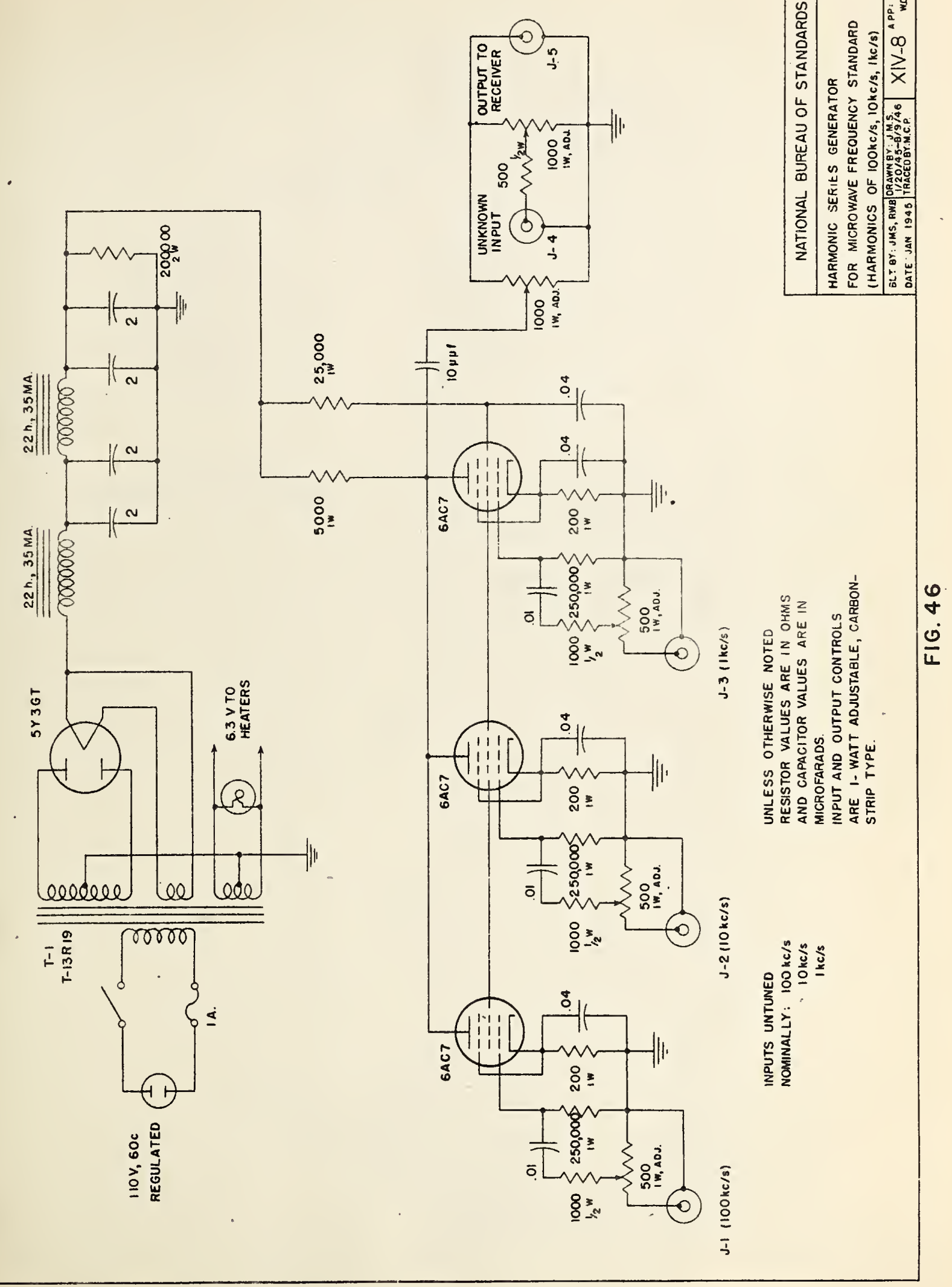





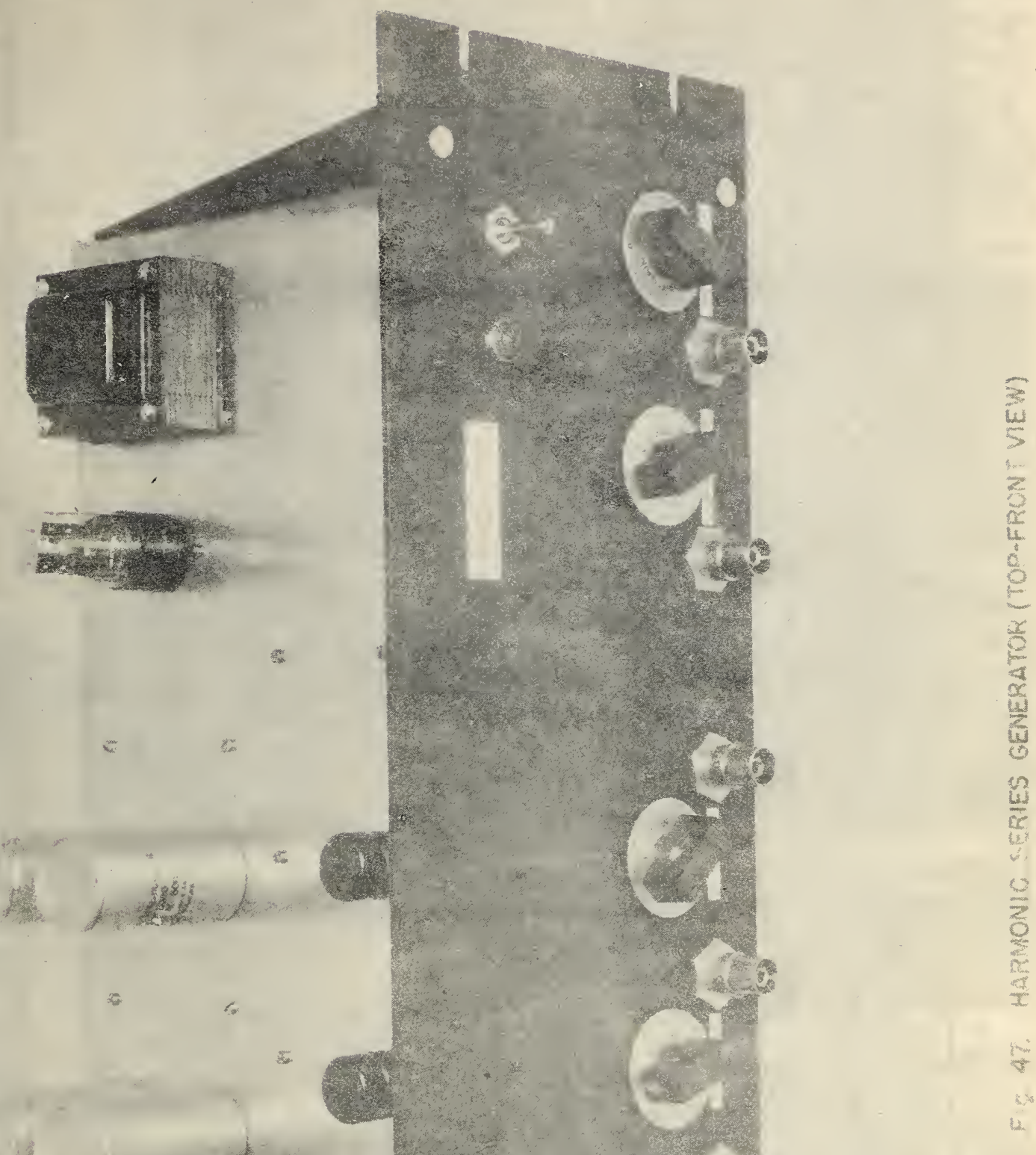

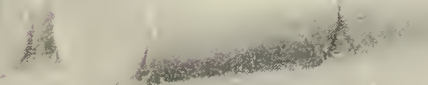




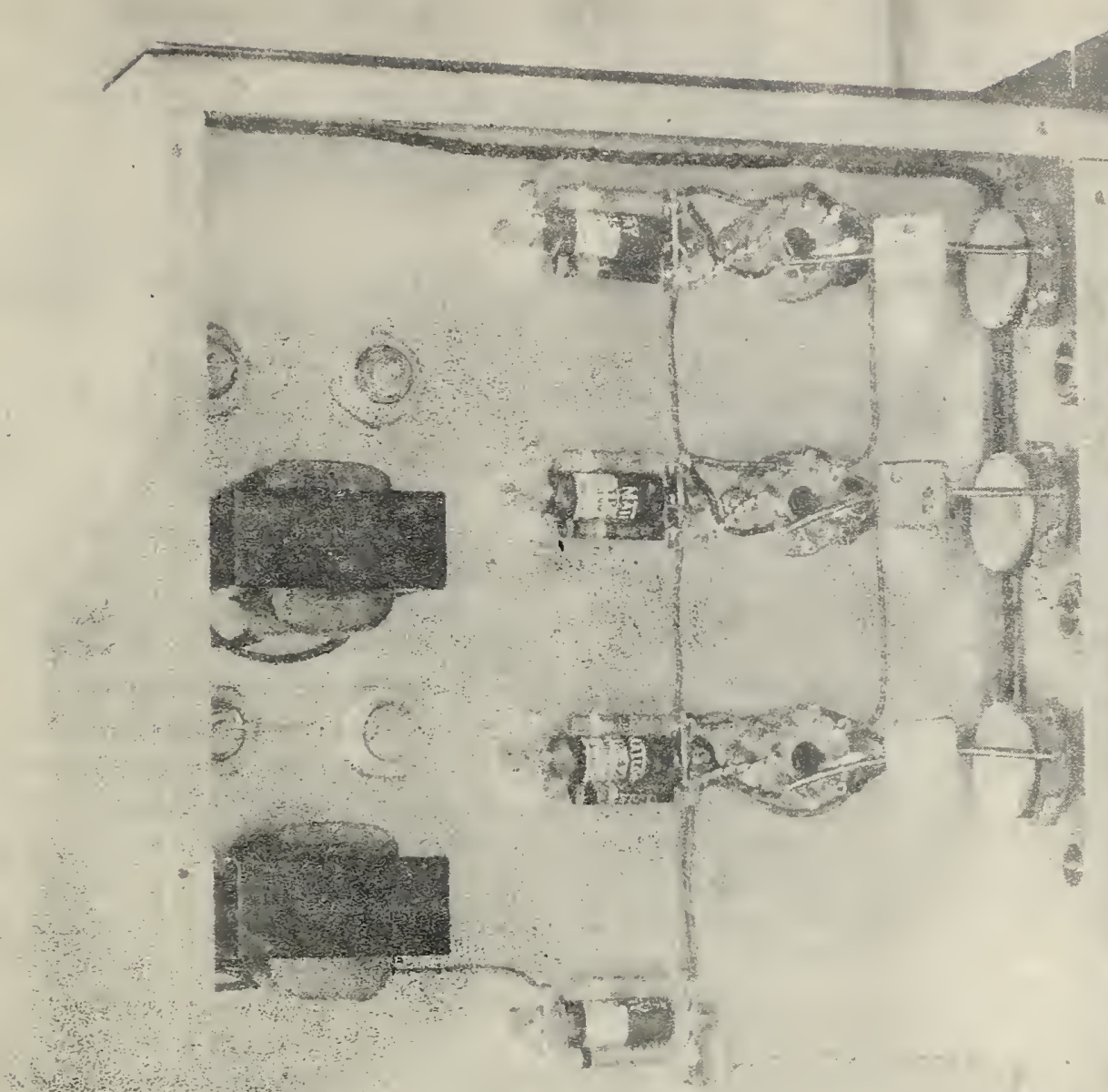

a
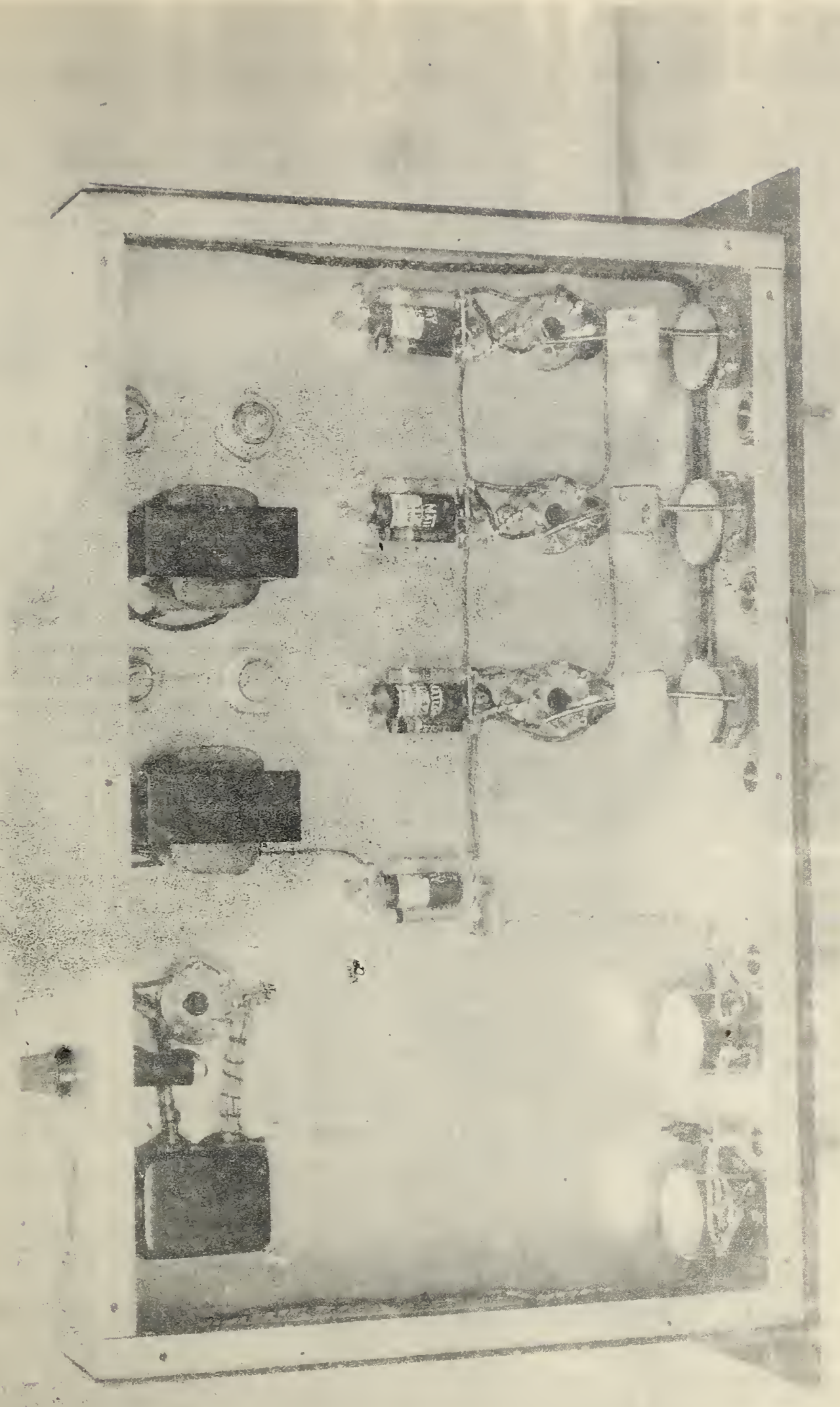


